Structural, Material, and Geotechnical Solutions to Levee and Floodwall Construction and Retrofitting - Physical Modeling

Wipawi Vanadit-Ellis, Eric W. Smith, Landris T. Lee,

December 2012

and Jared S. Case

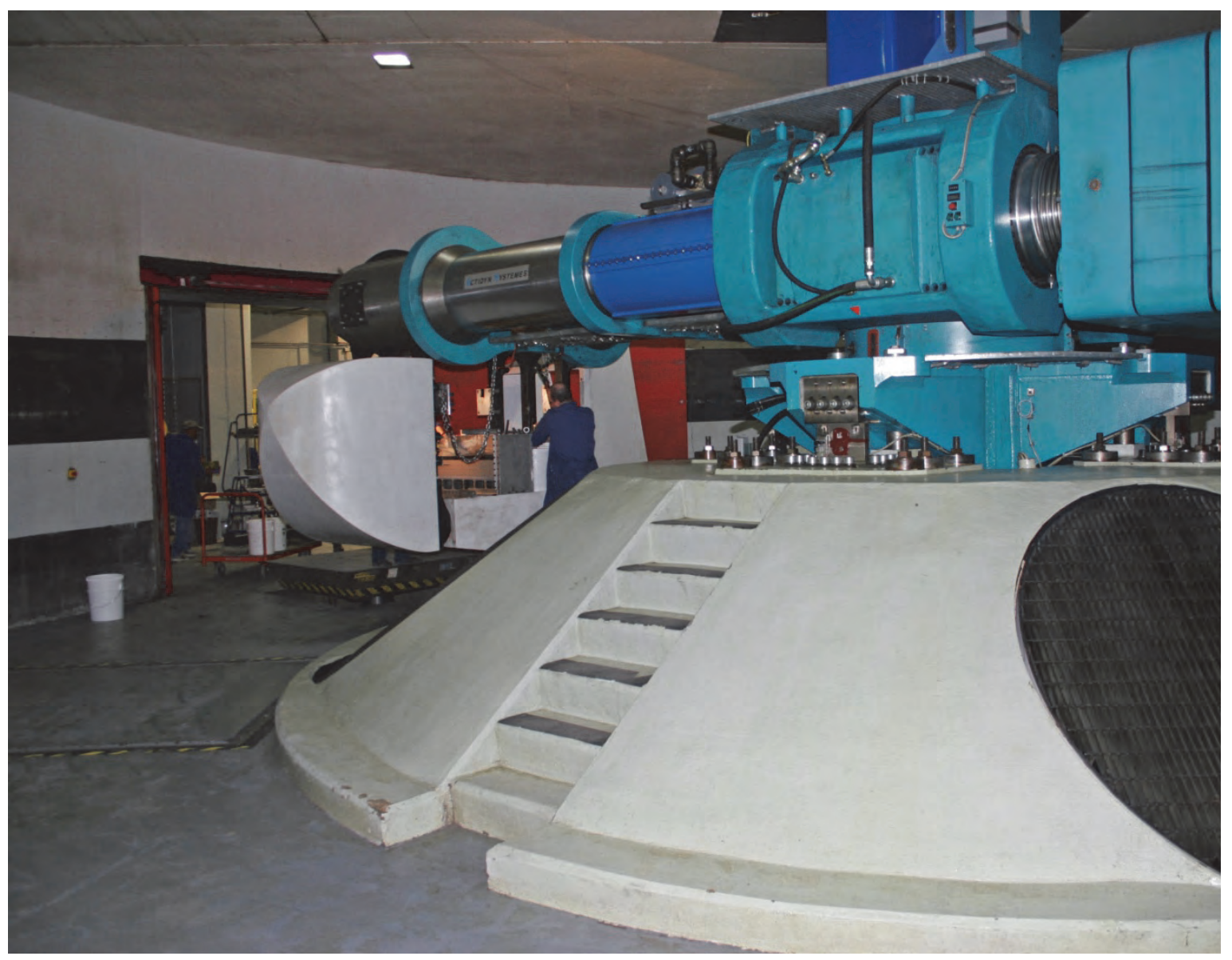




\section{Structural, Material, and Geotechnical Solutions to Levee and Floodwall Construction and Retrofitting - Physical Modeling}

Wipawi Vanadit-Ellis, Eric W. Smith, and Landris T. Lee

Geotechnical and Structures Laboratory

U.S. Army Engineer Research and Development Center

3909 Halls Ferry Road

Vicksburg, MS 39180-6199

Jared S. Case

University of Mississippi

227 Brevard Hall

University, MS 38677

Final report

Approved for public release; distribution is unlimited.

Prepared for The University of Mississippi

Department of Civil Engineering 106 Carrier Hall, University, MS 38677 


\section{Abstract}

This report presents the evaluations of two retrofitting methods for levees and floodwalls. Physical modeling in a centrifuge was used in testing the effectiveness of floodwall panel joint caps or "clips" and a gap filler. The clip connectors were U-shaped reinforced polymers with various thicknesses and strengths, mounted over the joints between I-wall panels. The expectation was that the clips would improve the overall performance of the wall if the panels were connected and behaved as a single unit. The second retrofit method evaluated was called the gap filler, which was a mixture of sand and bentonite. The mixture was entrenched along the levee on the riverside of a sheet wall. The belief was that as water pressure on the wall caused the wall to move (or rotate) toward the landside of the levee; the filler would drop down into the gap and expand, thus reducing seepage under the wall. All test models were constructed, then placed on the centrifuge platform, and subjected to various flood conditions representing those experienced during Hurricane Katrina.

DISCLAIMER: The contents of this report are not to be used for advertising, publication, or promotional purposes. Citation of trade names does not constitute an official endorsement or approval of the use of such commercial products. All product names and trademarks cited are the property of their respective owners. The findings of this report are not to be construed as an official Department of the Army position unless so designated by other authorized documents. 


\section{Contents}

Abstract...................................................................................................................................... if

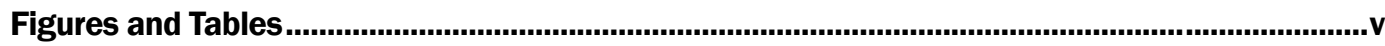

Preface ................................................................................................................................................vii

Unit Conversion Factors.........................................................................................................viif

1 Introduction................................................................................................................... 1

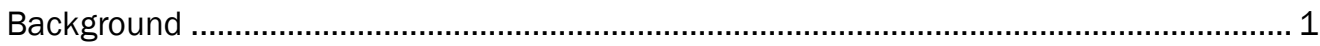

Purpose and scope of study .................................................................................. 1

2 Pretest Planning and Design Efforts to Accomplish Task 2............................................ 5

Previous modeling efforts ................................................................................. 5

Centrifuge model design and fabrication ..................................................................... 7

London Avenue I-wall prototype and centrifuge models .................................................. 8

Initial centrifuge test model setup ........................................................................ 13

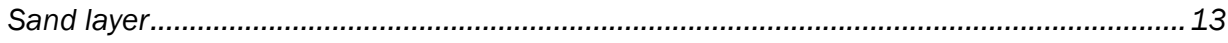

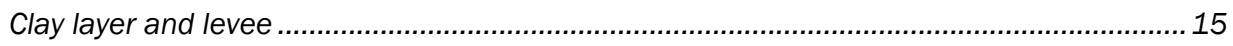

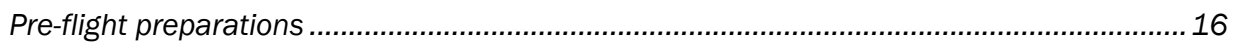

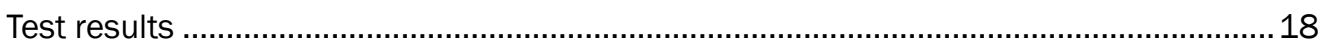

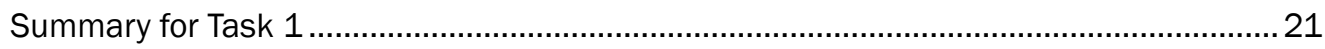

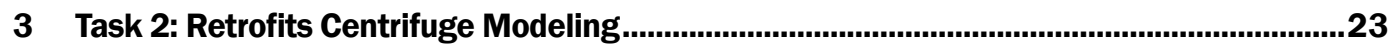

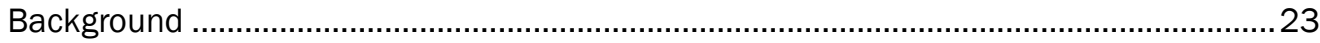

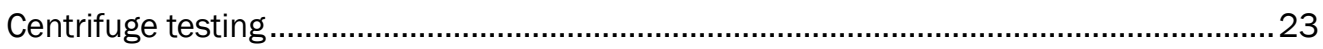

Tests 1 and 2: Centrifuge models of London Canal Avenue ............................................... 23

Preparation for remediation Option 1: Clip connection .....................................................2 24

Tests 3, 4 and 5: London Avenue mitigation tests for clip samples 4 and 5 ....................... 25

Tests 6 and 7: Centrifuge model of 17th Street with and without mitigation clips................28

Test 8: Centrifuge model of London Canal Avenue with gap filler mitigation method........... 28

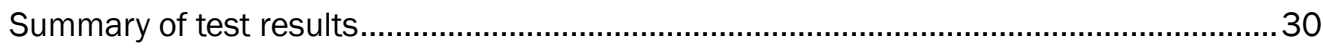

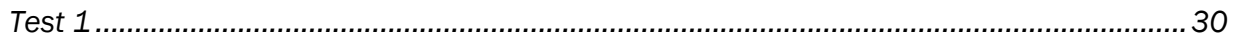

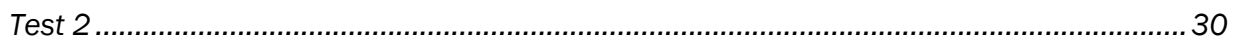

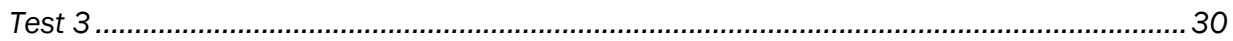

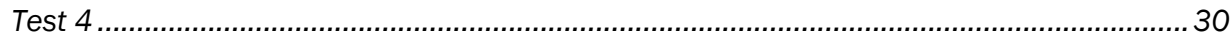

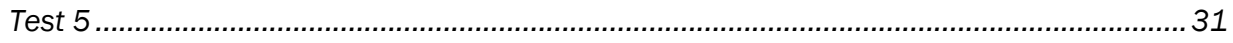

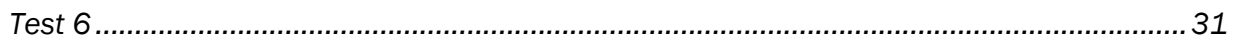

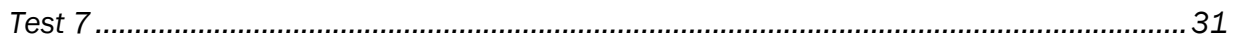

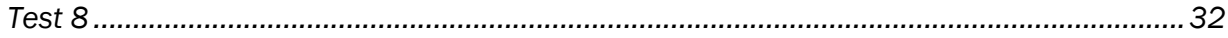

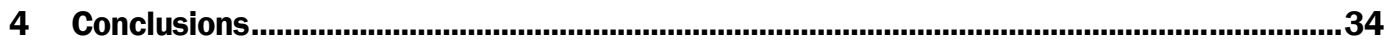

References.......................................................................................................................................36 


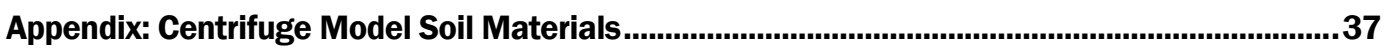

Report Documentation Page 


\section{Figures and Tables}

\section{Figures}

Figure 1. London Avenue Canal floodwall (I-wall) depicting wall deflection failure pattern.

Figure 2. London Avenue Canal I-wall showing joints between panels spaced

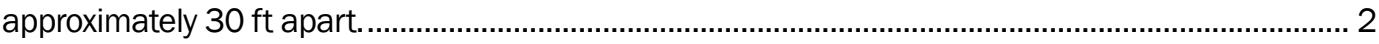

Figure 3. London Avenue I-wall general details........................................................................... 3

Figure 4. London Avenue I-wall construction details. ………............................................................... 4

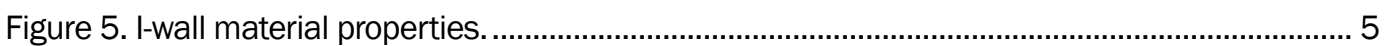

Figure 6. Numerical modeling results showing two-dimensional deflection at 7-ft water level. ............ 6

Figure 7. Numerical modeling results showing that the marsh/swamp clay layer failed,

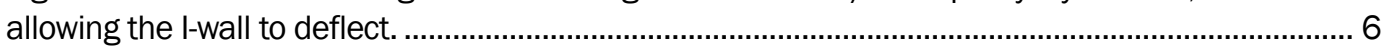

Figure 8. IPET I-wall was modeled with an aluminum plate scaled down by height and thickness for a 50-g centrifuge load................................................................................................. 7

Figure 9. Side view of IPET centrifuge model with material properties shown. .................................. 7

Figure 10. Proposed ERDC/UMiss I-wall centrifuge model, a concrete/sheet-pile prototype scaled down by height, thickness, weight, bending stiffness, and wall joint spacing. ....................... 8

Figure 11. Generalized prototype (constructed) London Avenue I-wall dimensions............................ 8

Figure 12. Details of the scaled-down London Avenue I-wall centrifuge model proposed for several centrifuge g-levels

Figure 13. Proposed scaled-down I-wall selected for 64-g centrifuge tests, showing vertical axis stiffness approximately 16 times horizontal axis stiffness. ........................................ 9

Figure 14. Prototype versus 64-g scaled model with water load.................................................... 10

Figure 15. Shop drawings for the two-component model I-wall......................................................... 10

Figure 16. Fabricated model I-wall. ........................................................................................... 11

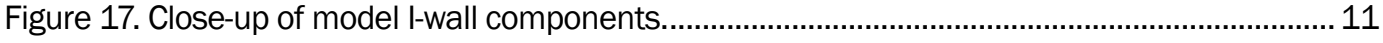

Figure 18. Wide centrifuge model box fabricated for this research task........................................ 11

Figure 19. Close-up of model I-wall inserted into the model box..................................................... 12

Figure 20. Exaggerated expected deflection pattern. ……………………………………….... 12

Figure 21. Sand pluviated through the water column. ..................................................................... 13

Figure 22. View toward I-wall showing top of 8-in.-thick sand layer.................................................. 14

Figure 23. Top of sand layer with inserted pore pressure transducers and laser mount brackets

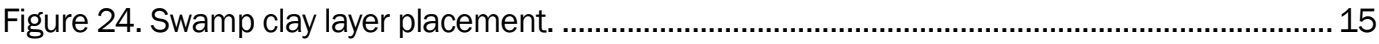

Figure 25. Close-up view of the completed swamp clay layer......................................................... 15

Figure 26. Kaolin clay levee in place. Cellophane wrap was placed on the soil to minimize moisture loss due to evaporation prior to centrifuge flight. ............................................................... 16

Figure 27. Schematic showing the pre-flight nominal dimensions.................................................. 16

Figure 28. Lasers to measure top of I-wall deflection. . .................................................................... 17

Figure 29. Pre-flight configuration. ........................................................................................... 18 
Figure 30. Test 1 laser (relative) displacement results. .............................................................. 19

Figure 31. Test 2 laser (relative) displacement results................................................................... 19

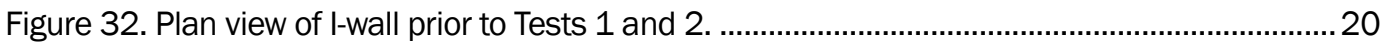

Figure 33. Plan view of I-wall positive movement scaled from Test 1 laser displacements during 64-g loading. 20

Figure 34. Plan view of I-wall positive movement scaled from Test 2 laser displacements

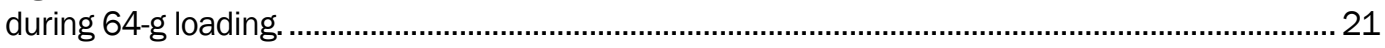

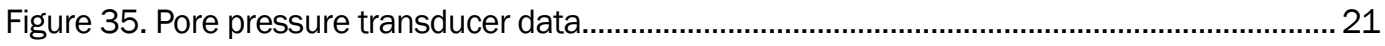

Figure 36. Schematic for London Canal Avenue model. ................................................................. 24

Figure 37. Positions of the binder clips between the flood wall sections......................................... 24

Figure 38. Samples of fiber reinforced polymers submitted for evaluation as clip connections............ 25

Figure 39. Typical schematic for strain gages on a clip connector.................................................... 26

Figure 40. Pressure cells on both sides of the I-wall sections. .........................................................26

Figure 41. Instrumented polymer clip placed over two I-wall sections.............................................. 27

Figure 42. Completed I-wall clip mitigation test with laser gages ready for centrifuge testing............. 27

Figure 43. Schematic of the 17th Street levee failure site modeled for centrifuge testing..............28

Figure 44. (a) Gap filler entrenched along the I-wall, (b) filler falling into the gap and

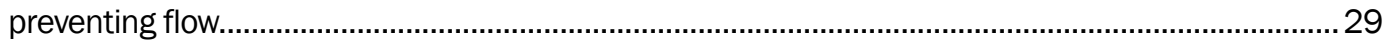

Figure 45. "Trenching" the levee, pouring in the filler, completed levee model..............................30

Figure 46. I-wall failure occurred without the clip mitigation. ............................................................30

Figure 47. Test 4, London Canal Avenue I-wall sections with the clip mitigation did not fail. ........... 31

Figure 48. Center sections of the I-wall with the clip mitigation did not separate or fail....................32

Figure 49. Laser gages show the l-wall displacement of about $2 \mathrm{ft}$ (scaled)..................................3 32

Figure 50. Visible clumps of clay and filler in the gap after a centrifuge test. ..................................33

Figure 51. Filler that expanded in-place was stuck to the I-wall. ........................................................33

Figure 52. View of riverside levee section with the gap filler trail roughly $5 \mathrm{ft}$ (scaled) down

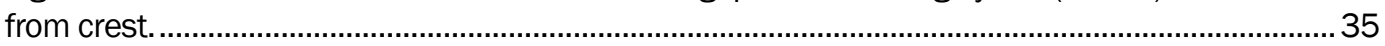

Figure 53. Cross-section of the levee showing final position of gap filler. .......................................35

\section{Table}

Table 1. Soil parameters from Adhikari 2009. 


\section{Preface}

This study was sponsored by the U.S. Department of Homeland Security (DHS) under the SERRI (Southeast Region Research Initiative) Project. The lead for the Structural, Material, and Geotechnical Solutions to Levee and Floodwall Construction and Retrofitting study was the University of Mississippi (UMiss), Department of Civil Engineering. Professor Chung Song, UMiss, the SERRI Program Lead, provided guidelines and monitored the work.

A Cooperative Agreement between the Geotechnical and Structures Laboratory (GSL) of the U.S. Army Engineer Research and Development Center (ERDC), Vicksburg, MS, and UMiss to accomplish collaborative research was signed in J anuary 2009. UMiss is the sponsor of the ERDCGSL research described herein. The study was conducted by GSL with technical oversight provided by Dr. Michael Sharp, Technical Director and Program Manager for Water Resources Infrastructure. The Project Leader was Wipawi Vanadit-Ellis, assisted by Eric W. Smith, and Landris T. Lee, all of the Geotechnical Engineering and Geoscience Branch, and J ared S. Case, University of Mississippi, University, Mississippi.

The work was carried out under the general supervision of Dr. Monte Pearson, Chief of the Geosciences and Structures Branch, GSL. Dr. David W. Pittman was Director, GSL.

COL Kevin J . Wilson was Commander and Executive Director of ERDC. Dr. J effery P. Holland was Director. 


\section{Unit Conversion Factors}

\begin{tabular}{|l|c|l|}
\hline Multiply & By & To Obtain \\
\hline cubic feet & 0.02831685 & cubic meters \\
\hline feet & 0.3048 & meters \\
\hline inches & 0.0254 & meters \\
\hline pounds (force) per foot & 14.59390 & newtons per meter \\
\hline pounds (force) per square foot & 47.88026 & pascals \\
\hline pounds (force) per square inch & 6.894757 & kilopascals \\
\hline pounds (mass) & 0.45359237 & kilograms \\
\hline pounds (mass) per cubic foot & 16.01846 & kilograms per cubic meter \\
\hline slugs & 14.59390 & kilograms \\
\hline
\end{tabular}




\section{Introduction}

\section{Background}

Because of its ongoing research on floodwalls (I-walls and T-walls) since Hurricane Katrina in 2005, the U.S. Army Engineer Research and Development Center (ERDC) Geotechnical and Structures Laboratory (GSL) has the physical and numerical modeling tools as well as the experience and expertise to address issues regarding the New Orleans-area Hurricane Protection System (HPS). These tools include physical modeling at the U.S. Army Centrifuge Research Center (CRC), two-dimensional and three-dimensional soil-structure-fluid coupled numerical modeling, and access to soil behavior data and field soil-structure interaction data on the HPS.

\section{Purpose and scope of study}

The overall program focuses on two distinct areas defined as follows:

- Numerical Modeling of Geotechnical Solutions for Levee and Floodwall Retrofitting: Provide necessary data on sections for analysis including levee/ floodwall geometry, properties of the levee embankment and foundation materials, and properties of the structural components. In addition, two-dimensional and three-dimensional soilstructure-fluid coupled analysis with either finite element methods or finite difference methods will be used to evaluate the potential geotechnical solutions. A description of this research is not part of this report.

- Physical Modeling of Geotechnical Solutions for Levee and Floodwall Retrofitting: This includes CRC modeling of the potential geotechnical solutions coordinated with the numerical modeling to validate the numerical models and proposed physical solutions.

ERDC CRC modeling of I-wall sections was proposed to (1) investigate UMiss-designed structural solutions to mitigate I-wall lateral deflection/ failure, and (2) validate UMiss numerical analyses, using Katrina levee and I-wall data. Figures 1 through 4 show the London Avenue Canal floodwall, the failure of which served as the impetus for this research task. Field test data drove detailed numerical modeling of this prototype floodwall system. 
This report describes efforts to accomplish UMiss/ ERDC Task 2. The purpose of Task 2 is to investigate structural solutions to increase the overall lateral resistance of the floodwall/ sheet-pile system for load transfer to geotechnically and structurally stronger sections.

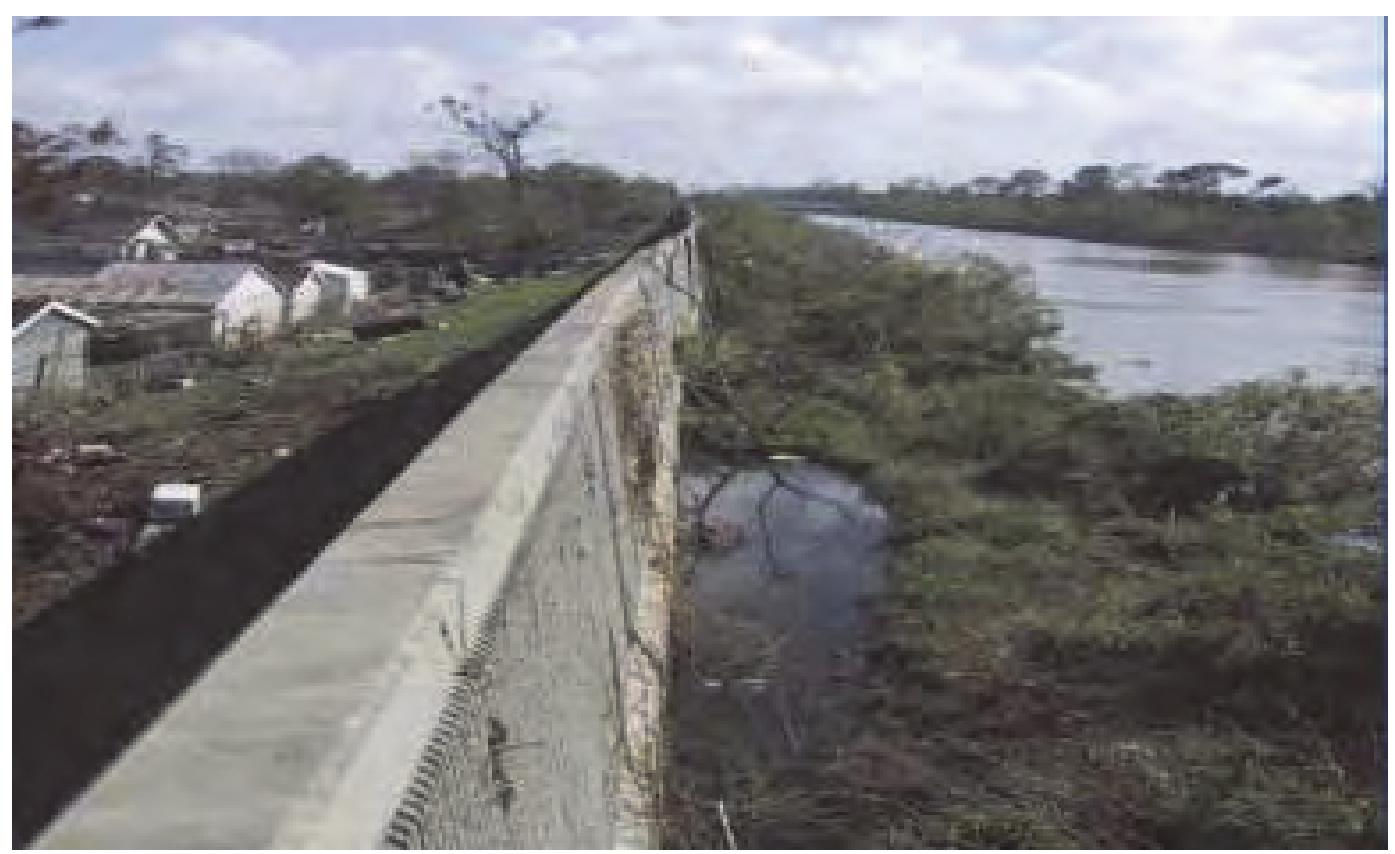

Figure 1. London Avenue Canal floodwall (I-wall) depicting wall deflection failure pattern. The I-wall is composed of concrete wall sections supported by steel sheet piles.

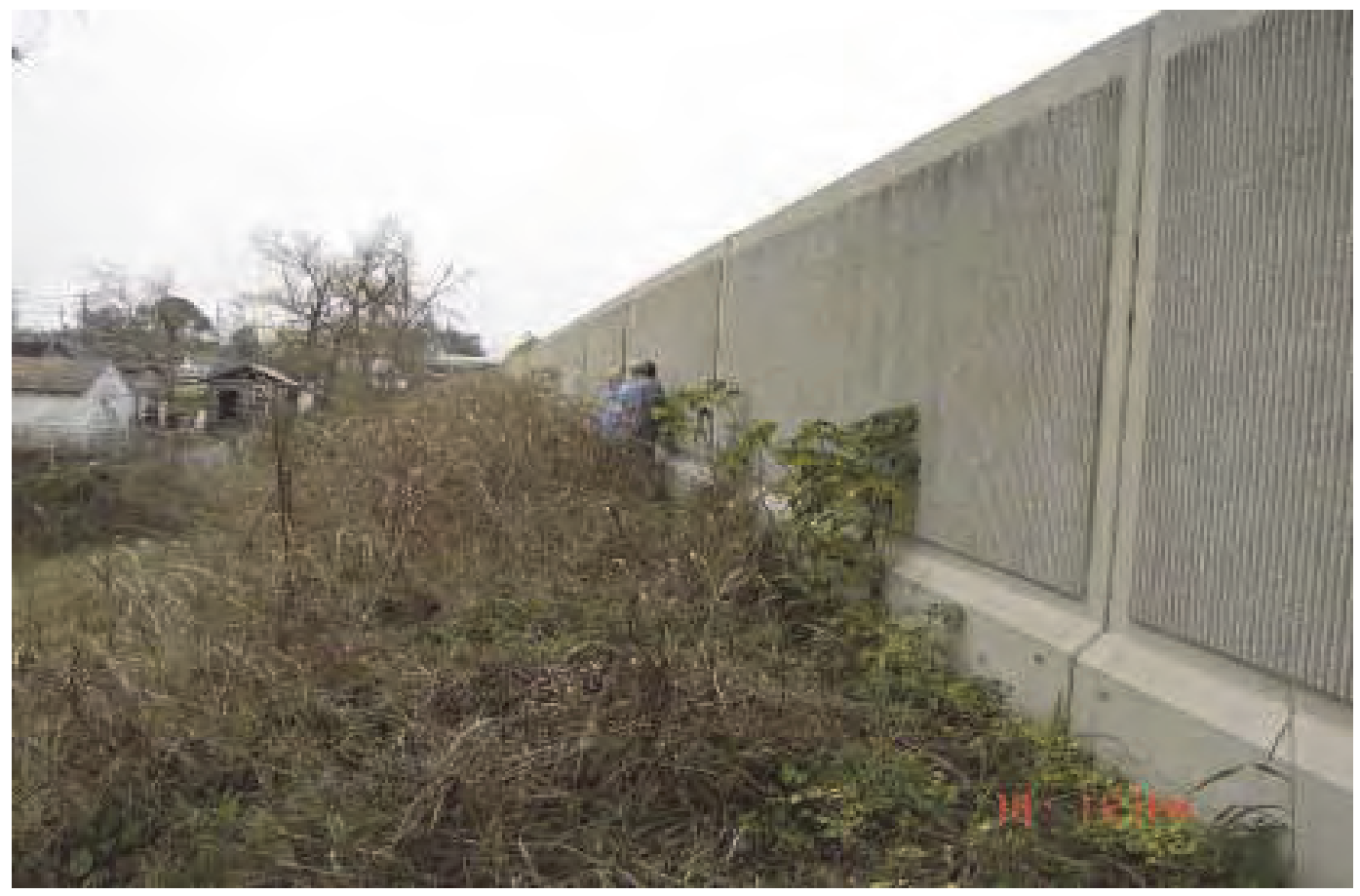

Figure 2. London Avenue Canal I-wall showing joints between panels spaced approximately 30-ft-apart. 


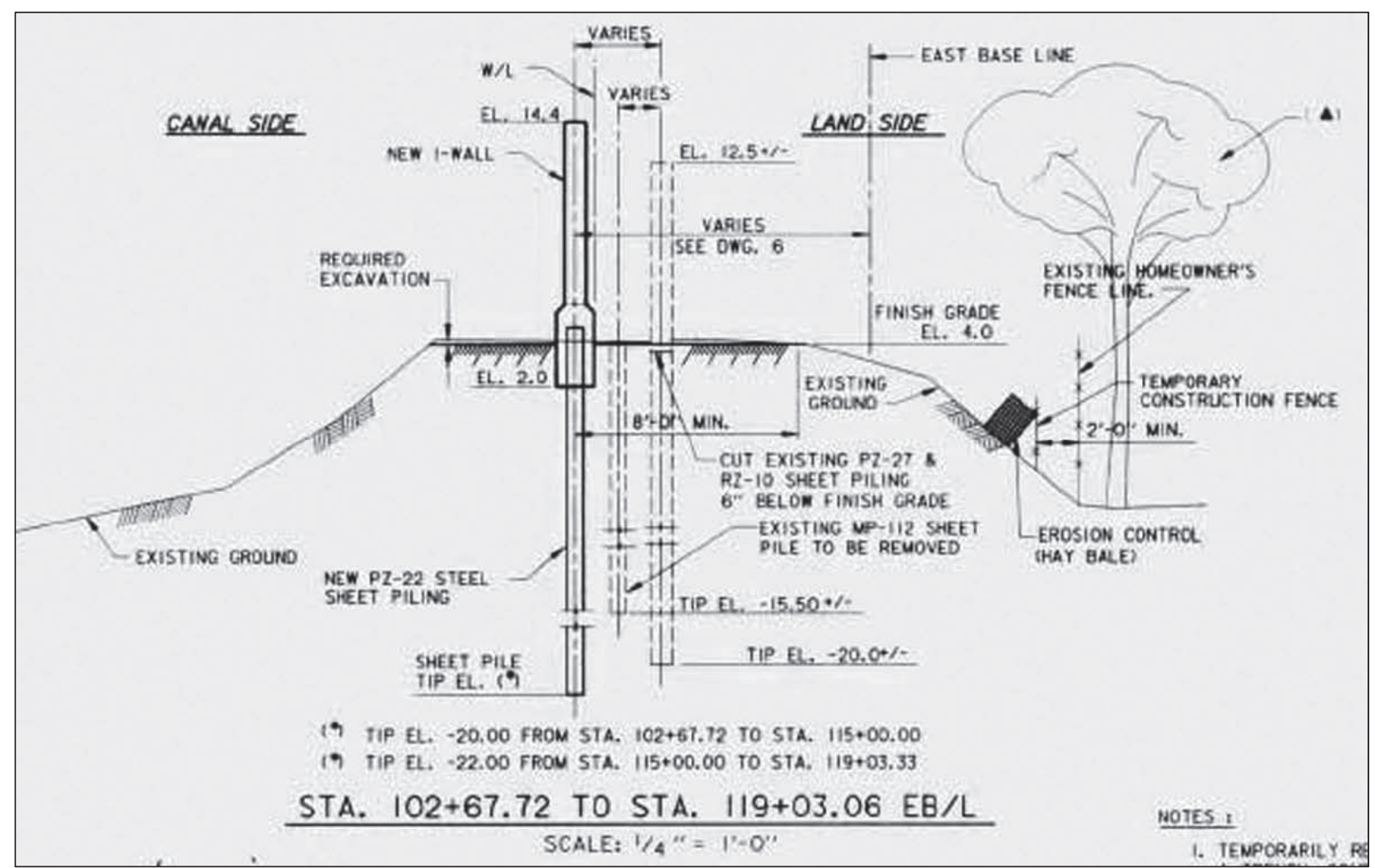

Figure 3. London Avenue I-wall general details. 


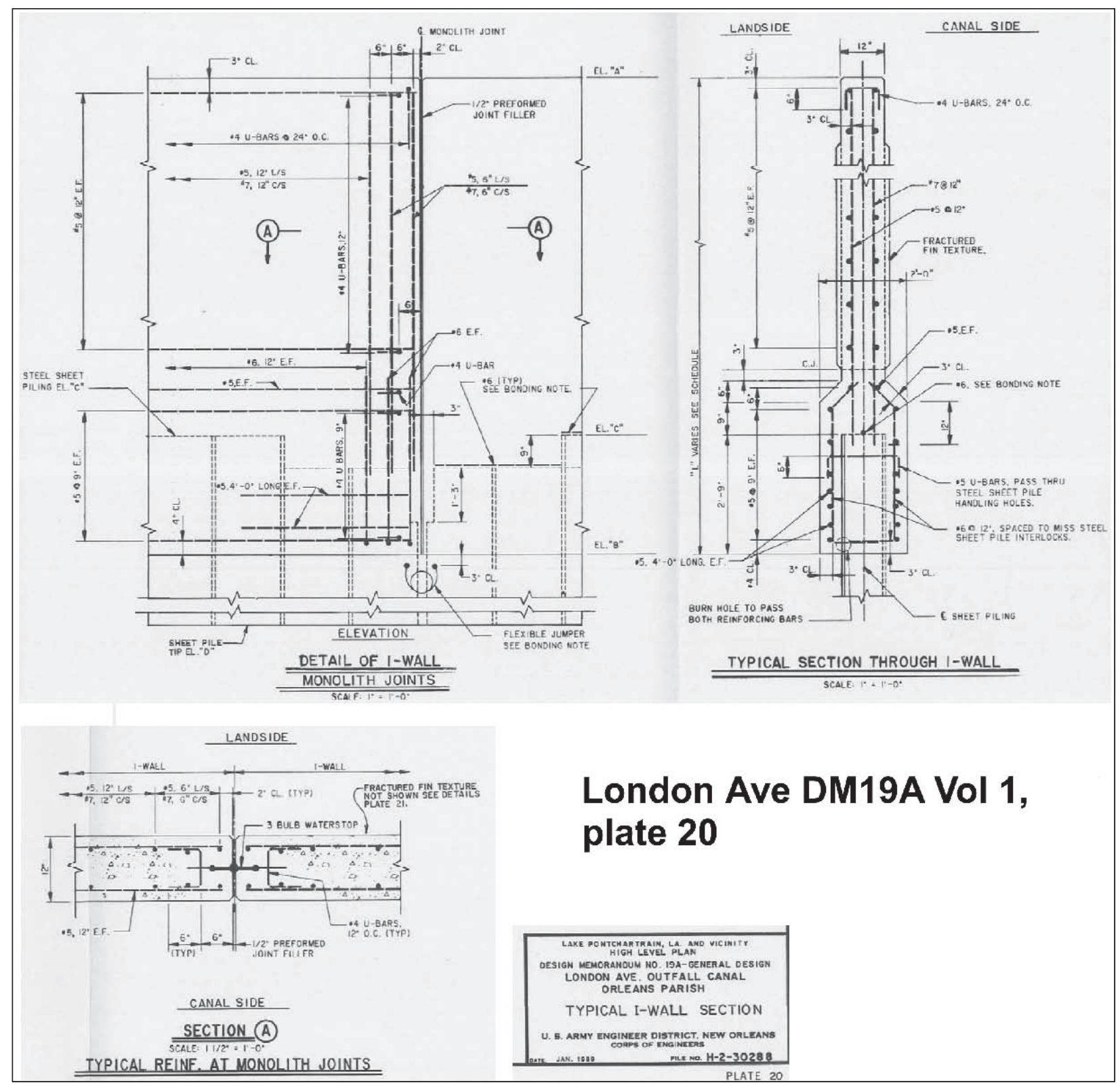

Figure 4. London Avenue I-wall construction details. 


\section{Pretest Planning and Design Efforts to Accomplish Task 2}

\section{Previous modeling efforts}

UMiss conducted numerical modeling, Fast Lagrangian Analysis of Continua (FLAC) of the London Avenue Canal, New Orleans floodwall system, using the materials and dimensions shown in Table 1 and Figures 5 through 7 (from Adhikari 2009).

Table 1. Soil parameters from Adhikari 2009.

\begin{tabular}{|c|c|c|c|c|}
\hline Material & Shear Strength & $\begin{array}{l}\text { Saturated density } \\
\text { (Slug/cf) }\end{array}$ & $\begin{array}{l}\text { El. Modulus } \\
\text { (Psf) }\end{array}$ & Poisson's ratio \\
\hline Levee-fill & $S u=900 P_{s f} \phi u=0^{\circ}$ & 3.39 & $8.28 \mathrm{E}+04$ & 0.48 \\
\hline Marsh(Toe) & $S u=300$ Psf,$\varphi u=0^{\circ}$ & 2.49 & $2.76 \mathrm{E}+04$ & 0.48 \\
\hline Marsh( Center) & $S u=400$ Psf, $\phi u=0^{\circ}$ & 2.49 & $3.68 \mathrm{E}+04$ & 0.48 \\
\hline Bay sound Clay & Su $=5000$ Psf,$\varphi u=0^{\circ}$ & 3.89 & $4.60 \mathrm{E}+05$ & 0.48 \\
\hline Relic Beach Sand & $c^{\prime}=0, \varphi^{\prime}=36^{\circ}$ & 3.73 & $1.38 \mathrm{E}+05$ & 0.41 \\
\hline Silty Sand & $c^{\prime}=0, \varphi^{\prime}=30^{\circ}$ & 3.59 & $1.38 \mathrm{E}+05$ & 0.43 \\
\hline
\end{tabular}

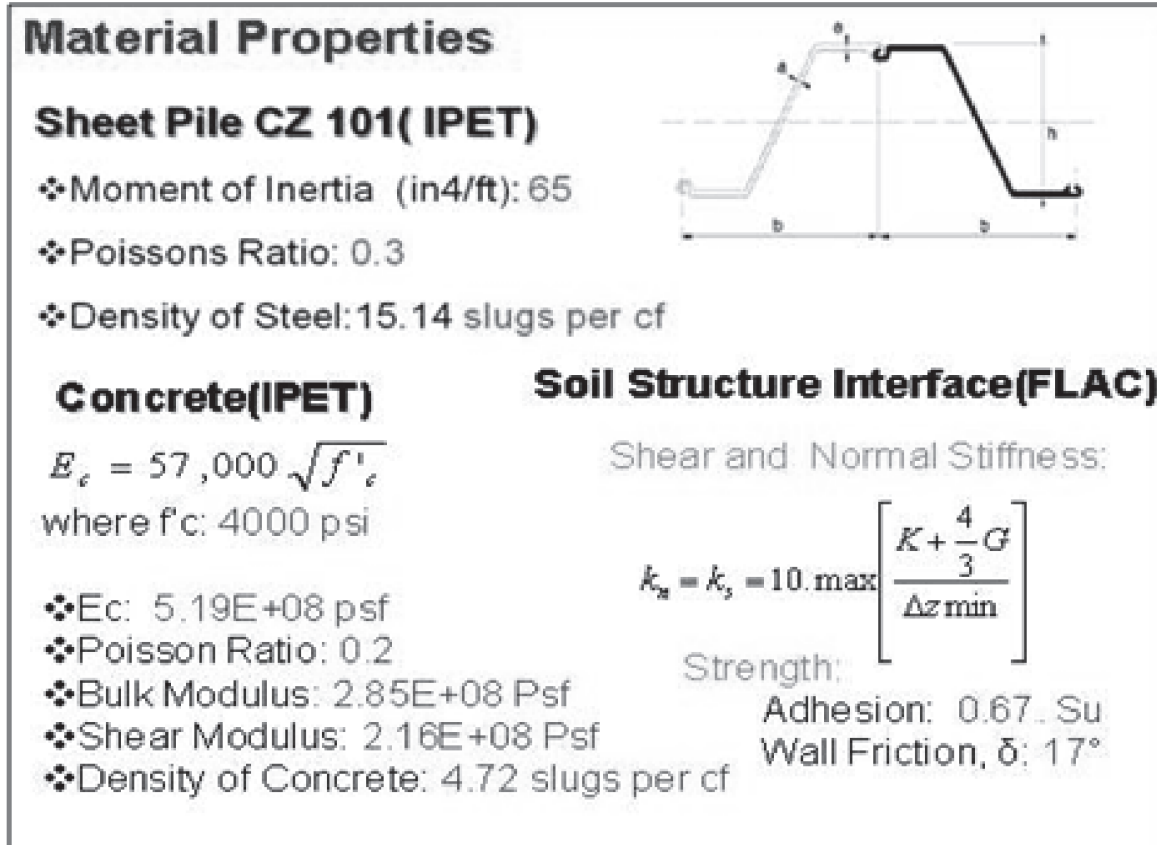

Figure 5. I-wall material properties (from Adhikari 2009). 


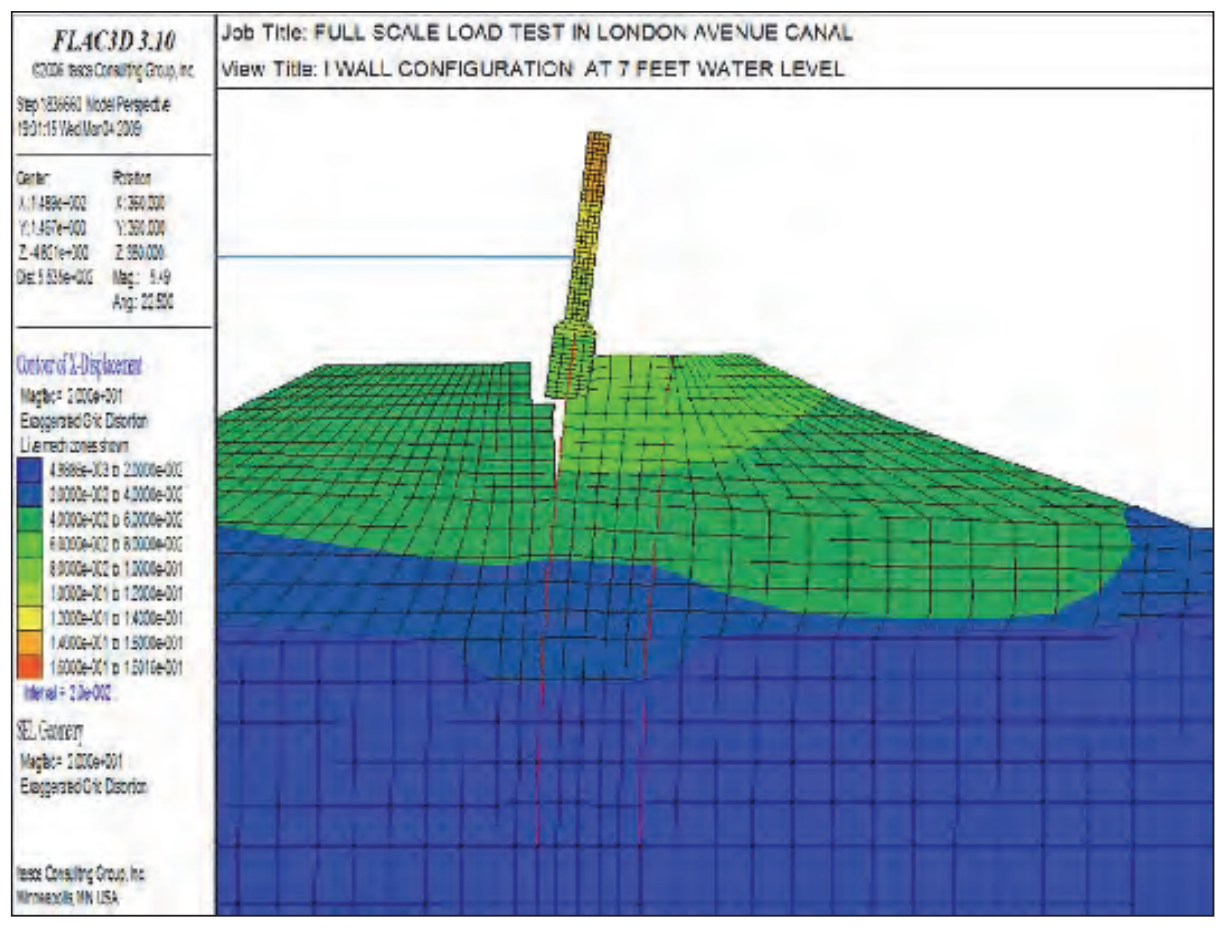

Figure 6. Numerical modeling results showing two-dimensional deflection at $7-\mathrm{ft}$ water level (from Adhikari 2009).

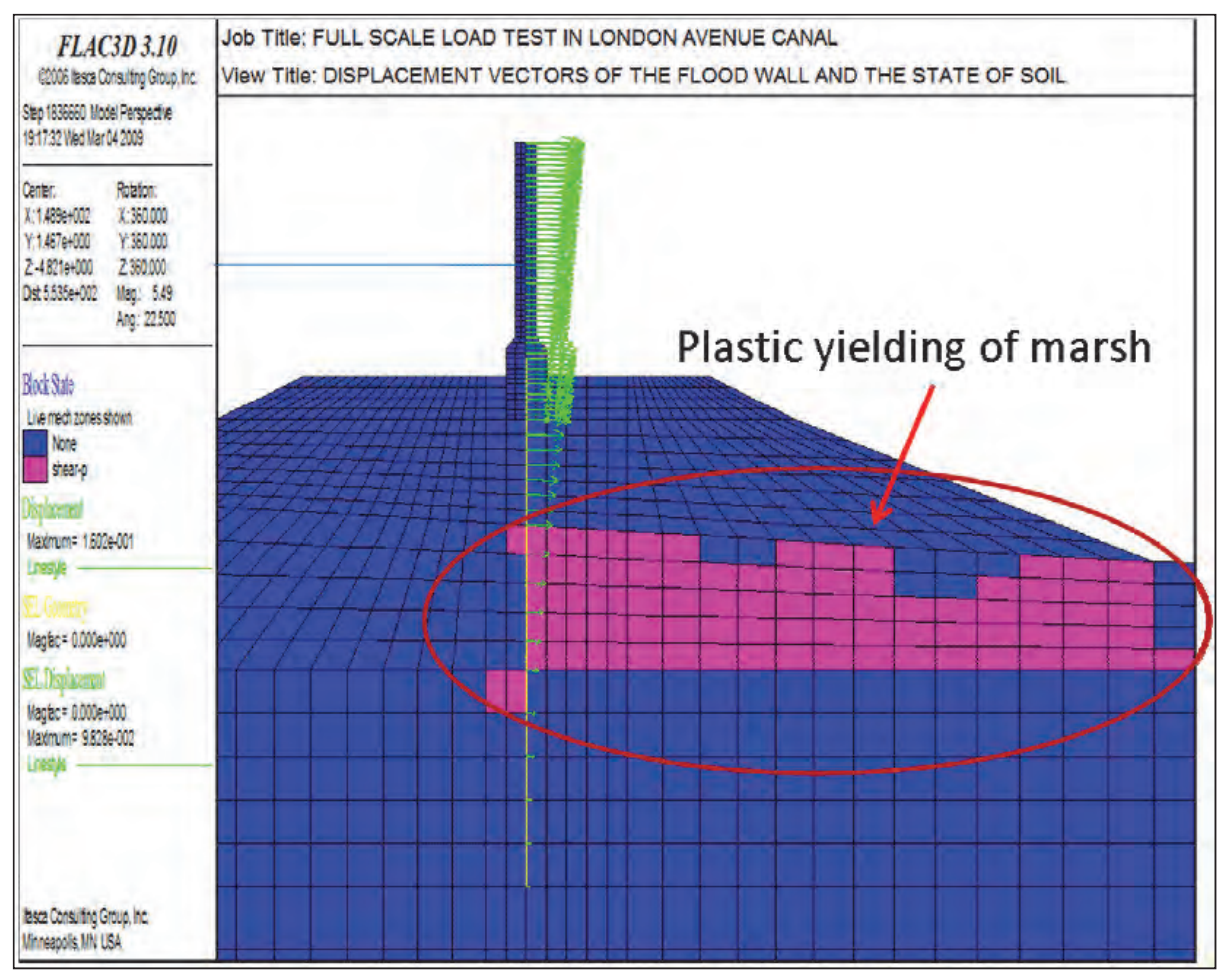

Figure 7. Numerical modeling results showing that the marsh/swamp clay layer failed, allowing the I-wall to deflect (from Adhikari 2009). 
Other research efforts included the findings from previous ERDC/ Interagency Performance Evaluation Task Force (IPET) centrifuge models. Several centrifuge models were flown during the post-Katrina IPET investigation of the HPS I-wall failures, including the London Avenue Canal model. Figures 8 and 9 illustrate the London Avenue Canal models detailed in the IPET report, Volume 5, Appendix 5 (IPET 2007).

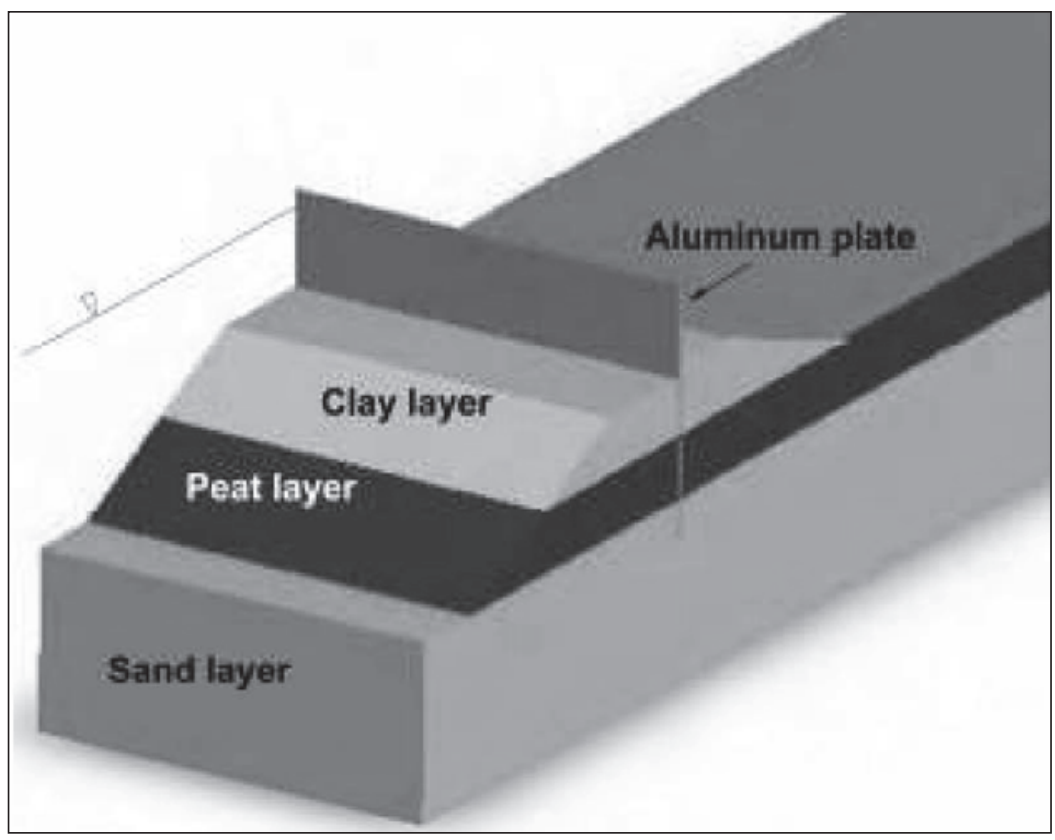

Figure 8. IPET I-wall was modeled with an aluminum plate scaled down by height and thickness for a 50-g centrifuge load.

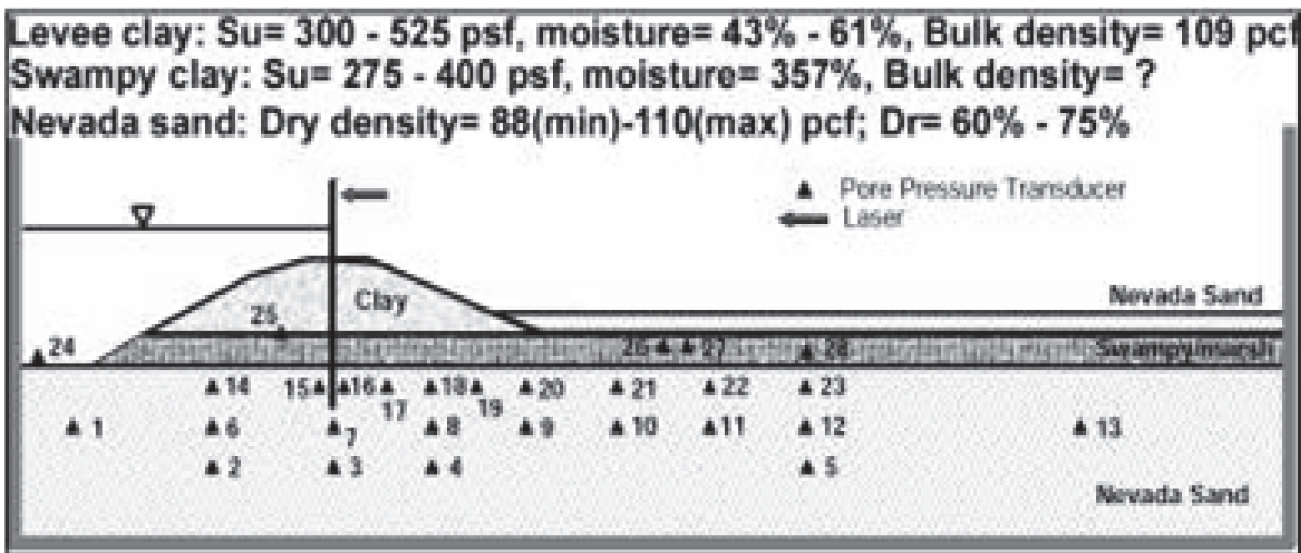

Figure 9. Side view of IPET centrifuge model with material properties shown.

\section{Centrifuge model design and fabrication}

The proposed initial UMiss/ ERDC centrifuge model is based on the London Avenue IPET model, illustrated in Figure 10. Note that the I-wall con- 
figuration differs from that of the IPET models in that the I-wall is composed of segmented steel plates resting on top of an aluminum sheet. The steel plates are surrogates for the jointed concrete wall sections cast in place over existing steel sheet piles.

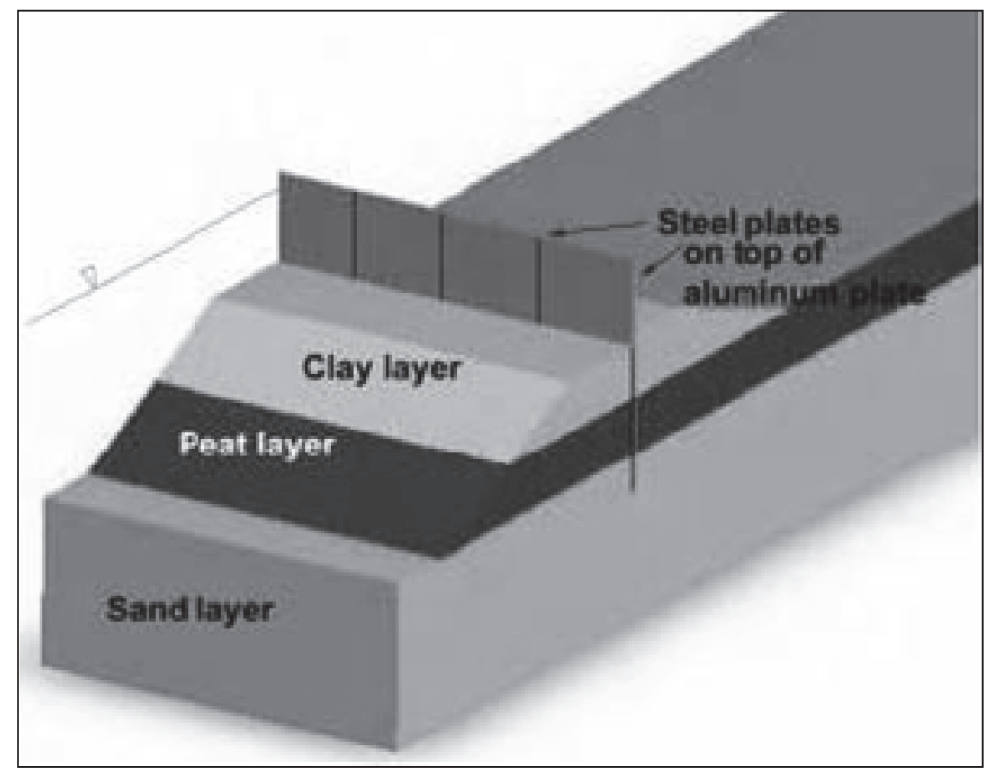

Figure 10. Proposed ERDC/UMiss I-wall centrifuge model, a concrete/sheet-pile prototype scaled down by height, thickness, weight, bending stiffness, and wall joint spacing.

\section{London Avenue I-wall prototype and centrifuge models}

Figure 11 shows a generalized cross section to be scaled down for centrifuge modeling. Figure 12 shows details of the scaled-down I-wall proposed for centrifuge model acceleration levels. Figures 13-20 show the design process for scaled I-wall model.

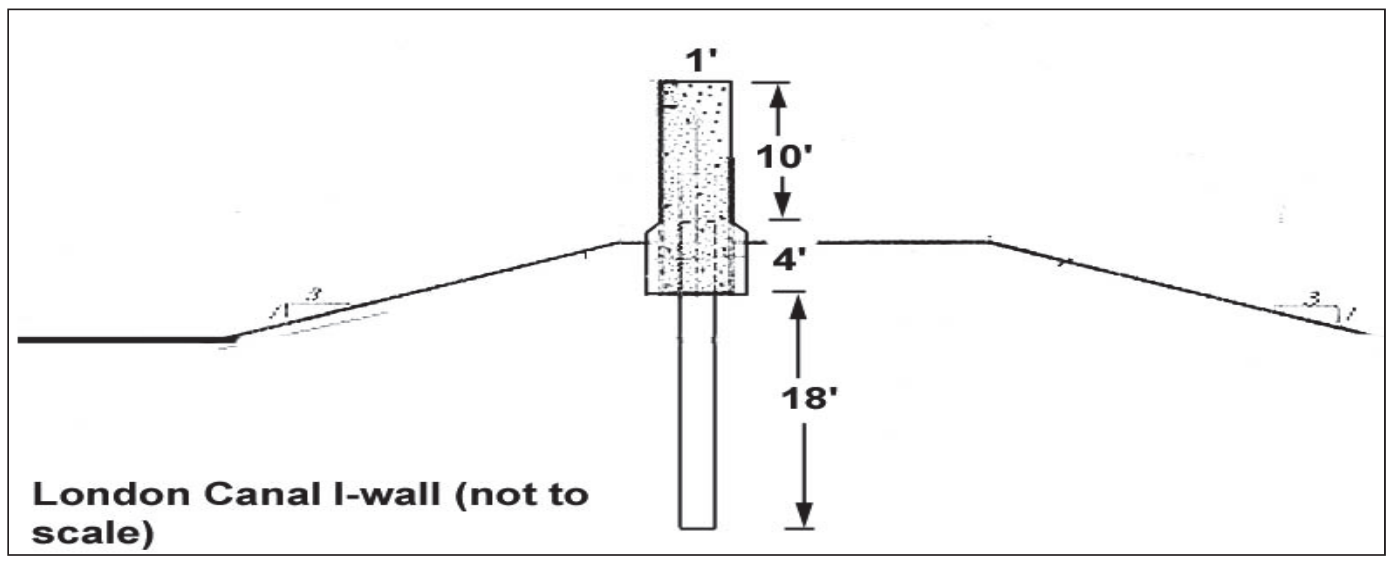

Figure 11. Generalized prototype (constructed) London Avenue l-wall dimensions. Top portion is cast-in-place concrete wall sections and bottom portion is embedded sheet pile. 


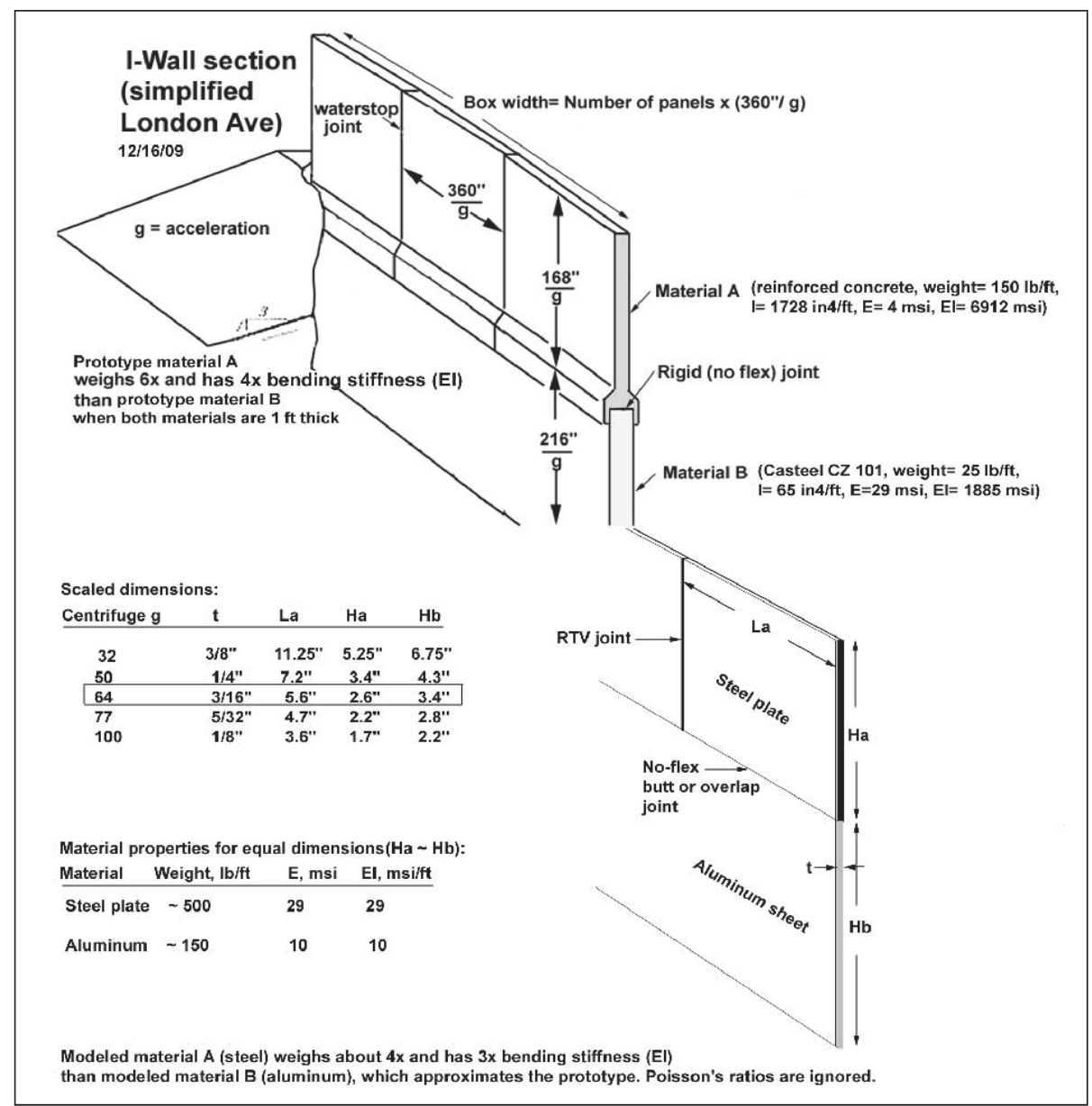

Figure 12. Details of the scaled-down London Avenue I-wall centrifuge model proposed for several centrifuge g-levels.

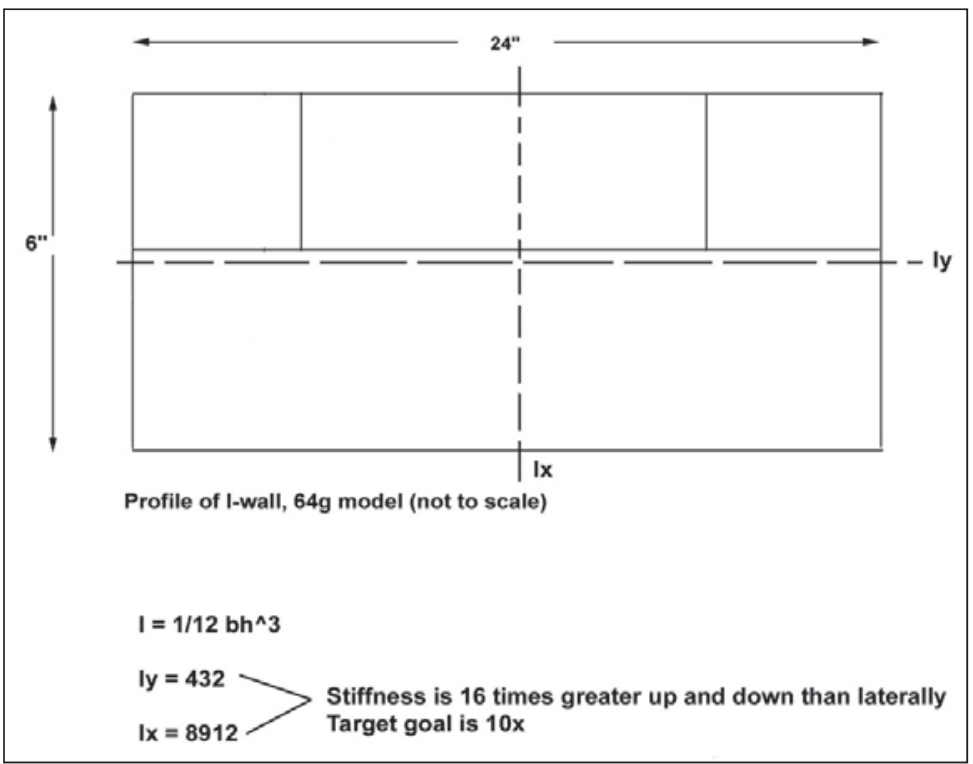

Figure 13. Proposed scaled-down I-wall selected for 64-g centrifuge tests, showing vertical axis stiffness approximately 16 times horizontal axis stiffness. The target stiffness factor was 10. 


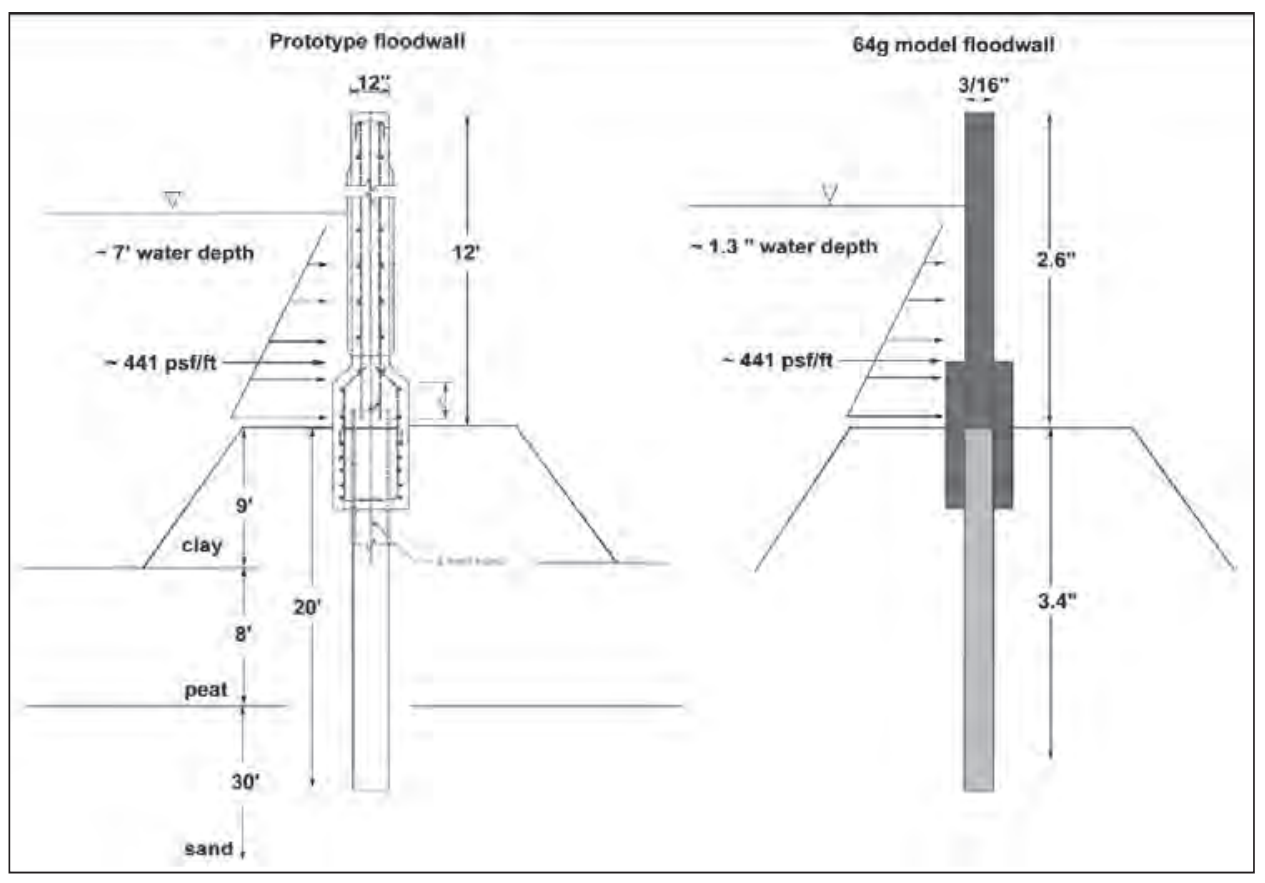

Figure 14. Prototype versus 64-g scaled model with water load.

\section{Centrifuge model box}

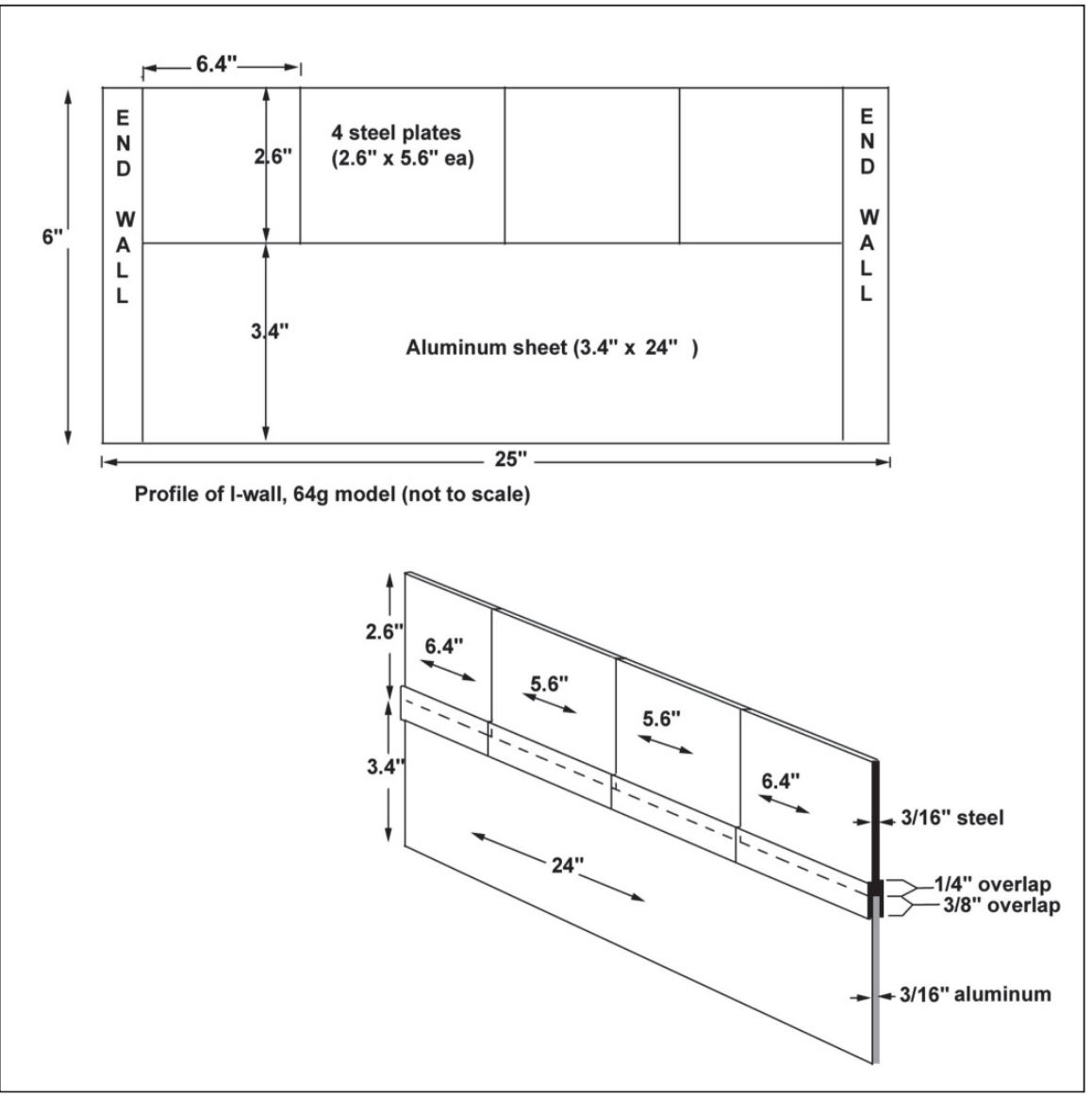

Figure 15. Shop drawings for the two-component model I-wall. 


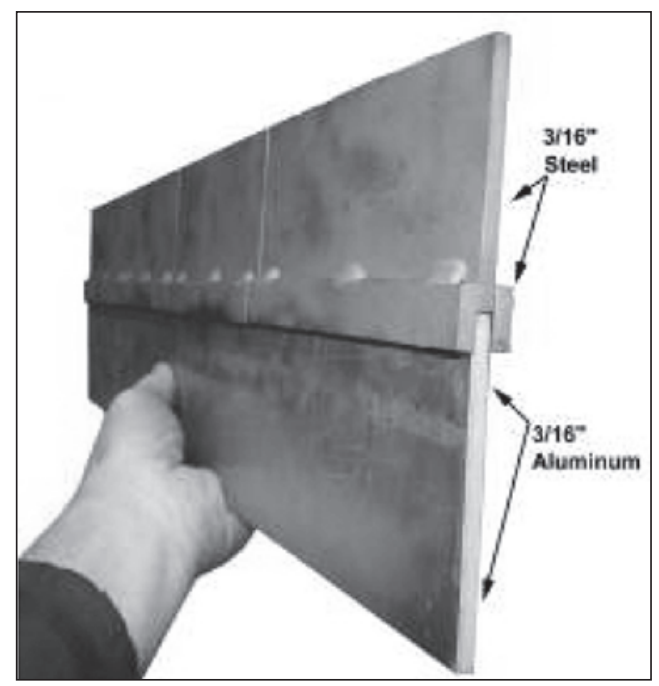

Figure 16. Fabricated model I-wall.

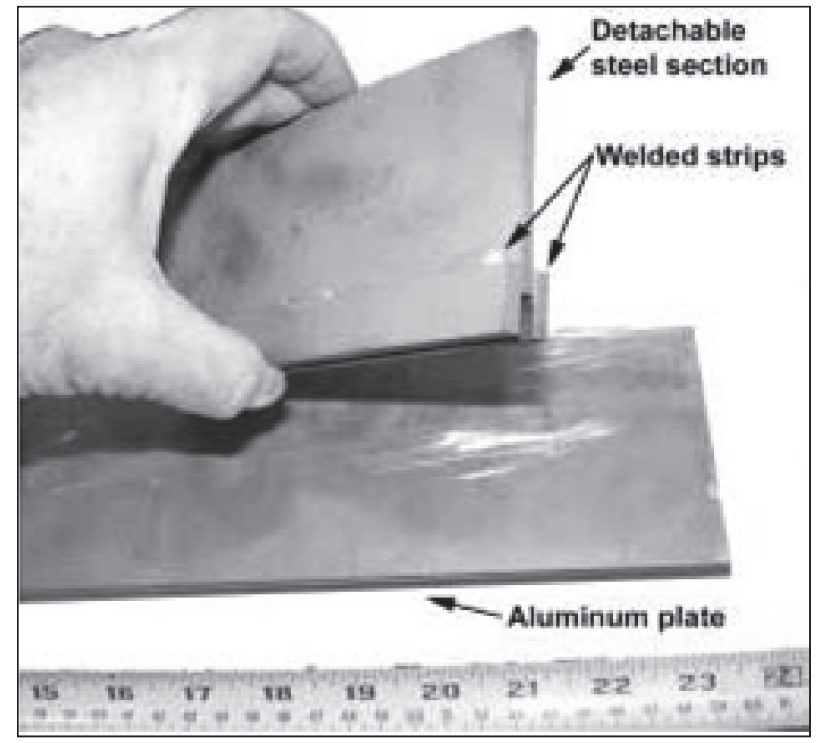

Figure 17. Close-up of model I-wall components.

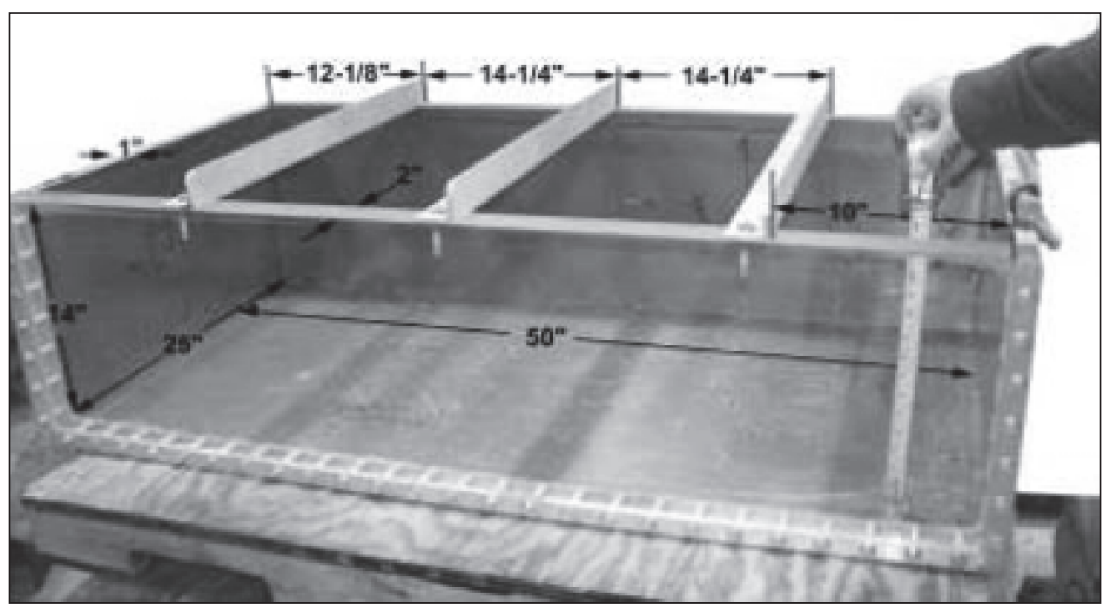

Figure 18. Wide centrifuge model box fabricated for this research task. 


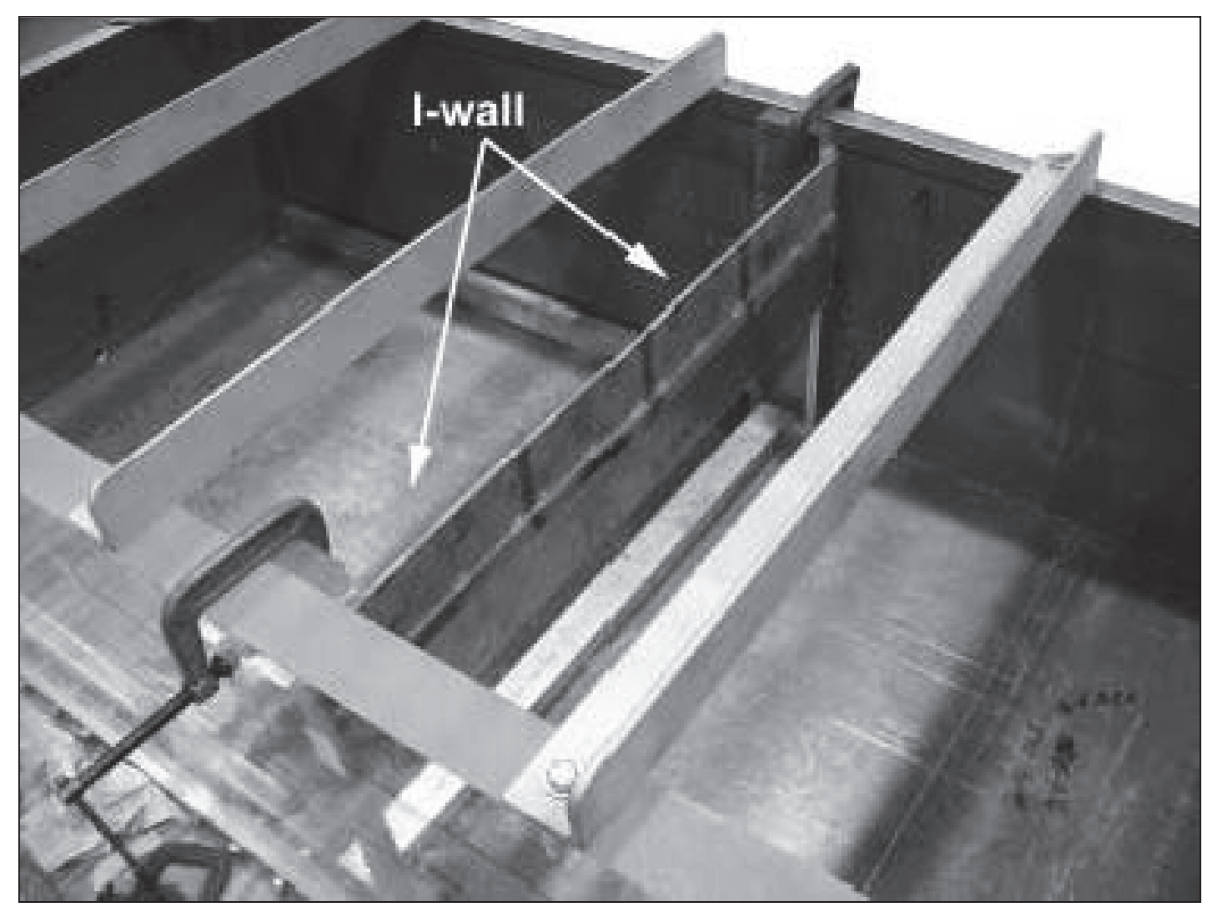

Figure 19. Close-up of model I-wall inserted into the model box. The I-wall rests on thin aluminum shims caulked to the Plexiglas end wall protrusions. The protrusions are clamped to the box sides to prevent I-wall lateral and rotational movement at the box sides, simulating a roller-type boundary condition. A roller-type boundary

mimics a field condition where the l-wall end sections are founded in soil conditions stronger than the weaker soils spanned by the I-wall center sections.

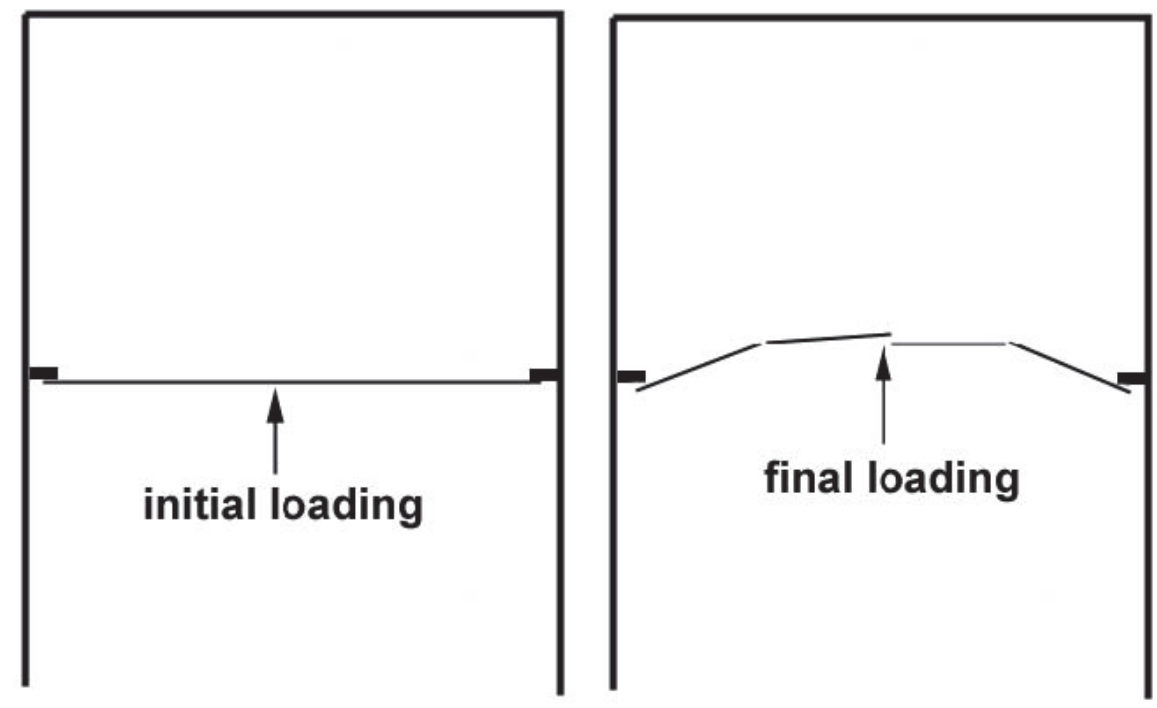

Figure 20. Exaggerated expected deflection pattern. View from top of model box before 64-g load (left) and after 64-g load (right) showing simplified conceptual failure pattern of the I-wall. End walls allow the I-wall to bend but prevent water flow around the I-wall sides. The end wall protrusions (Plexiglas, shown in Figure 19) simulate a roller or hinged boundary condition as opposed to an unrestrained end wall boundary condition used in all the IPET models. 


\section{Initial centrifuge test model setup}

\section{Sand layer}

A different procedure was utilized for placing the 8-in.-thick ${ }^{1}$ sand layer in the model box. In addition, "Nevada" sand, used in IPET models, was not readily available, so substitute sand was purchased from a local building supply store. The material properties for this poorly graded (USCS classification SP) sand were determined to be very similar to those of Nevada sand, with the exception that its D50 was slightly coarser $(0.5 \mathrm{~mm}$ versus $0.2 \mathrm{~mm}$ ). Material properties are shown in the Appendix.

Instead of pluviating the dry sand into the model box and subsequently saturating it from the bottom up, it was decided to pluviate the dry sand directly into the water column (Figure 21). Total saturation of the sand was thus achieved much more quickly, and measurements showed that the inplace saturated density (97 pcf) was comparable to the IPET model inplace dry density (100 pcf) prior to water saturation. No IPET reference was found for the in-place saturated density. The in-place saturated density target was loose sand mimicking a poor foundation under the I-wall center sections.

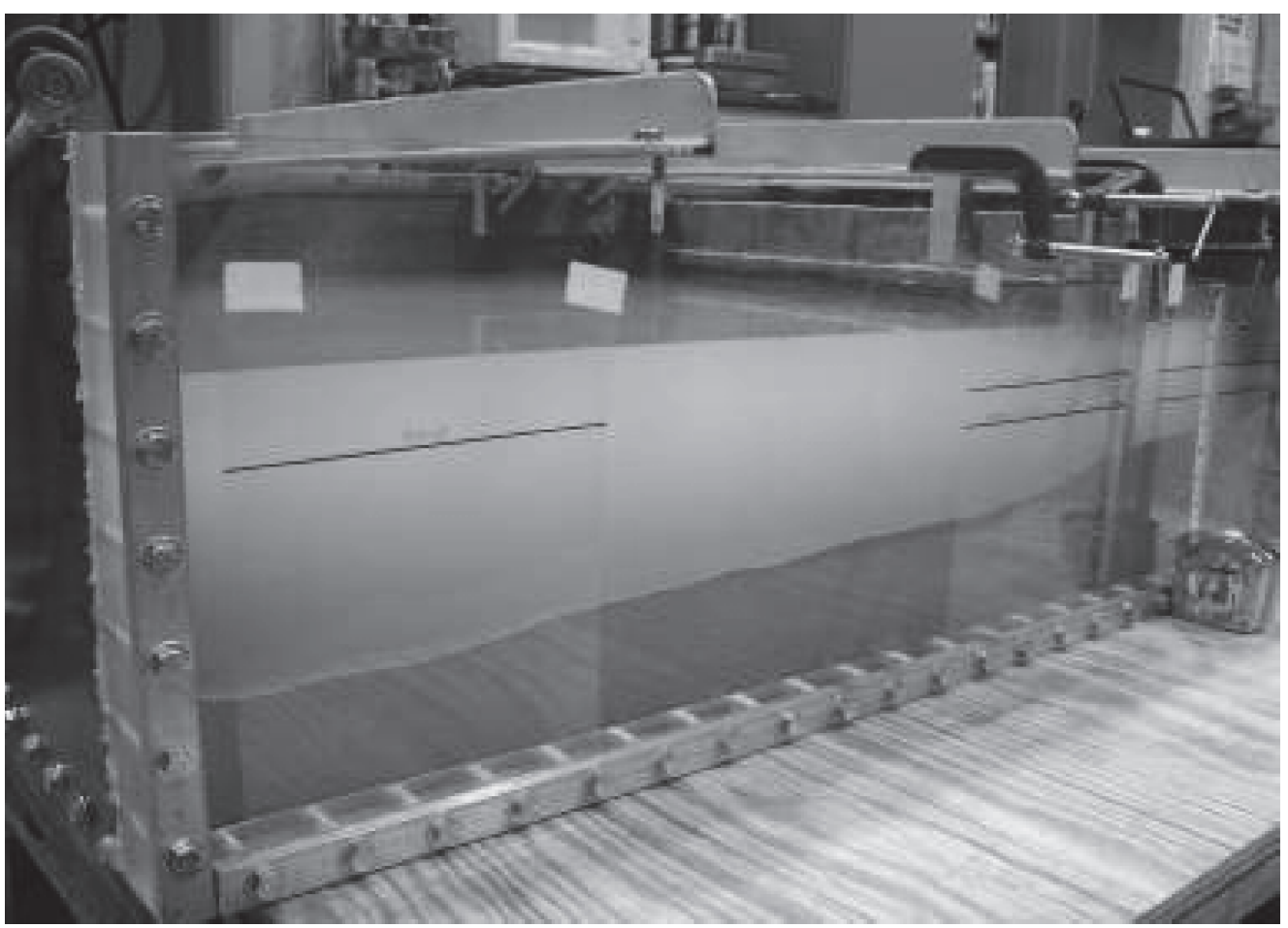

Figure 21. Sand pluviated through the water column.

\footnotetext{
${ }^{1} \mathrm{~A}$ table of factors for converting non-SI units of measure to SI units is found on page vii.
} 
After the 8-in.-thick sand layer was placed, the excess surface water was drained off, completing the saturated loose sand layer (Figure 22). Ten pore pressure transducers were vacuum-saturated with water and placed in the sand, and customized laser mount brackets were fabricated and installed (Figure 23).

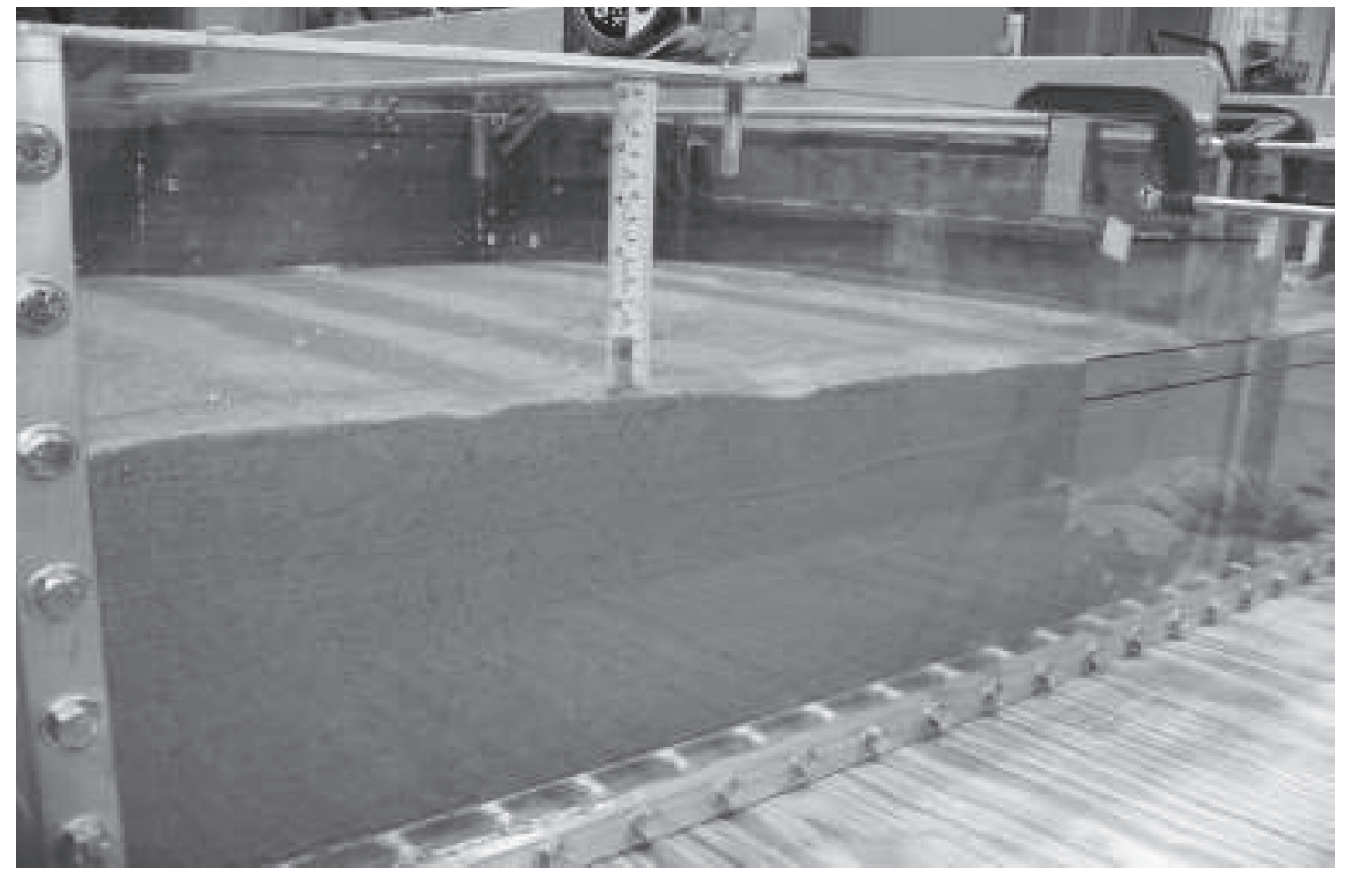

Figure 22. View toward I-wall showing top of 8-in.-thick sand layer.

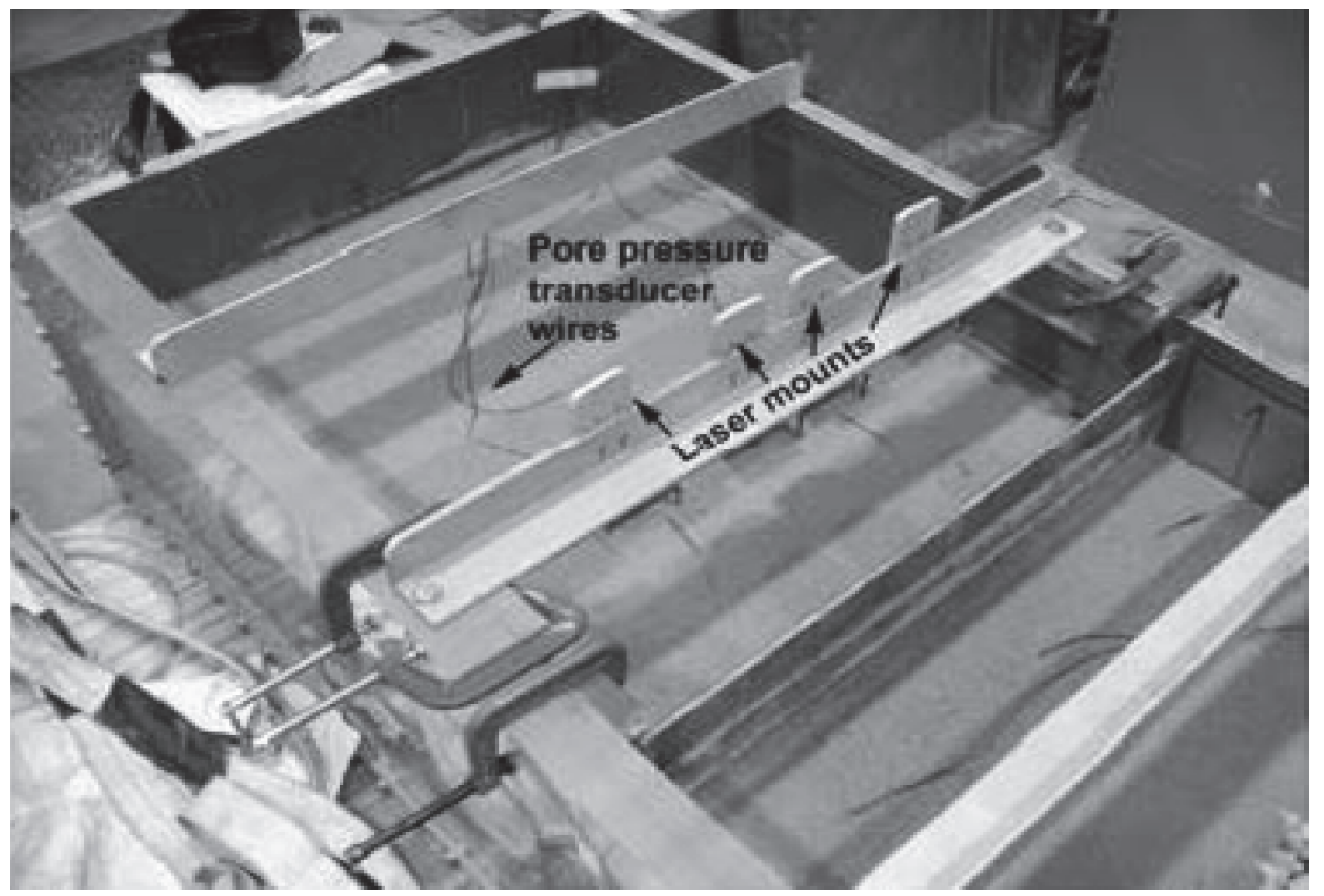

Figure 23. Top of sand layer with inserted pore pressure transducers and laser mount brackets. 


\section{Clay layer and levee}

The swamp clay layer, scaled to 1/64th prototype thickness, was placed into the model box avoiding voids, cracks, and joints as much as feasibly possible in a physical model (Figures 24 and 25). The scaled kaolin clay levee was likewise placed on top of the swamp clay layer. Care was taken to provide a good seal to the steel I-wall. A heavy-duty cellophane wrap was placed on top of any exposed soil to minimize any moisture loss due to evaporation prior to the centrifuge flight (Figure 26). Figure 27 shows a schematic of test model and dimensions.

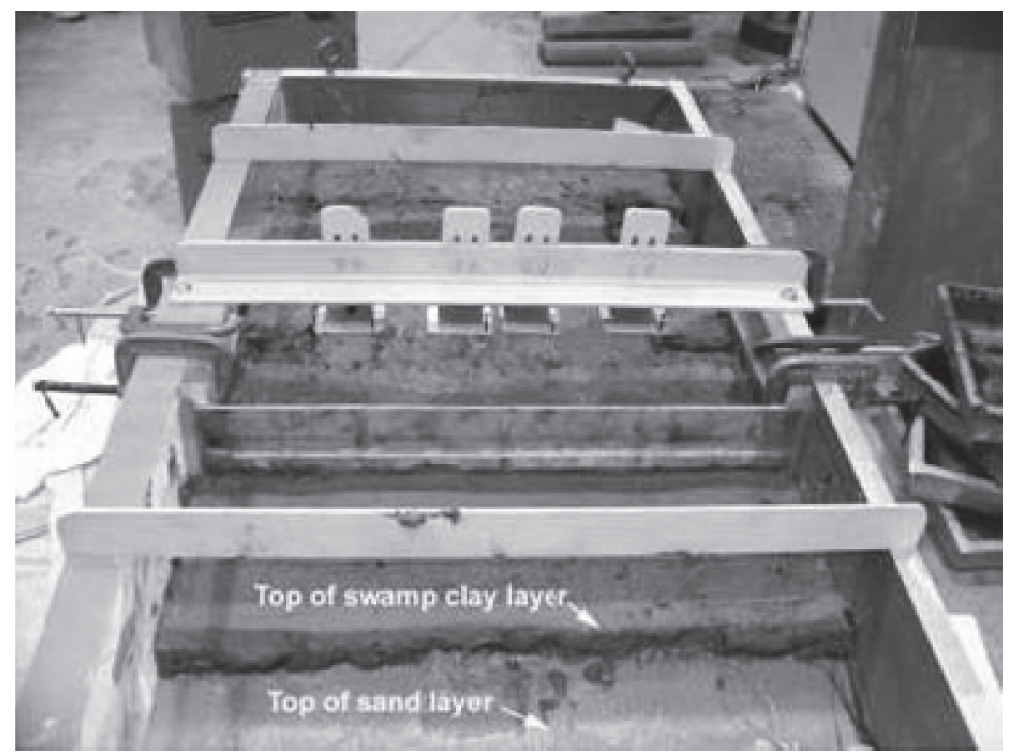

Figure 24. Swamp clay layer placement.

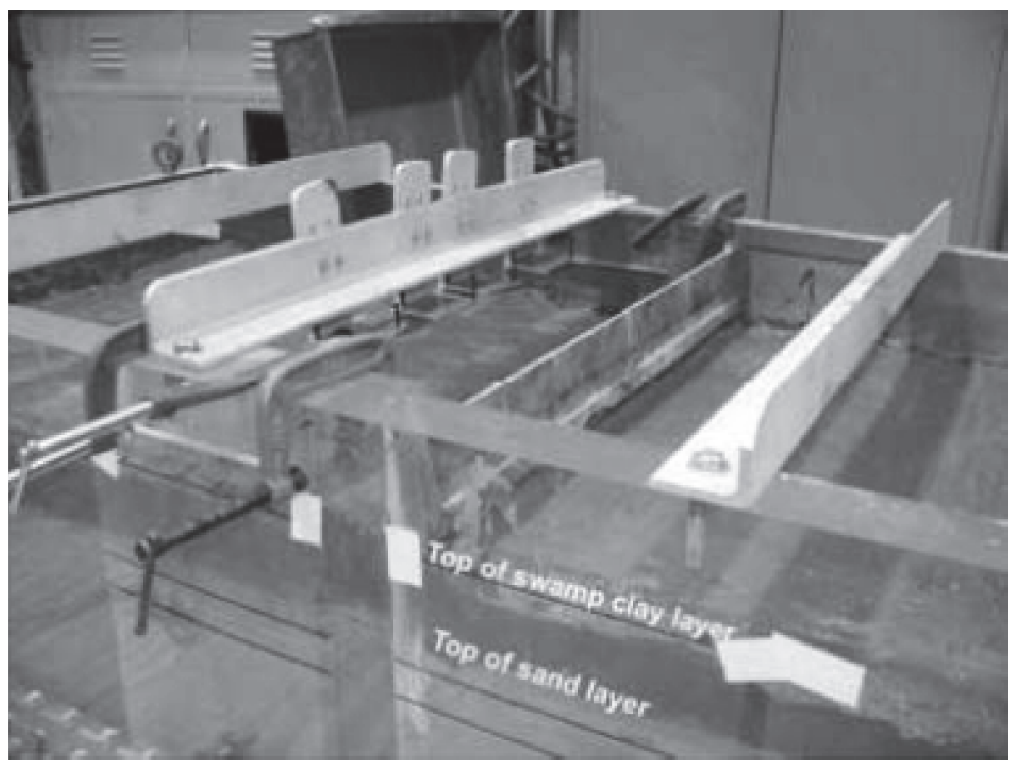

Figure 25. Close-up view of the completed swamp clay layer. 


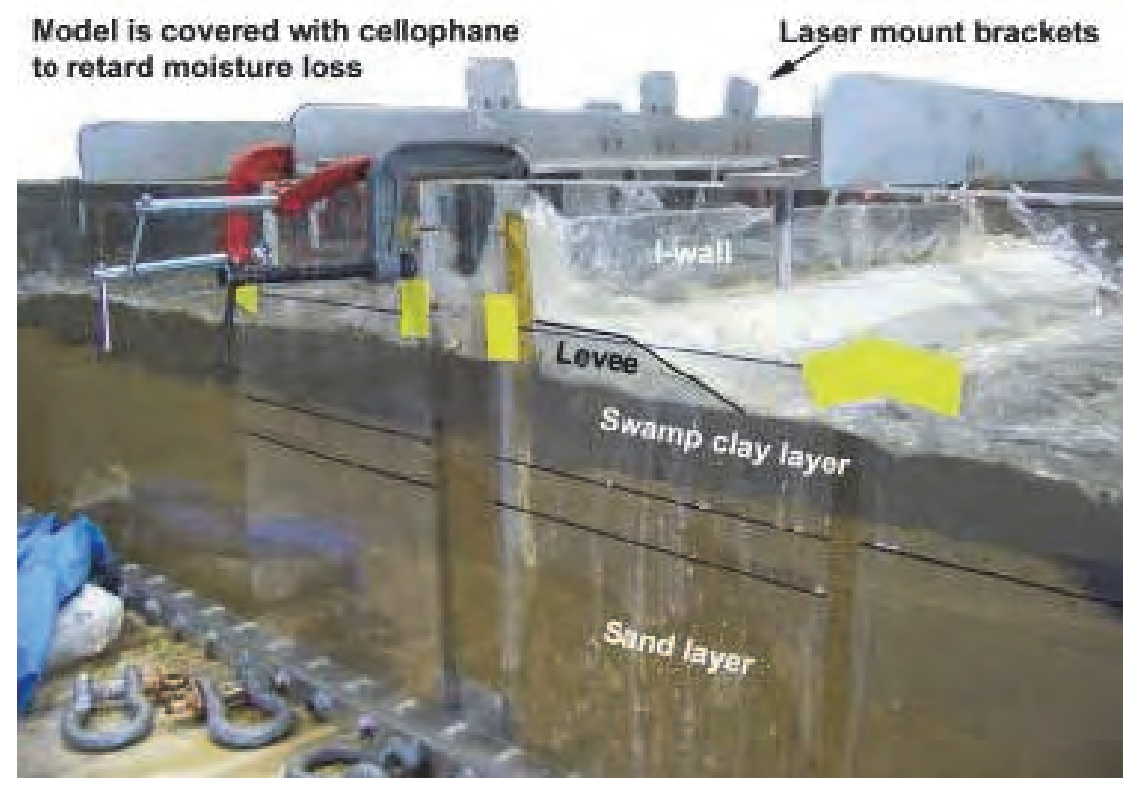

Figure 26. Kaolin clay levee in place. Cellophane wrap was placed on the soil to minimize moisture loss due to evaporation prior to centrifuge flight.

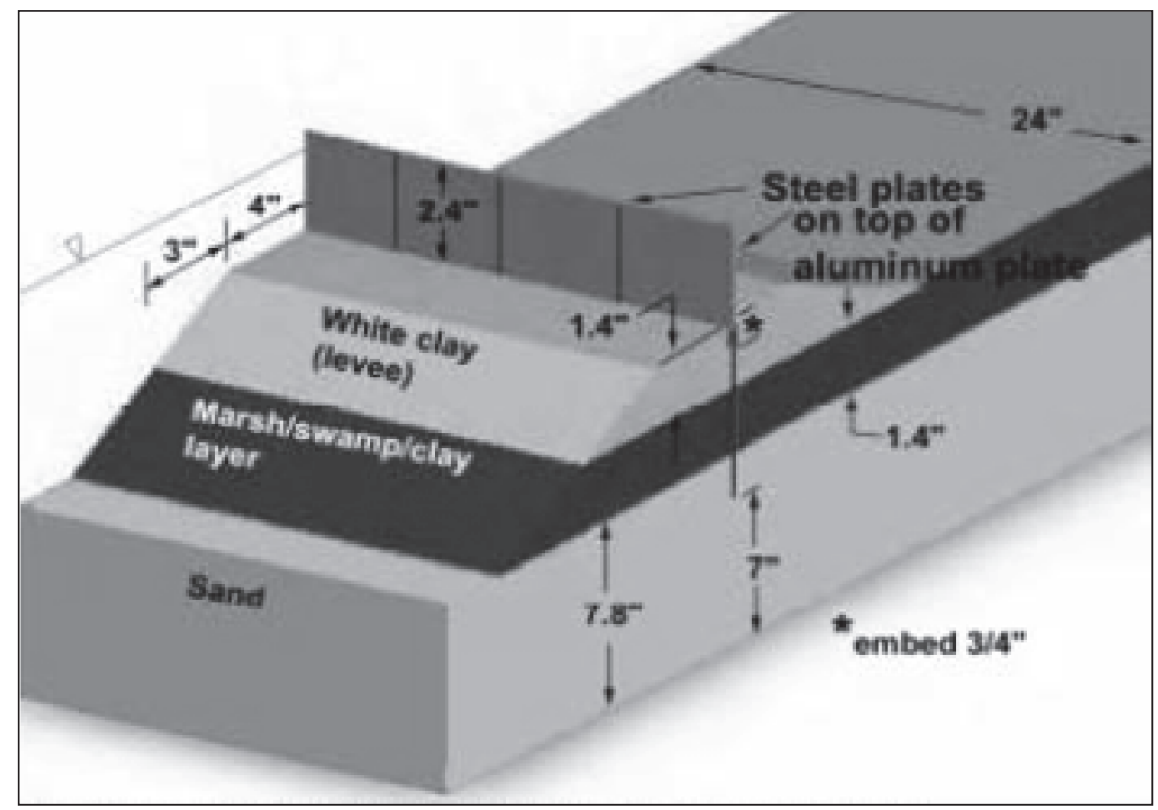

Figure 27. Schematic showing the pre-flight nominal dimensions.

\section{Pre-flight preparations}

Four laser measurement devices were installed on the model box (Figure 28). These lasers had a useable range up to $6 \mathrm{in}$. and were aimed at the steel I-wall to detect any deformation or deflection during flight. 


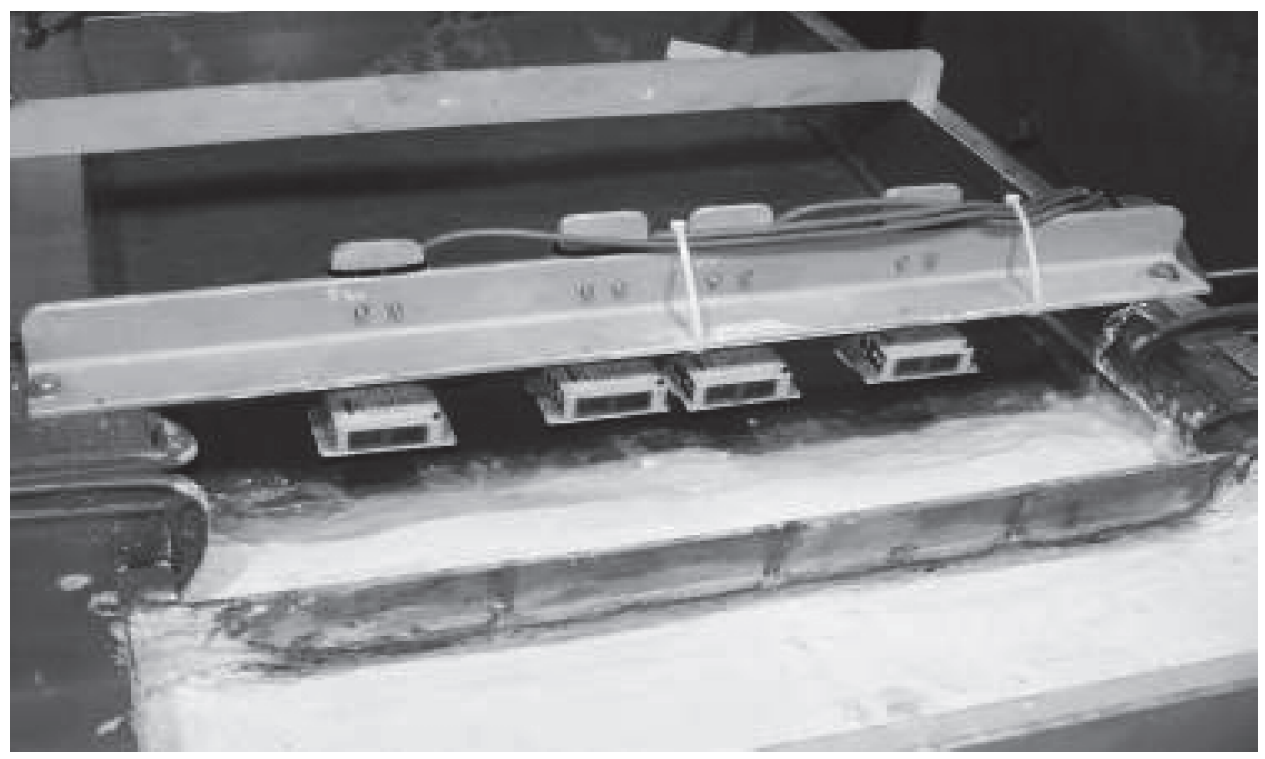

Figure 28. Lasers to measure top of I-wall deflection.

A 1/ 4-in. water supply tube was installed to provide in-flight filling of the canal side. Gravel was placed on the top of the canal-side sand layer to prevent sand or clay erosion during the in-flight water filling.

Prior to construction of the model, the box had been hydrostatically leaktested by filling with water and flying at a $100-\mathrm{g}$ load. No leaks were detected. After the model had been constructed, and immediately prior to its first flight, water was added via the water supply pipe to verify proper operation and to detect any preferential seepage paths in the soil layers as the water height was increased to the top of the I-wall. No attempt was made to correlate the water supply inflow rate to the prototype hurricane storm surge rise. It was determined that the relatively low inflow rate via the 1/4-in. tubing would not fill the basin faster than any underseepage would develop because of the relative foundation weakness and presence of numerous possible preferential flow paths through the very soft organic clay layer. As the water level was raised, it was noted that underseepage through the clay layer developed approximately 4 in. beyond the landside toe of the levee. The approximate seepage gradient was 0.14 .

It was decided to modify the seepage characteristics of the model by effectively sealing off any potential linkage between water level and soil layers. An impervious plastic sheet was placed to cover the water basin up to the top of the I-wall, thus preventing any communication between water and the soil layers. In other words, the foundation soil layer and wall deflection effects were negated to obtain data pertinent only to water pressure/ wall deflection. Figure 29 illustrates this pre-flight change. 


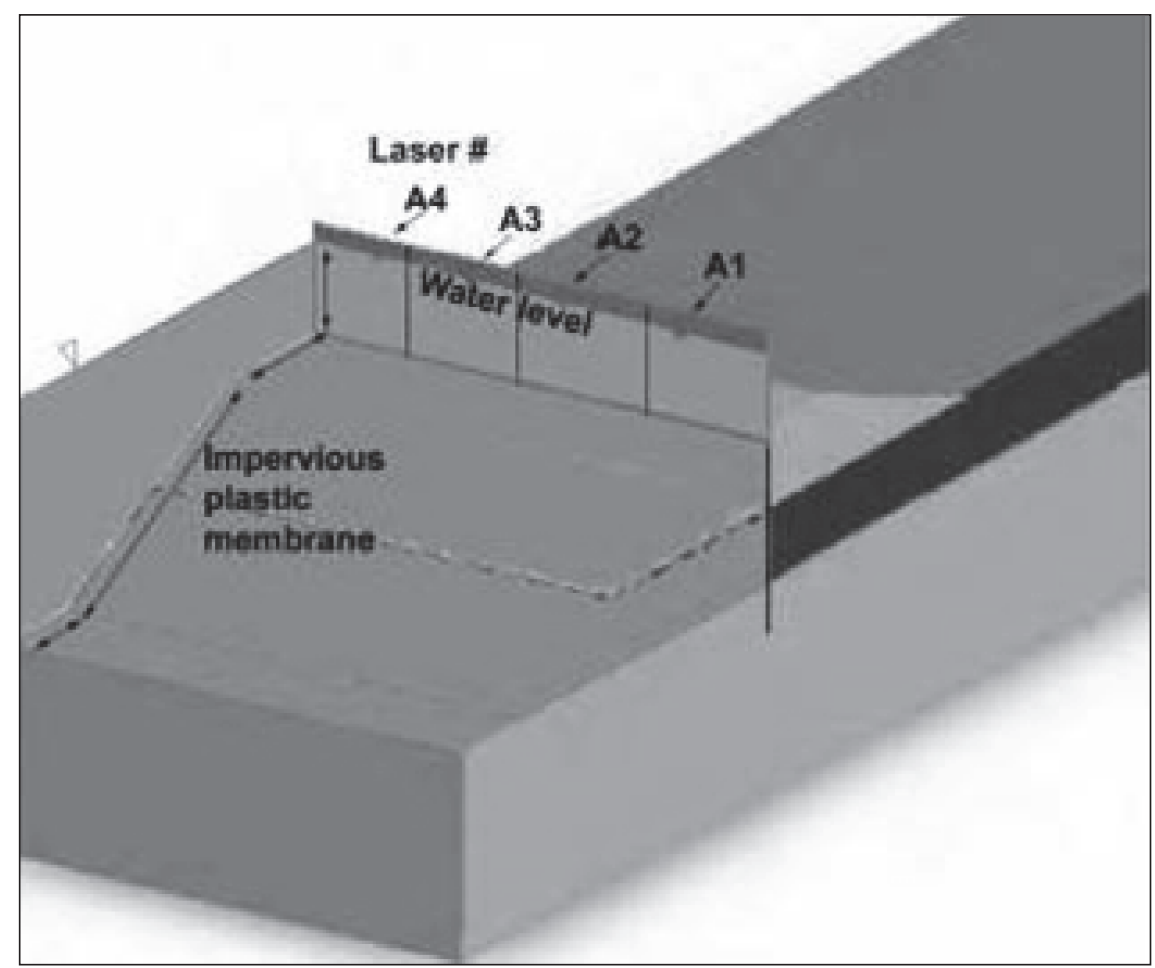

Figure 29. Pre-flight configuration. The water level was raised during the flight to its maximum height (approximately 1 in. below top of wall) just prior to reaching the 64-g loading.

\section{Test results}

The model was flown on two separate flights. The first flight was configured as shown in Figure 29. The second flight had two changes to this configuration. The silicone caulk was cut between each of the four I-wall panels, thus isolating each panel joint from adjacent plates. In addition, the second flight was performed with the preconsolidated organic clay layer that had been compressed approximately $0.125 \mathrm{in}$. during the first flight. The consolidation process strengthened the soil and levee layers by increasing their density and lowering their moisture content; but since no foundation effects were introduced in these tests, the soil strength changes were not measured.

Figures 30 and 31 show the relative laser-measured displacements for the top-of-I-wall segments A1 through A4, for the first and second flights, respectively.

Figure 32 is a scaled top-of-I-wall plan view prior to the first test. Figure 33 shows the scaled top-of-I-wall plan view of the maximum relative displacements during the 64-gloading during Test 1 . The plate joints were caulked 


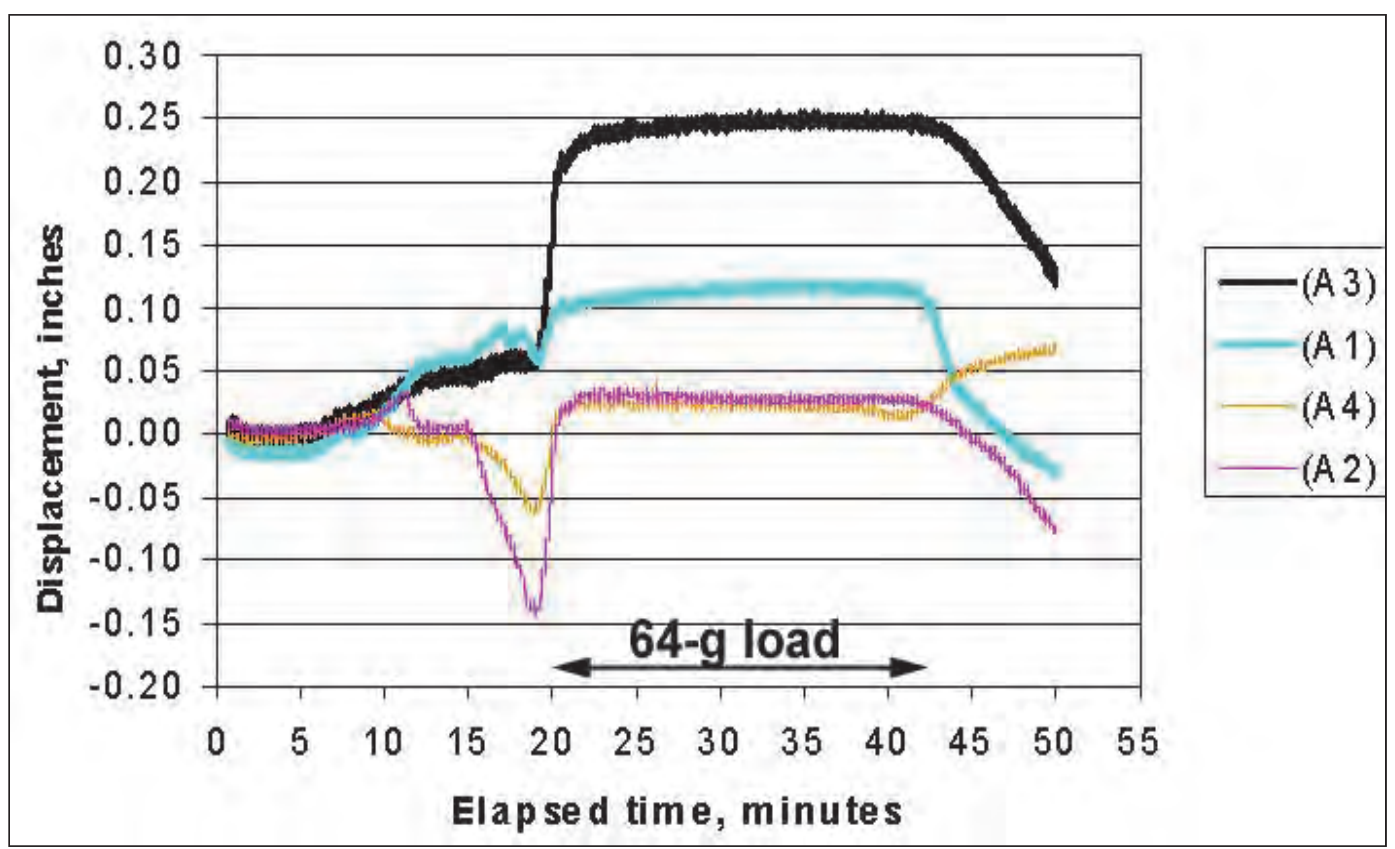

Figure 30. Test 1 laser (relative) displacement results. Positive displacement is toward the landside of the levee. Note the negative (toward the water) relative displacement of plates A2 and A4 during initial water inflow.

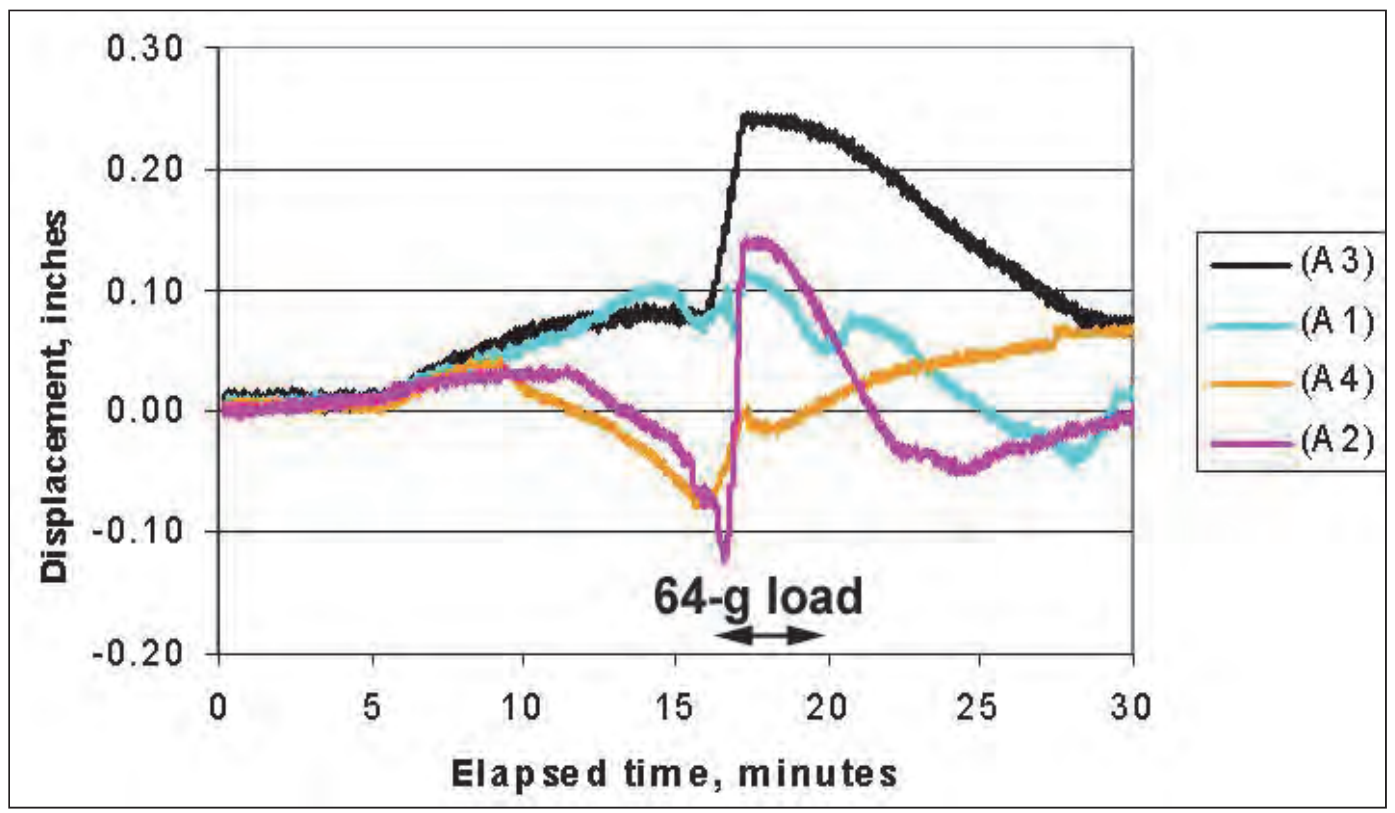

Figure 31. Test 2 laser (relative) displacement results. Positive displacement is toward the landside of the levee. Note the negative (toward the water) relative displacement of plates A2 and A4 during initial water inflow. 


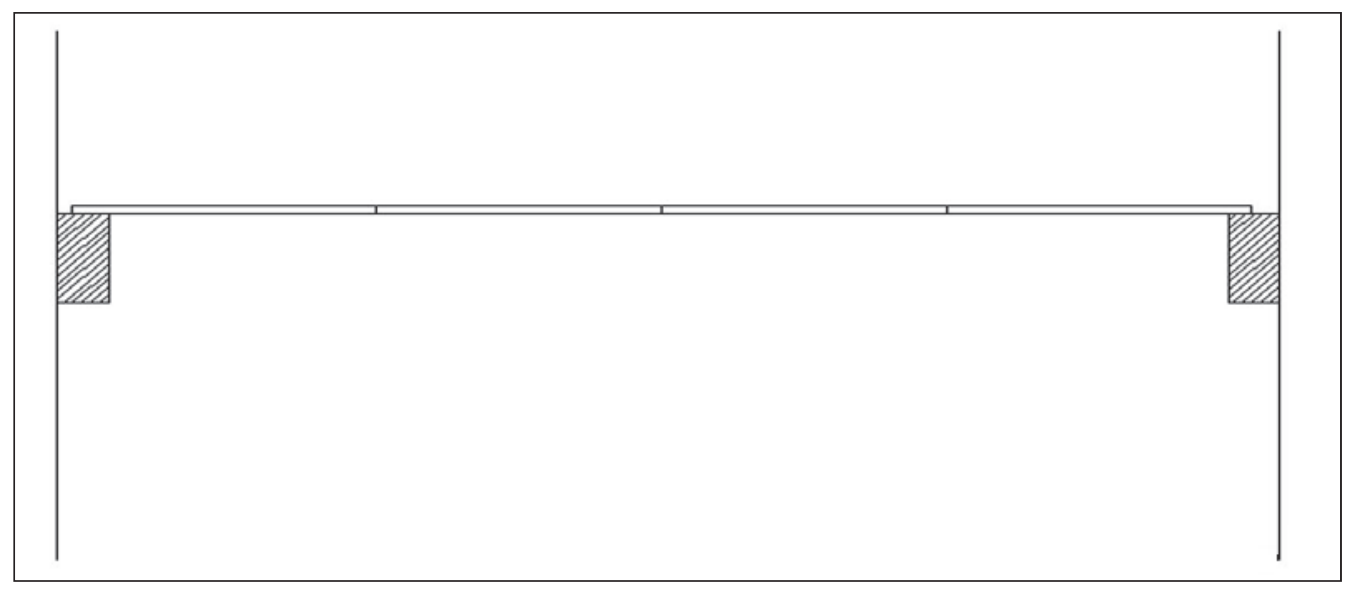

Figure 32. Plan view of I-wall prior to Tests 1 and 2.

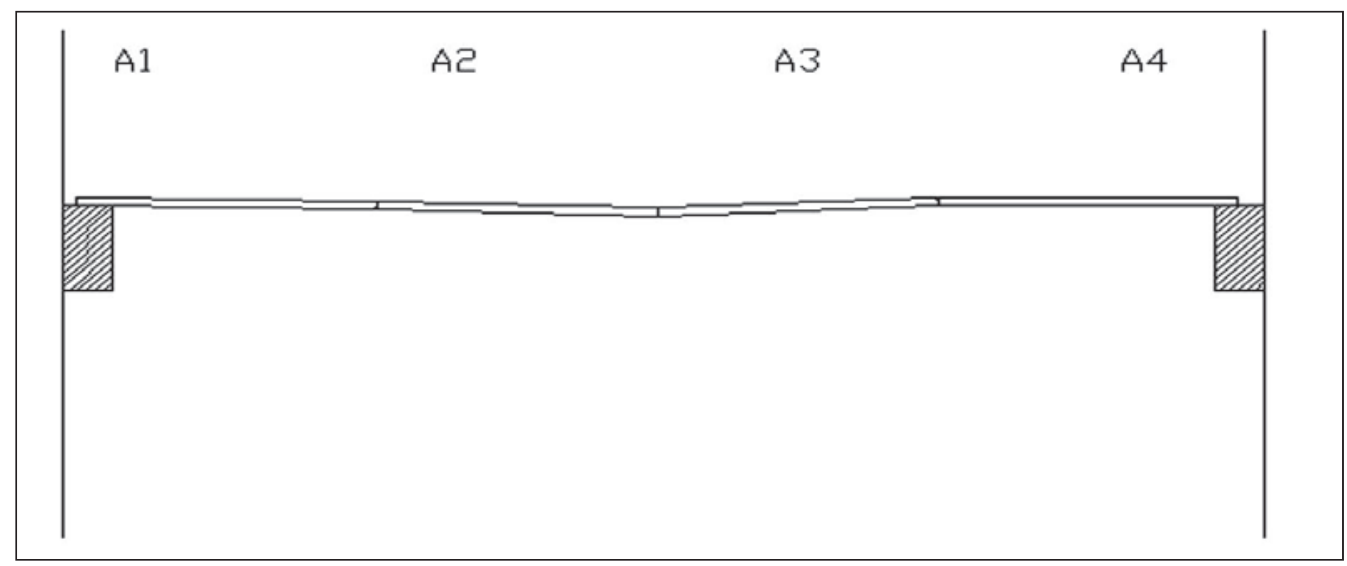

Figure 33. Plan view of I-wall positive movement scaled from Test 1 laser displacements during 64-g loading. Water level was approximately 1 in. below top-of-wall. Plate A4 had virtually no movement.

with flexible silicon caulking in Test 1. Figure 34 shows the scaled top-ofI wall plan view of the maximum relative displacements during the $64-\mathrm{g}$ loading during Test 2 . The plate joints were unconstrained by caulking in Test 2.

Although no underseepage was allowed during the tests, the pore pressure transducer data from both tests was collected and is shown in Figure 35.

Post-test model teardown provided no evidence of any vertical I-wall displacement. No I-wall deformation or bending was evident, indicating that the model I-wall "failure" was due solely to water pressure pushing the steel plates apart. The plates had returned to their pretest positions, and no permanent damage was evident in either the steel plates or the aluminum sheet composing the model I-wall. 


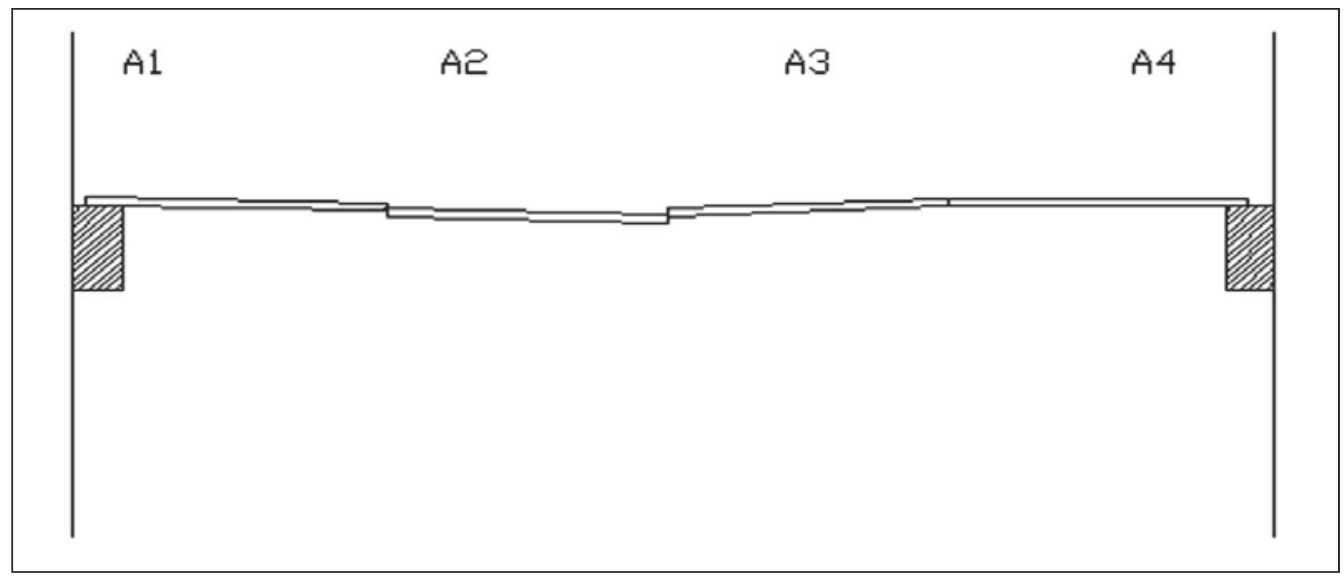

Figure 34. Plan view of I-wall positive movement scaled from Test 2 laser displacements during 64-g loading. Water level was approximately $1 \mathrm{in}$. below top-of-wall. Plate A4 had virtually no movement.

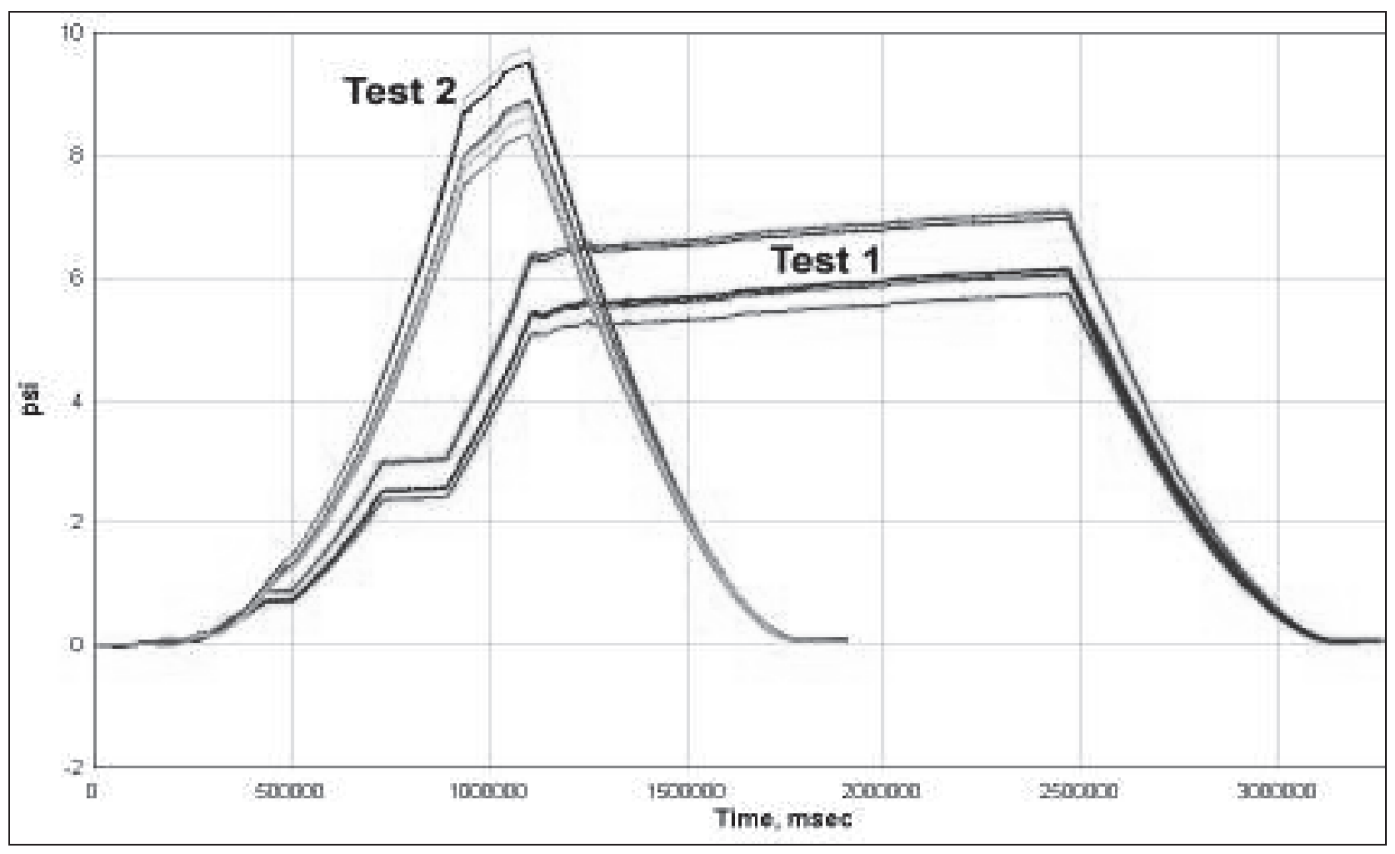

Figure 35. Pore pressure transducer data. Note that the pressures were higher during Test 2, indicative of ongoing soil compression (consolidation) and/or elevated water pressure caused by water leaking through the unsealed steel plate joints during Test 2 .

\section{Summary for Task 1}

The primary purpose of this test effort was to collect small-scale I-wall deflection data to enable design, fabrication, and small-scale modeling of the UMiss I-wall retrofit. A unique two-component model I-wall was designed and fabricated at ERDC to imitate the London Avenue Canal prototype more realistically than had been attempted during previous CRC 
studies. Subsequent CRC testing will be accomplished after design and fabrication of the scaled retrofit are completed by the sponsor.

A secondary purpose of this effort was to provide additional data regarding the foundation-induced failure pattern (lateral gap and plastic yielding of soil layers) observed from numerical models and field tests. This was not accomplished because of the high probability of underseepage-induced model failure prior to obtaining useful wall deflection data, which necessitated isolating the model foundation from the water inflow. Isolating the foundation prevented the lateral gap formation leading to hydrostatic water pressure buildup in the foundation, which was the focal failure mechanism concluded from the IPET studies. Regardless, this study showed that differential wall movement did occur due to rising water levels against the I-wall.

In summary, based on data from four laser displacement points, the water level caused maximum relative deflection in plate A3 of up to $0.25 \mathrm{in}$. The flexible silicone caulking between plates (mimicking the flexible rubber water stop in the prototype) provided some benefit by slightly reducing the maximum relative deflection in plate A2. With no caulking, the plates appeared to move more freely, relative to each other. It is suggested that further testing be conducted separately to explore the relationships between the surrogate water stop material, the concrete-sheet-pile structural connection, expected boundary conditions, and the expected foundation behavior to enable proper design and fabrication of the structural retrofit(s). 


\section{Task 2: Retrofits Centrifuge Modeling}

\section{Background}

As stated in the previous chapter, the primary effort for the centrifuge modeling in Task 1 was to collect small-scale I-wall deflection data to enable design, fabrication, and small-scale modeling of the UMiss I-wall retrofit. This study showed that differential wall movement did occur because of rising water levels against the I-wall.

The purpose of the Task 2 modeling effort was to test remediation alternatives involving wall cap panels. The geotechnical foundation properties of the model matched those of the IPET tests for the 17th Street and London Canal Avenue canal models. The floodwall also matched the structural properties used in the IPET models but was modified to a segmented wall to enable determination of individual wall panel response. The first remediation option to be tested was a U-shaped "clip" connection made from multiply reinforced polymers. The second remediation option consisted of placing a special soil mixture, referred to as the gap filler, in the space between the floodwall and the levee to prevent the formation of a gap. The performance of all models was qualified based on the following data collected during the tests: timehistories of measured wall deflections, pore pressure time-histories, floodwater levels during flood raise, video, and still photography.

\section{Centrifuge testing}

All soil properties and construction efforts were duplicated from the IPET testing.

\section{Tests 1 and 2: Centrifuge models of London Canal Avenue}

Figure 36 shows the schematic of the centrifuge model of the London Canal Avenue failure site. The major difference for this series of tests is that the I-wall comprised four separate sections, whereas the IPET wall was a single component. Test 1 was conducted without any remediation, and the I-wall failed. In Test 2, three 3/4-in. paper binder clips were used to simulate the UMiss mitigation clip design, because the actual clips were not available for this test. The mitigation clips were placed over the top of the I-wall centered at the joints with the expectation that the connection between the wall panels would increase the overall resiliency of the wall to floodwater loading (Figure 37). 


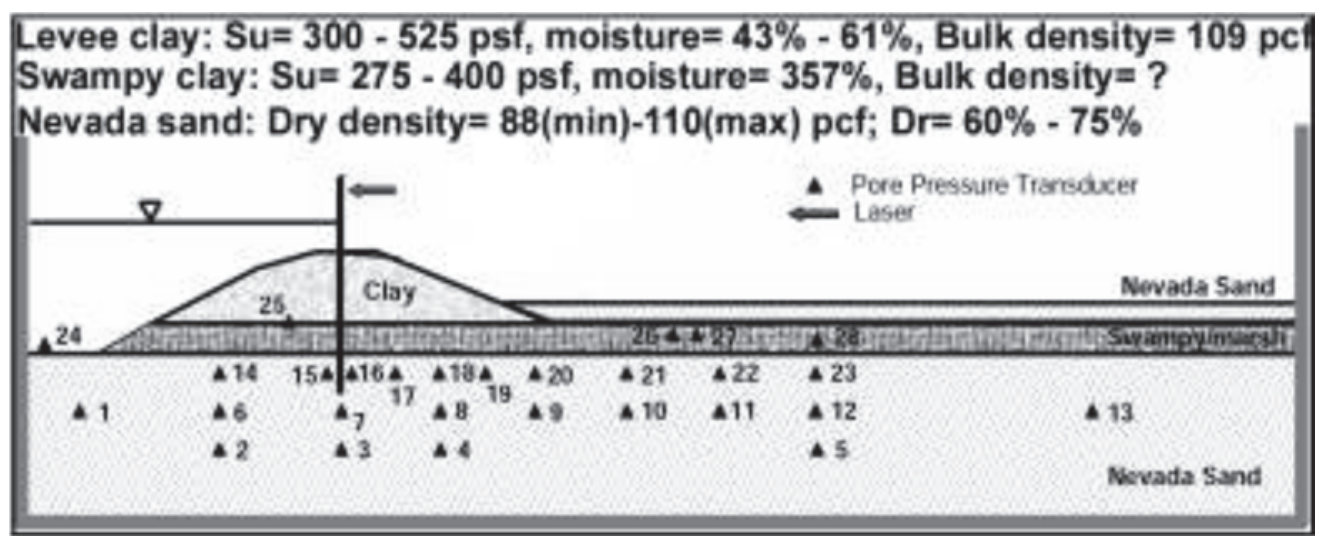

Figure 36. Schematic for London Canal Avenue model.

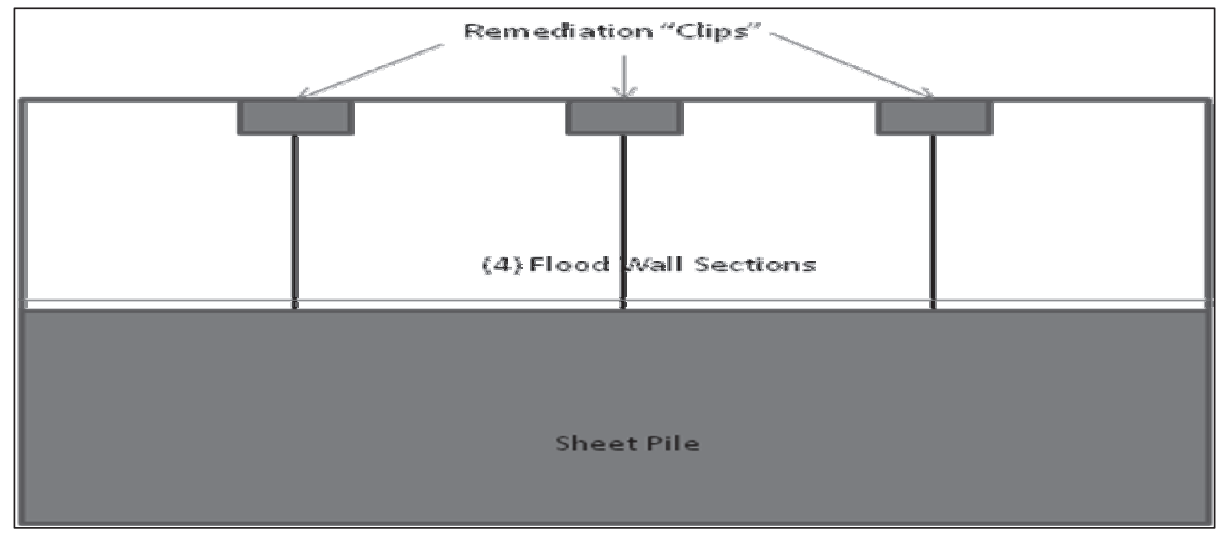

Figure 37. Positions of the binder clips between the flood wall sections.

\section{Preparation for remediation Option 1: Clip connection}

The designed clip connectors were made from folded sheets of reinforced polymers. Six samples were received from Dutta Technologies, Inc., Palm Beach Gardens, FL. The samples measured 5-in.-square flat, folded over into a U-shape with a width of $2.5 \mathrm{in}$. The material properties are as follows:

- Sample 1: 0/90 1-ply, 0.002 in. (approximate thickness)

- Sample 2: 0/90 2-ply, 0.013 in.

- Sample 3: (+/-) 45 Biaxial 1-ply, 0.17 in.

- Sample 4: 0/ (+/-) 45 Biaxial 2-ply, 0.040 in.

- Sample 5: 0/ (+/-) 45 Biaxial 2-ply, 0.045 in.

- Sample 6: 0/ (+/-) 45 Biaxial/90 3-ply, 0.090 in.

Samples 1, 2, and 3 were too thin and porous, and Sample 6 was too thick; thus, the four samples were eliminated from the evaluation. Samples 4 and 5 were cut into three clip sections, $1.25 \mathrm{in}$. long and 0.75 -in.-wide; circled in Figure 38, each section represents a full-scale connection clip 6.7-ft-long and 4-ft-wide. 


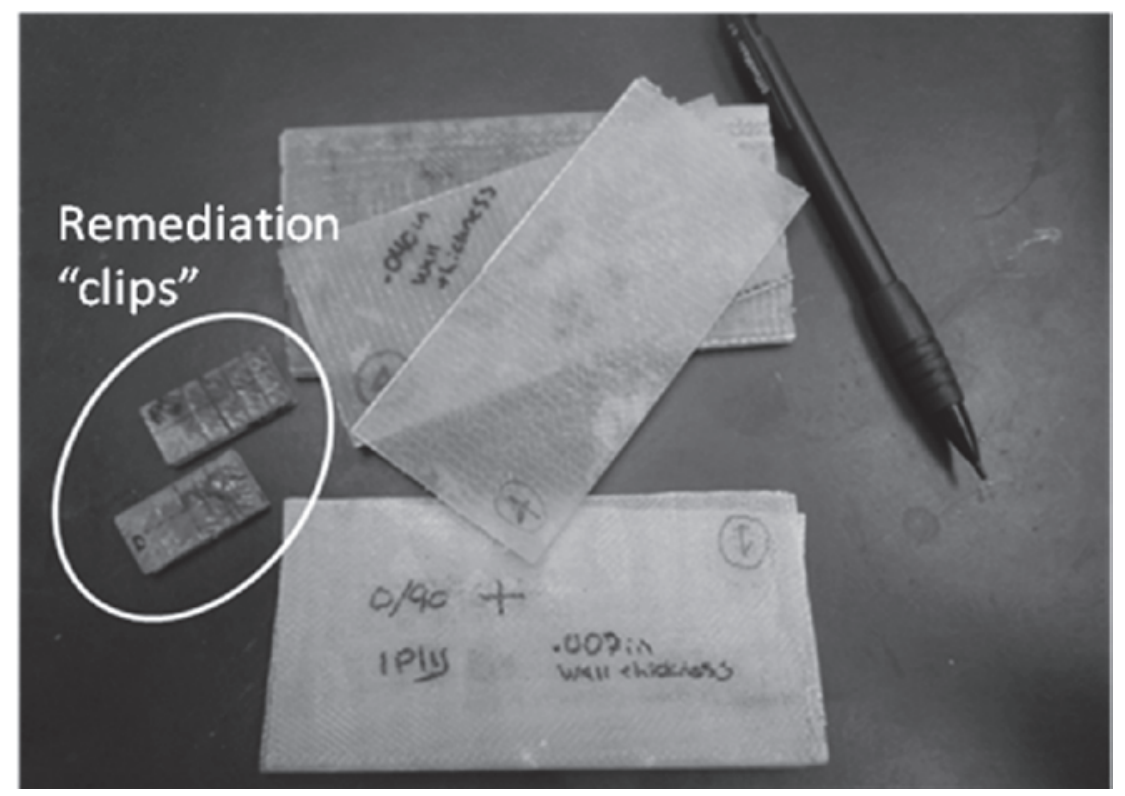

Figure 38. Samples of fiber reinforced polymers submitted for evaluation as clip connections.

\section{Tests 3, 4 and 5: London Avenue mitigation tests for clip samples 4 and 5}

A small area on each clip was sanded to a smooth surface (without fraying the fiber) for placement of the strain gages. Figure 39 shows a typical instrumentation plan for the clips. Similar procedures were followed for the pressure cells, which were mounted on the I-wall sections. Test 3 had pressure cells on both sides of the I-wall (Figure 40); however, the protuberance of the pressure cells caused the clips to flare out, thus reducing the required contact of the clip instrumentation with the I-wall. The modifications included mounting the pressure cells only on the landside and milling down the I-wall by $0.017 \mathrm{~mm}$ (thickness of the pressure cell) to emplace the pressure cell flush into the I-wall. Figure 41 shows a clip in place over two I-wall sections and a pressure cell on the back side of the wall. Laser gages were also positioned behind the I-wall center sections (see complete test setup in Figure 42). Four video cameras were also positioned around the model container for multiple views of the test.

Instrumentation data collected for Test 3, with clip sample 4, were deemed to be inaccurate because of the poor contact between the sensors on the I-wall panels and the clip connectors. Test 4, also with clip sample 4, was conducted with the instrumentation modifications. Test 5 mitigation test was conducted using clip sample 5. 


\section{I-Woll Model}

Front View - Cap 2

Larndsicte

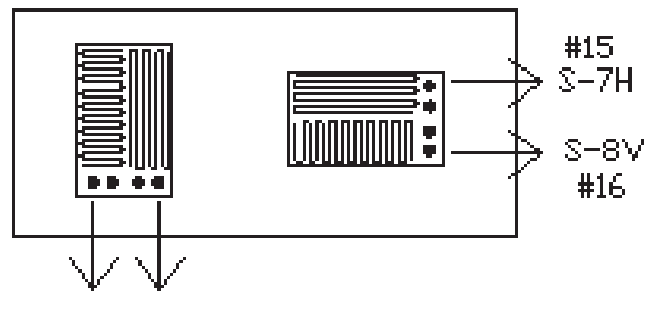

$S-6 \mathrm{H} \$-5 \mathrm{~V}$

\#14 \#13
Rlversalde

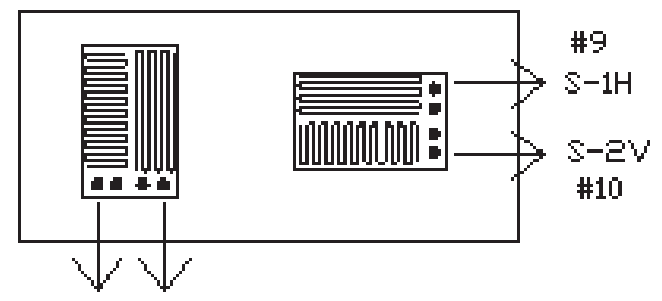

$\mathrm{S}-4 \mathrm{H} \mathrm{S}-3 \mathrm{~V}$

$\# 12 \quad \# 11$

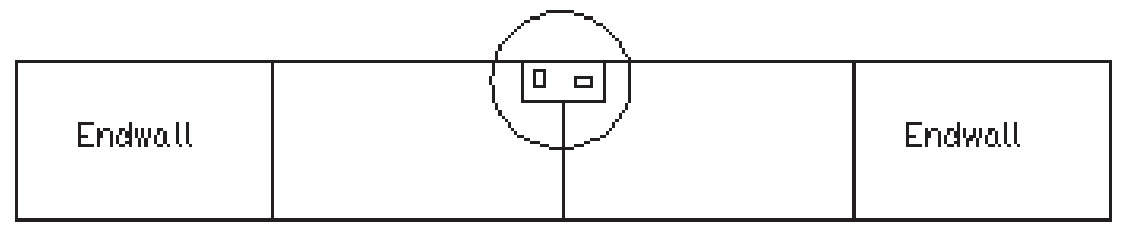

Figure 39. Typical schematic for strain gages on a clip connector.

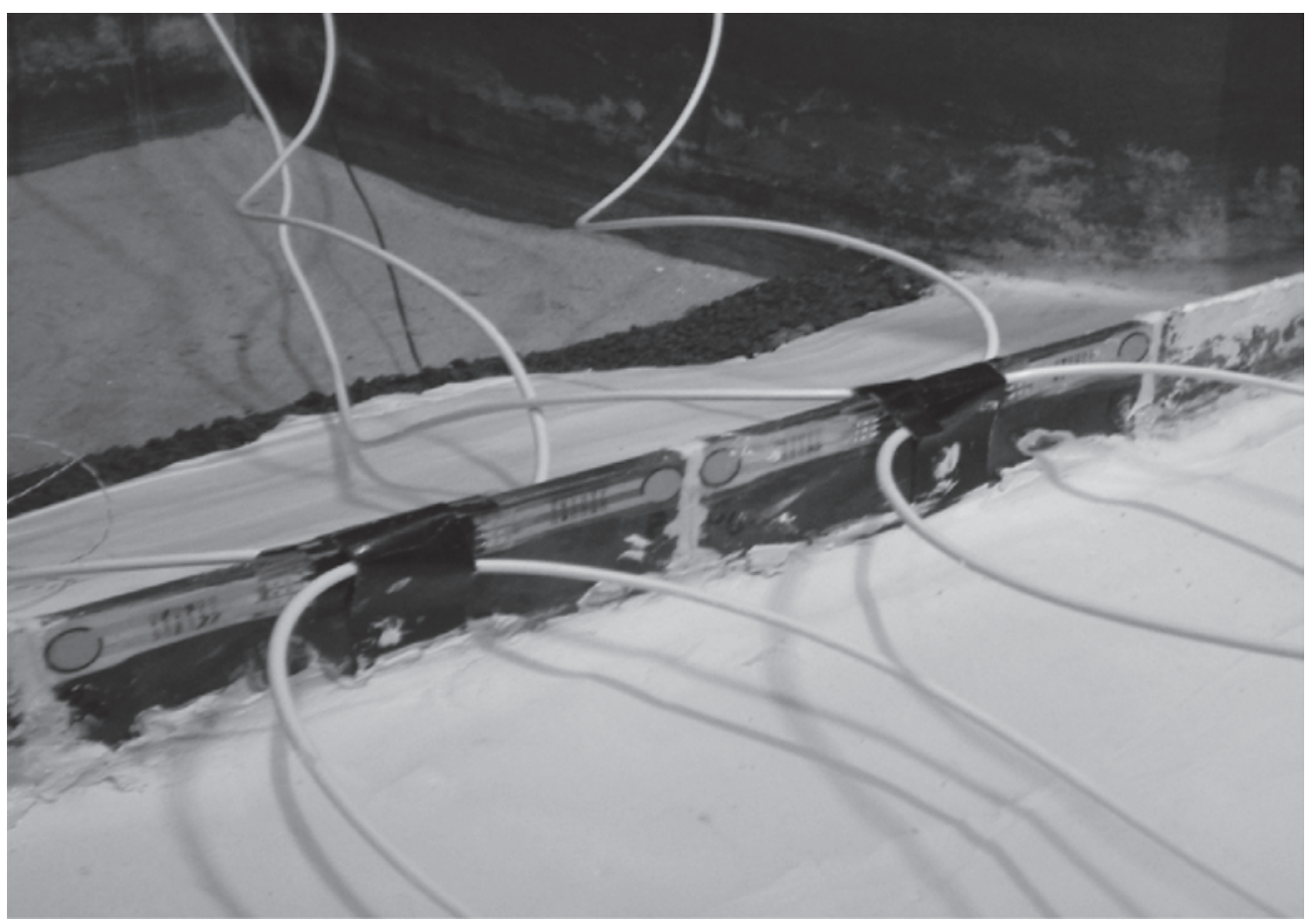

Figure 40. Pressure cells on both sides of the l-wall sections. 


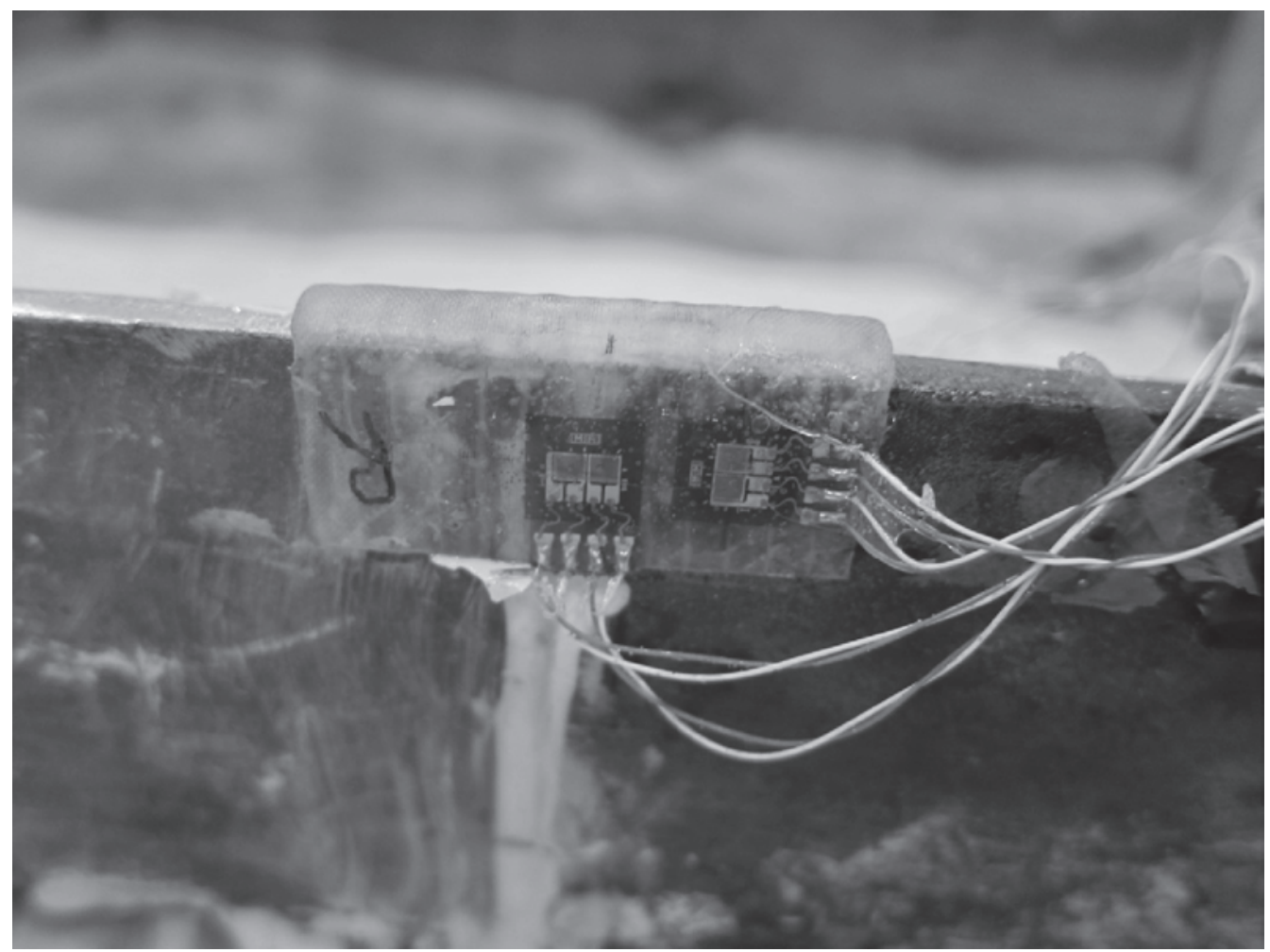

Figure 41. Instrumented polymer clip placed over two I-wall sections.

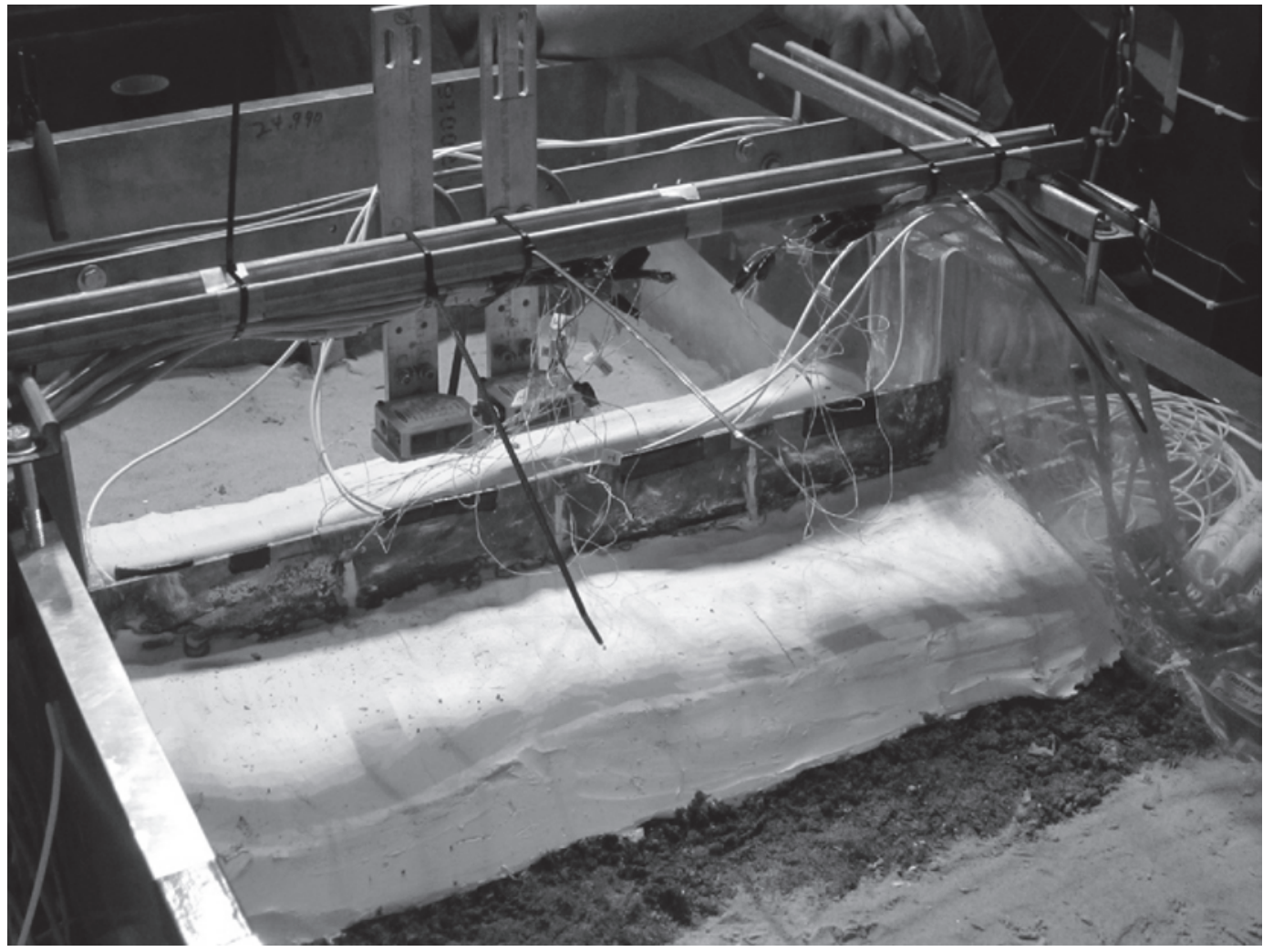

Figure 42. Completed I-wall clip mitigation test with laser gages ready for centrifuge testing. 
Flight procedures for the centrifuge tests were as follows:

- Spin up to 10-g's and check the balance of the machine.

- At 50-g's, introduce water into the model container.

- Spin up to desired test level of 64-g's.

- Check instrument readings and turn on video.

- Raise water to desire level.

- Maintain test level at 64-g's until the desired model behavior is reached.

- Shut down all systems and stop boom.

Tests 6 and 7: Centrifuge model of 17th Street with and without mitigation clips

Figure 43 shows the schematic of the 17th Street levee failure site. During the consolidation process some facility issues that disrupted the consolidation process were discovered. The foundation clay was over consolidated with an undrained shear strength of 600 psf. The clay for the levee was within the target range of $400 \mathrm{psf}$. Since the focus of the centrifuge experiment was to evaluate the effectiveness of the mitigation method, the clay was considered to be acceptable if the I-wall failure could be induced. The I-wall in Test 6, conducted without mitigation, failed in rotational mode only. The IPET results for this site showed both rotation and translation modes of failure. Test 7 was the last test in the clip mitigation series. Only one clip was used in this model at the midsection joint. The joints at the end sections were left unmitigated.

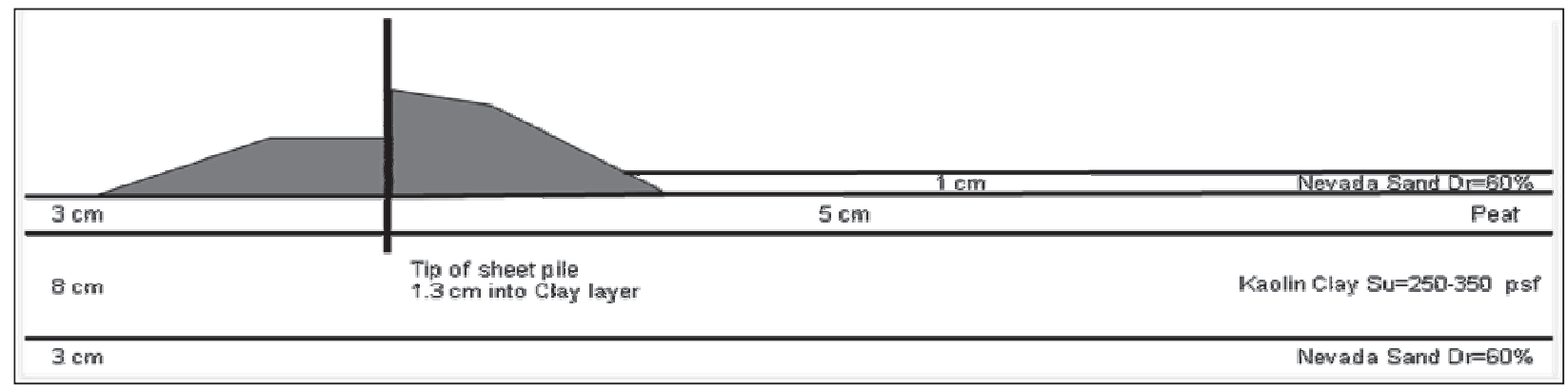

Figure 43. Schematic of the 17th Street levee failure site modeled for centrifuge testing.

Test 8: Centrifuge model of London Canal Avenue with gap filler mitigation method

The gap filler mitigation method was proposed as a self-sealing bentonite apron to be embedded in the levee. The postulation was that the bentonite would plug the gap created as the wall moved under load. This gap 
phenomenon was observed from previous centrifuge IPET studies, both at ERDC CRC and at Rensselaer Polytechnic Institute (RPI), of levee failures caused by the surge events from Hurricane Katrina. The gap was formed as the floodwater pushed the I-wall toward the landside of the levee leaving a gap between the riverside of the wall and the levee material. Test 8 was designed to evaluate the effectiveness of the bentonite apron for mitigating the gap phenomenon. The filler was a sand and bentonite mix (60:40) and had a dry unit weight of $1500 \mathrm{k} / \mathrm{m}^{2}$ and moisture content of 4.66 percent. The proposed design was to fill a shallow 1-ft-square trench by the riverside of the I-wall with the dry mixture that would cascade into the gap as the I-wall moved (Figure 44a).

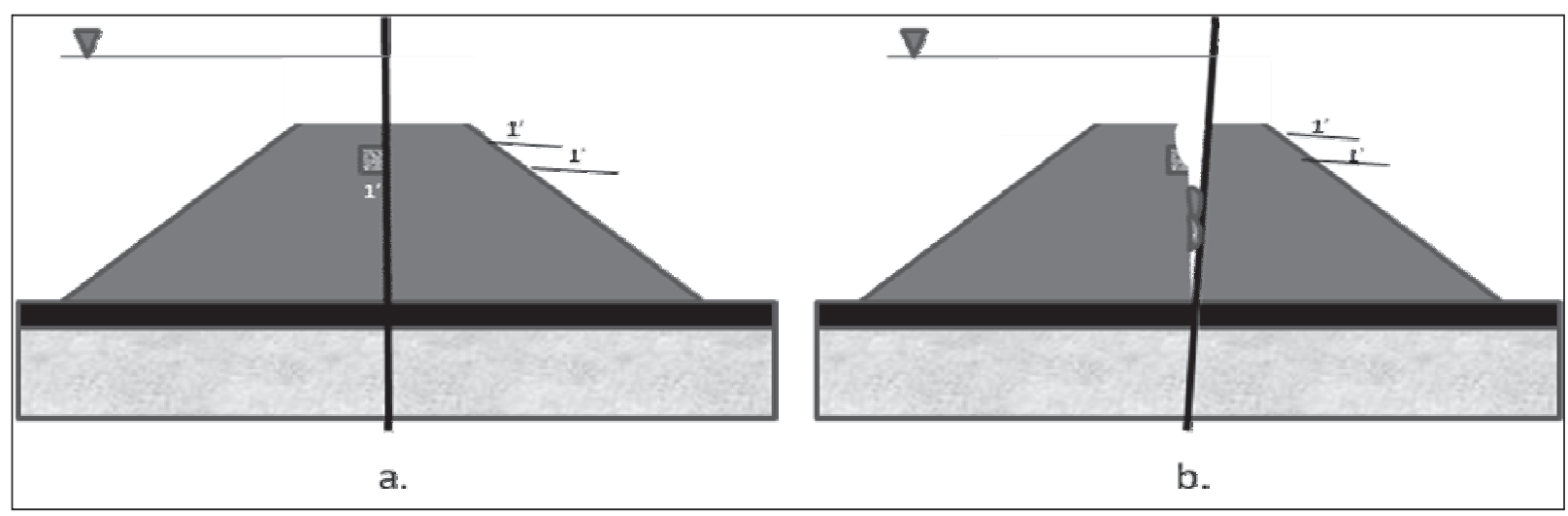

Figure 44. (a) Gap filler entrenched along the I-wall, (b) filler falling into the gap and preventing flow.

Model construction for Test 8 was very different from that of previous test models. A single wall panel was used instead of the multiple I-wall sections to focus on the gap filler mitigation method. The sand and bentonite mixture was laced with gold glitter to facilitate, tracing the movement and final position of the filler material. Construction of the levee sections from consolidated clay was standard practice. The riverside levee section was the mitigated side, where a 1-ft-square trench was "grooved" into the side of the levee $1 \mathrm{ft}$ (prototype scale) below the crest (see schematic in Figure 44a). A thin plastic sheet (saran) was used to encase the filler to prevent in-place expansion and to facilitate the fall of the filler into a gap (Figure 44b). The plastic sheet was trimmed so that it was in contact only with the clay levee and not with the I-wall. The crest part of the grooved clay was peeled back to expose the trench. The bentonite-sand mixture was then placed against the I-wall in the model container. Once the levee section was in position, the filler mixture was poured into the trench; and the clay was folded back over to cover the fill. Various model construction procedures are shown in Figure 45. The model was spun up to 64-g. Failure of the I-wall occurred shortly after the specified g-force was reached. 

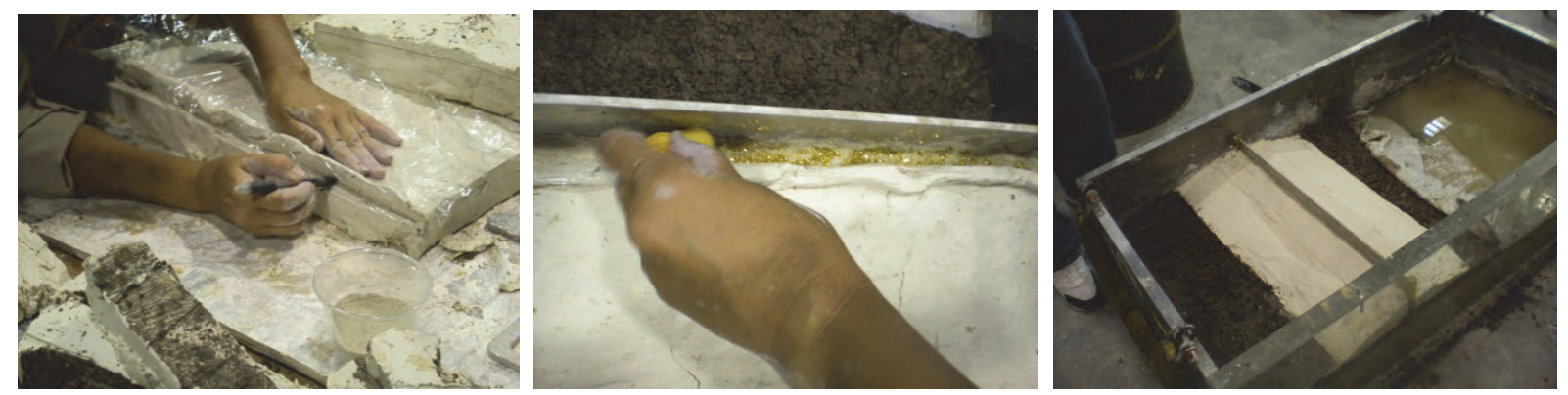

Figure 45. "Trenching" the levee, pouring in the filler, completed levee model.

\section{Summary of test results}

\section{Test 1}

The London Canal Avenue levee model without mitigation failed. Figure 46 shows the I-wall failure.

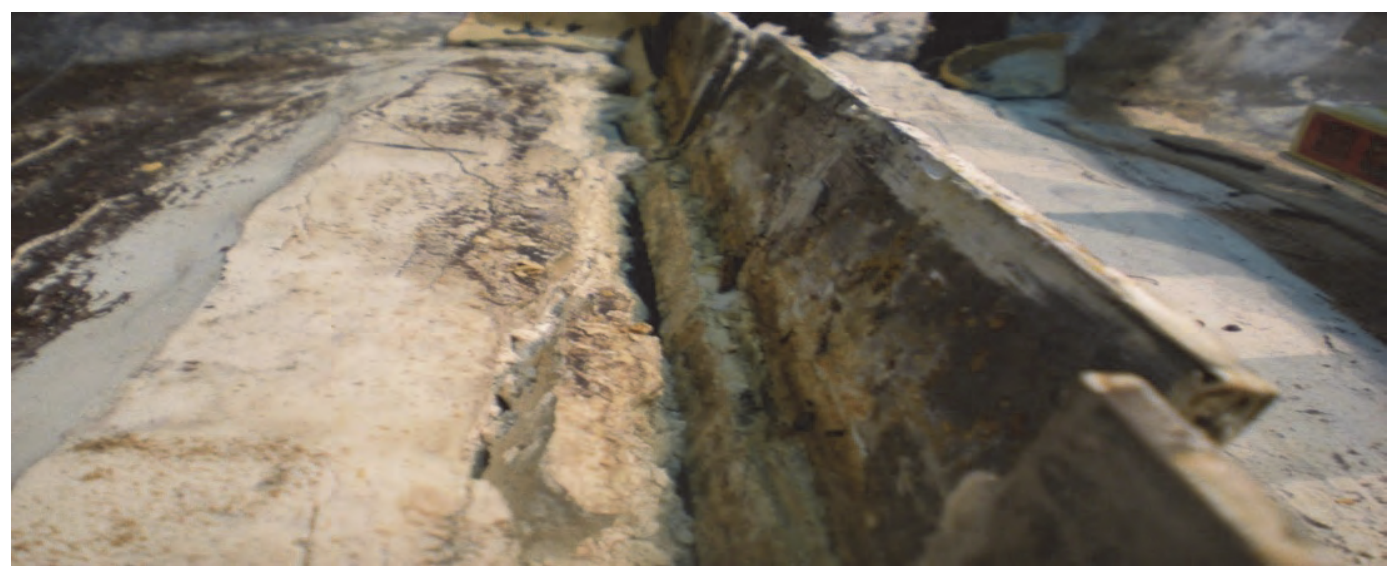

Figure 46. I-wall failure occurred without the clip mitigation.

\section{Test 2}

The London Canal Avenue levee model with three binder clips did not fail.

\section{Test 3}

The London Canal Avenue levee model with three polymer clips (sample 4) did not fail. However, instrumentation data was not accurate because of poor contact between the clip and wall section.

\section{Test 4}

The London Canal Avenue levee model with three polymer clips (sample 4) did not fail. This was a retest of Test 3 with modifications to the instrument- 
ation. Because the I-wall did not fail at 64-g, the level was raised to 100-g in an attempt to induce the failure. Laser gages showed slight wall movement at 100-g, but no failure occurred and centrifuge testing was terminated. See Figure 47 for post-test results.

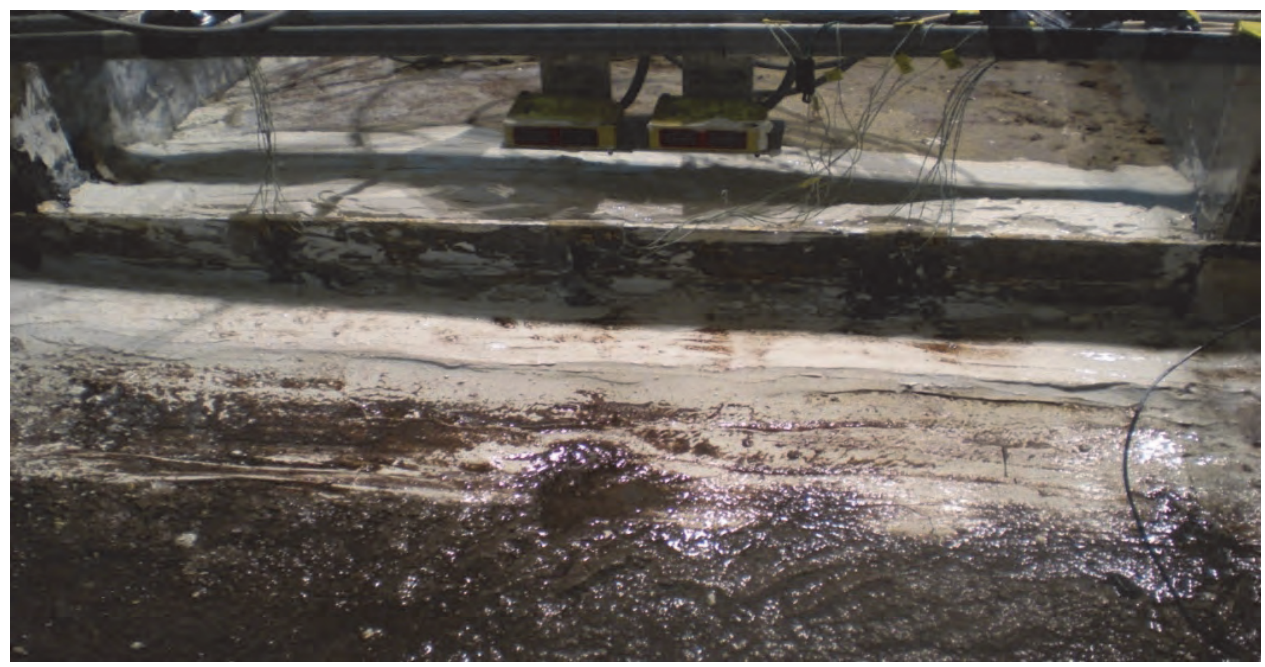

Figure 47. Test 4, London Canal Avenue I-wall sections with the clip mitigation did not fail.

\section{Test 5}

The London Canal Avenue levee model with polymer clips (sample 5) did not fail. The gravity level was also raised to $100-\mathrm{g}$ for this test with no wall failure.

\section{Test 6}

The 17th Street levee model, with no mitigation, failed.

\section{Test 7}

The 17th Street levee model was tested with one polymer clip (sample 4) positioned at the center joint between sections and none at the other joints. The joints without mitigation clips rotated in the direction of the load, causing the wall to fail; however, the joint with the mitigation clip did not separate or fail. The failed levee model is shown in Figure 48. Figure 49 shows a displacement plot of the wall sections where the center sections, with the clip, stayed together but failed in rotation caused by failure in the unmitigated end sections. 


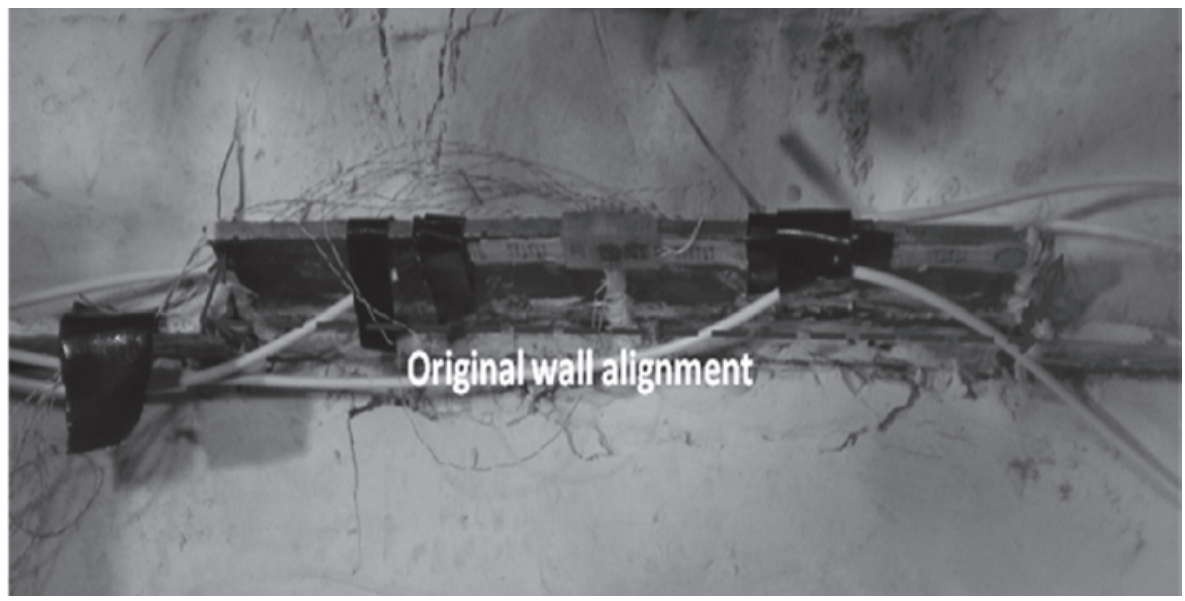

Figure 48. Center sections of the I-wall with the clip mitigation did not separate or fail. Both end sections, without any clips, failed.

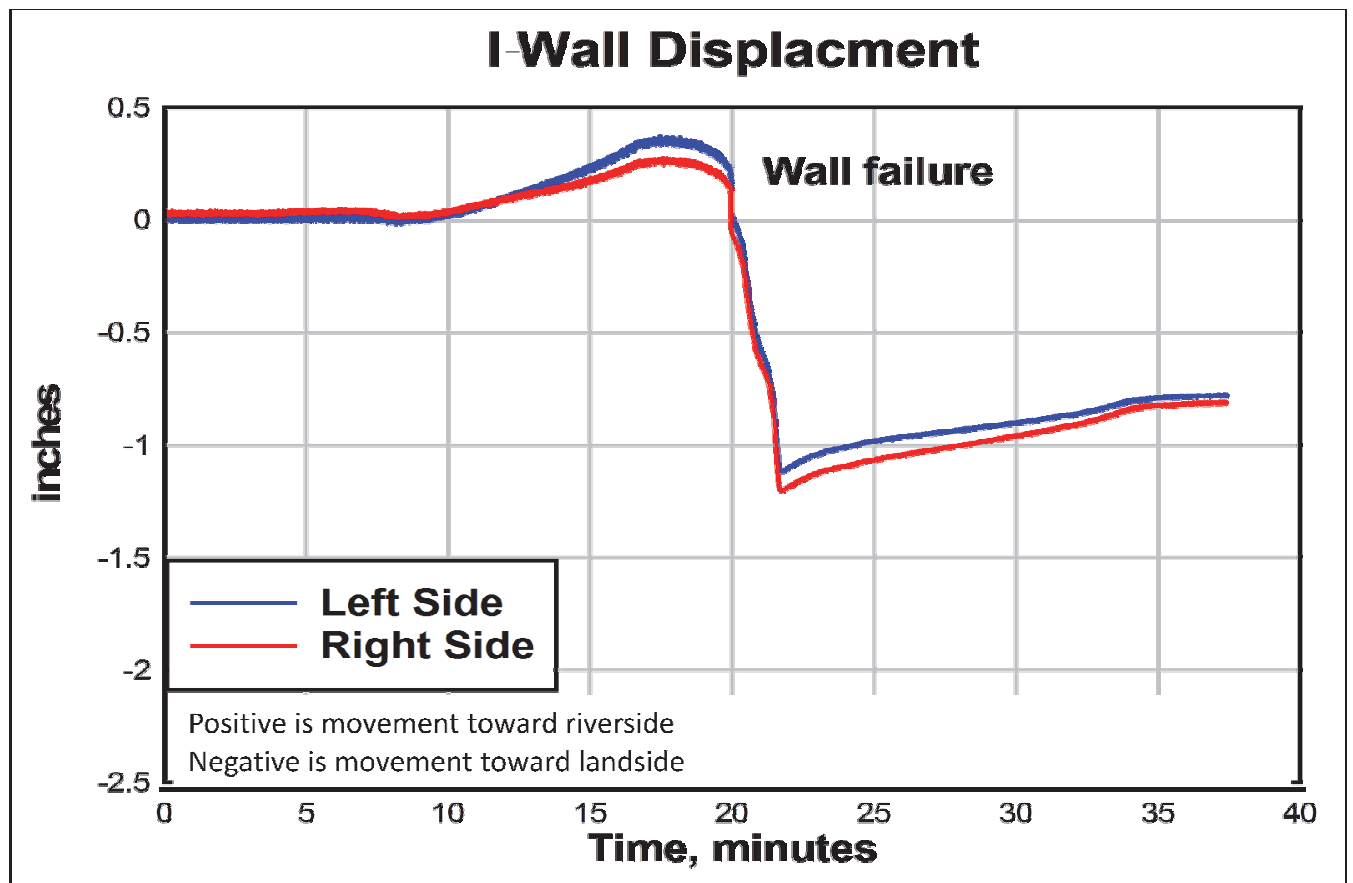

Figure 49. Laser gages show the I-wall displacement of about $2 \mathrm{ft}$ (scaled).

\section{Test 8}

The London Canal Avenue levee model was tested with the gap filler. Figure 50 shows the gap opening filled with clumps of the clay (levee) before the water was drained out of the container. Some of the filler expanded in place and stuck to the I-wall at several places, as shown in Figure 51. The rest of the filler, along with the plastic wrap, fell into the gap roughly $5 \mathrm{ft}$ (scaled) from the crest, or $3 \mathrm{ft}$ from origin. 


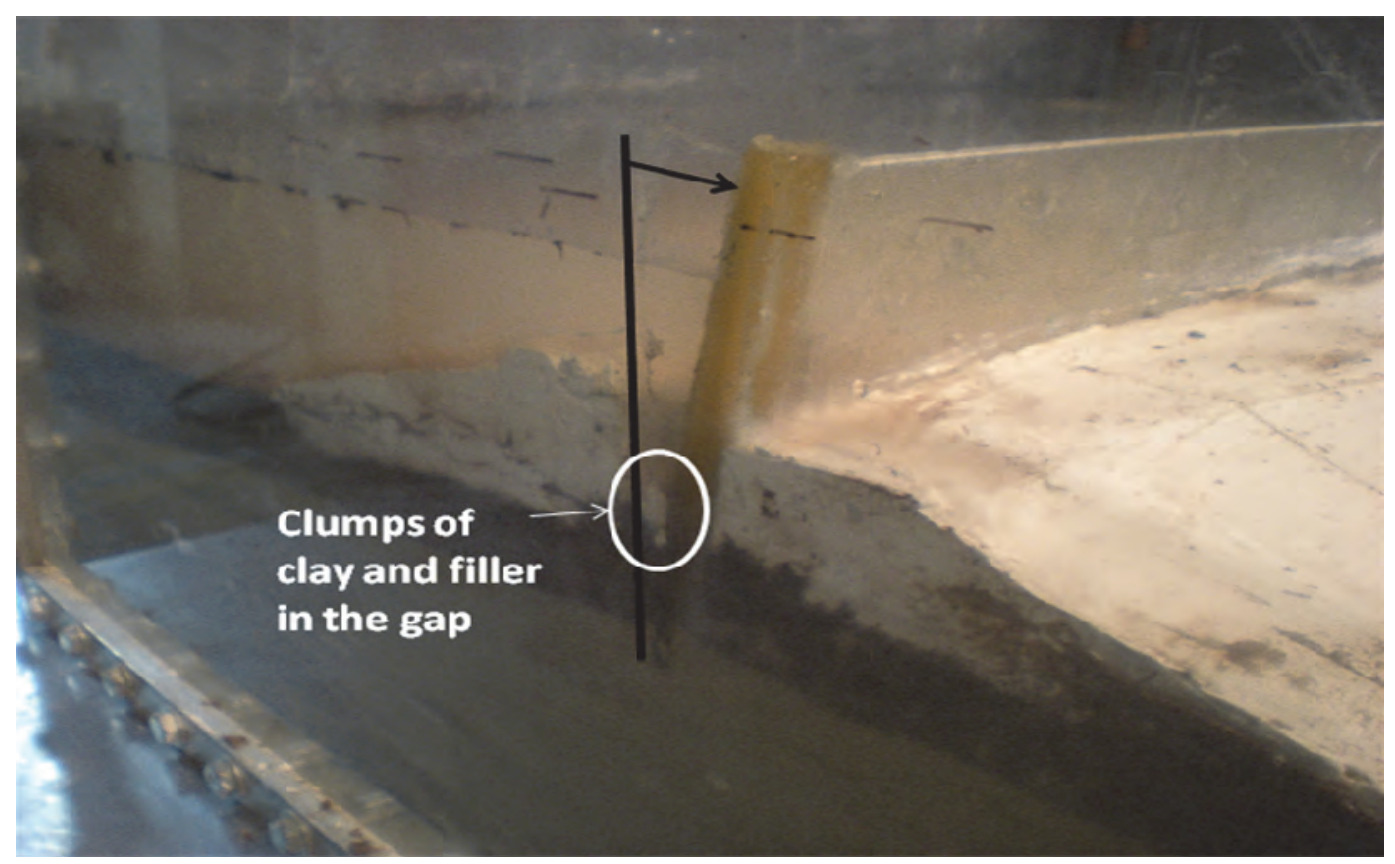

Figure 50 . Visible clumps of clay and filler in the gap after a centrifuge test.

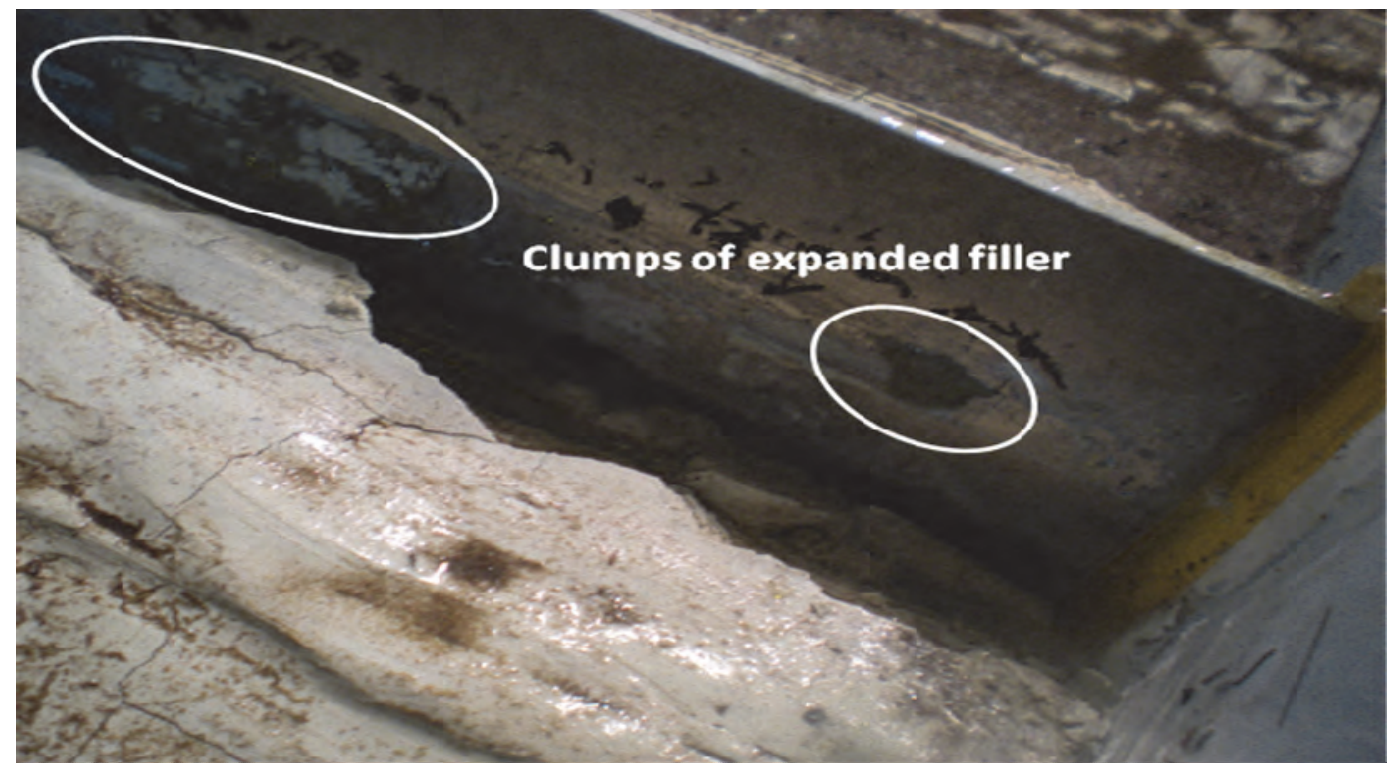

Figure 51. Filler that expanded in-place was stuck to the I-wall. 


\section{Conclusions}

Centrifuge testing results show promising potential for both the polymer clip connectors and the gap filler methods. Though some sliding of the clips occurred, none came off during the centrifuge testing. For this series of tests, the clips were simply placed over the I-wall sections, centered at the joints. Proper adhesion of the clips to the I-wall would eliminate the sliding. Test results clearly validate the effectiveness of the clips as a viable mitigation for I-wall failure caused by differential panel rotation at the joints. It is recommended that this method be evaluated for effectiveness in mitigating vertical (differential) displacement at the joints of I-wall sections.

The gap filler method was relatively effective for preventing floodwater from flowing down the interface between the levee and the sheetpiling into the underlying foundation material. The one major issue was keeping the gap filler material dry. The plastic wrap in Test 8 kept the moisture in the clay levee away from the filler but did not keep out all the floodwater that seeped downward into the filler. Some filler in the trench areas had water intrusion prior to the wall failure. See Figures 52 and 53 for final test results. This intrusion caused the bentonite to expand in its original position/place. Encasement and placement method for the proposed gap filler must be carefully considered to improve the overall effectiveness of this proposed mitigation. 


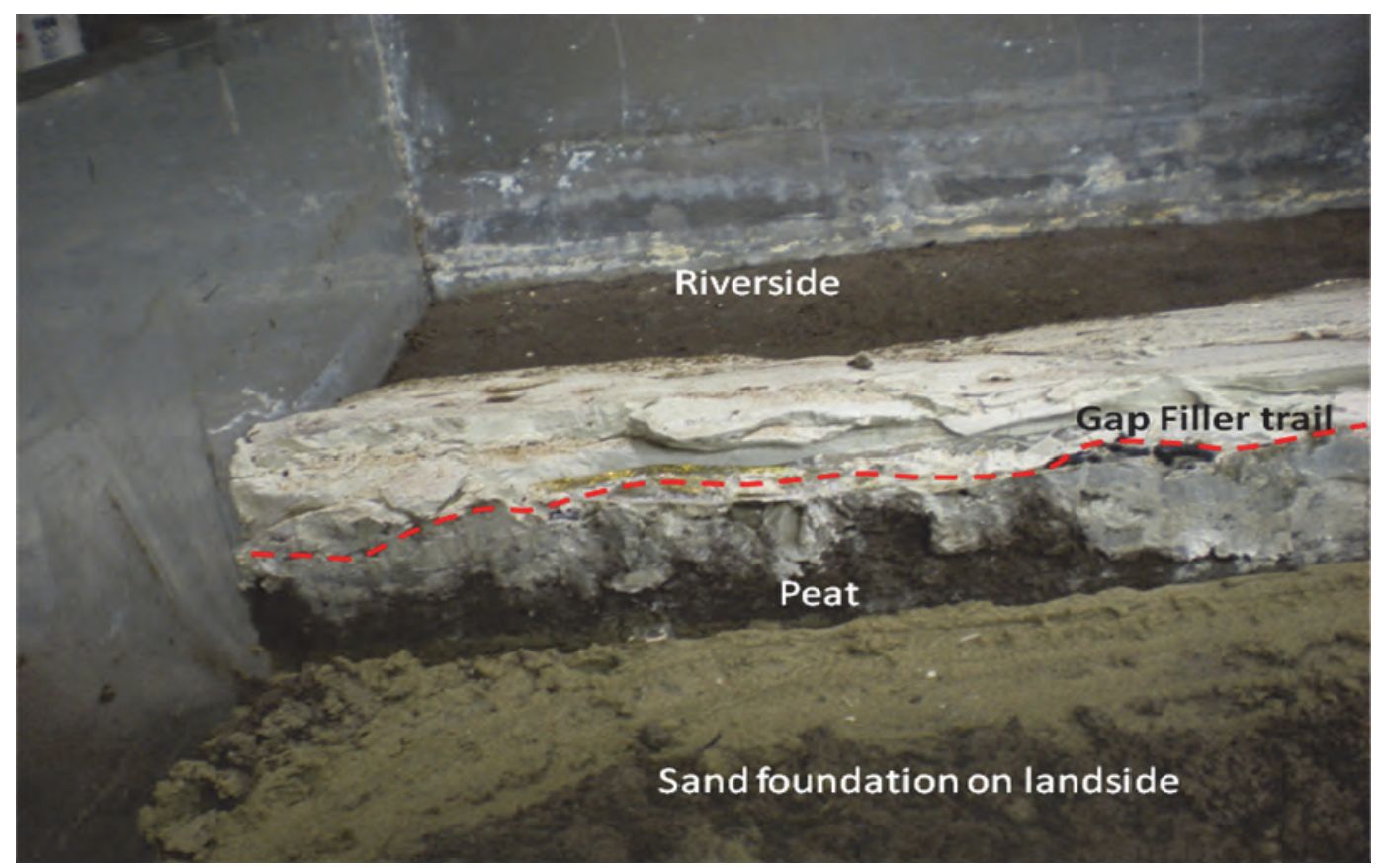

Figure 52. View of riverside levee section with the gap filler trail roughly 5-ft (scaled)-down from crest.

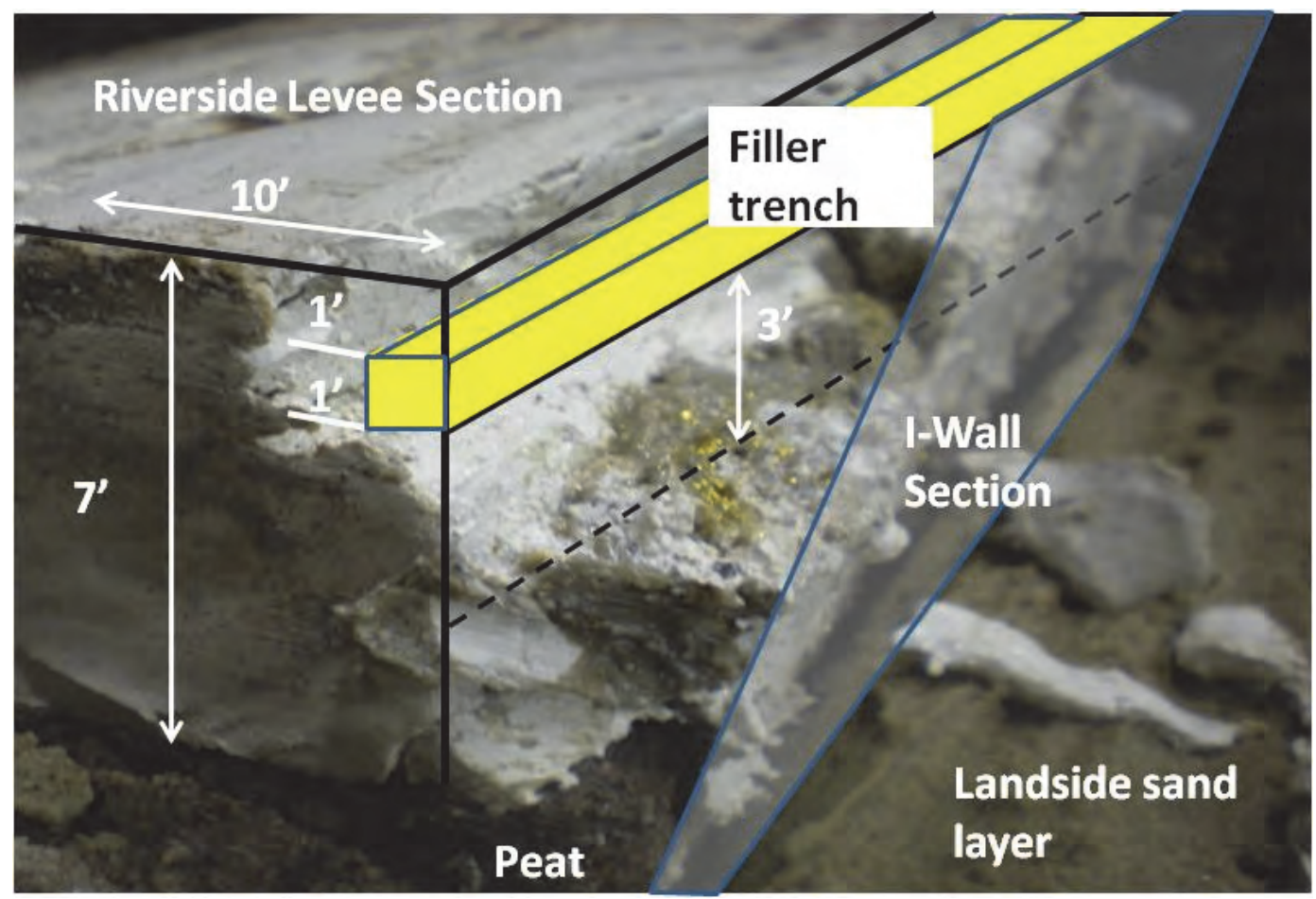

Figure 53. Cross-section of the levee showing final position of gap filler. 


\section{References}

Adhikari, S. 2009. "Two-dimensional numerical simulation of I-wall for retrofitting design of flood protection systems in New Orleans, " PowerPoint Presentation for SERRI Levee Project, prepared for Department of Homeland Security.

University, Mississippi: University of Mississippi.

Interagency Performance Evaluation Team (IPET). 2007. Performance Evaluation of the New Orleans and Southeast Louisiana Hurricane Protection System, Interim Draft Final Report of the Interagency Performance Evaluation Task Force, Volumes 1 through 9. Washington, DC: U.S. Army Corps of Engineers. http://ipet.wes.army.mil/ 


\section{Appendix: Centrifuge Model Soil Materials}

All measurements in this appendix were taken prior to the centrifuge flight.

\section{Sand layer}

Playground sand, a screened and washed sand for use in playgrounds, obtained from a local building supply store:

Dry sand moisture content $=4 \%$

Saturated sand moisture content $=21 \%$

Loose dry density $=91 \mathrm{pcf}(1.47-\mathrm{g} / \mathrm{cc})$

Loose saturated density $=93 \mathrm{pcf}(1.49-\mathrm{g} / \mathrm{cc})$

Dense dry density $=115 \mathrm{pcf}(1.84-\mathrm{g} / \mathrm{cc})$

Dense saturated density $=112 \mathrm{pcf}(1.8-\mathrm{g} / \mathrm{cc})$

Used $\sim 10.5$ bags of sand to get saturated volume of $5.8 \mathrm{cu} \mathrm{ft}$

Used dry sand weight $=560 \mathrm{lb}$ for 8-in. layer height

In-place saturated density $=97 \mathrm{pcf}(1.55-\mathrm{g} / \mathrm{cc})$

\section{Swamp clay layer}

The swamp clay layer material was obtained from a Mississippi River backwater alluvial deposit. In situ moisture content was not measured, but the material was highly organic, plastic, very soft, and saturated. In the laboratory, the material was manually screened to remove roots and detritus. It was then placed into shallow pans and manually compressed to obtain horizontal layers approximately 2-in.-thick. Moisture content averaged 51 percent.

Strength measurements of the in-place clay layers were taken using a pocket penetrometer and a hand-held torsion vane shear tester. Both instruments yielded shear strengths ranging from 160 to 200 psf, equivalent to a very soft clay consistency. 


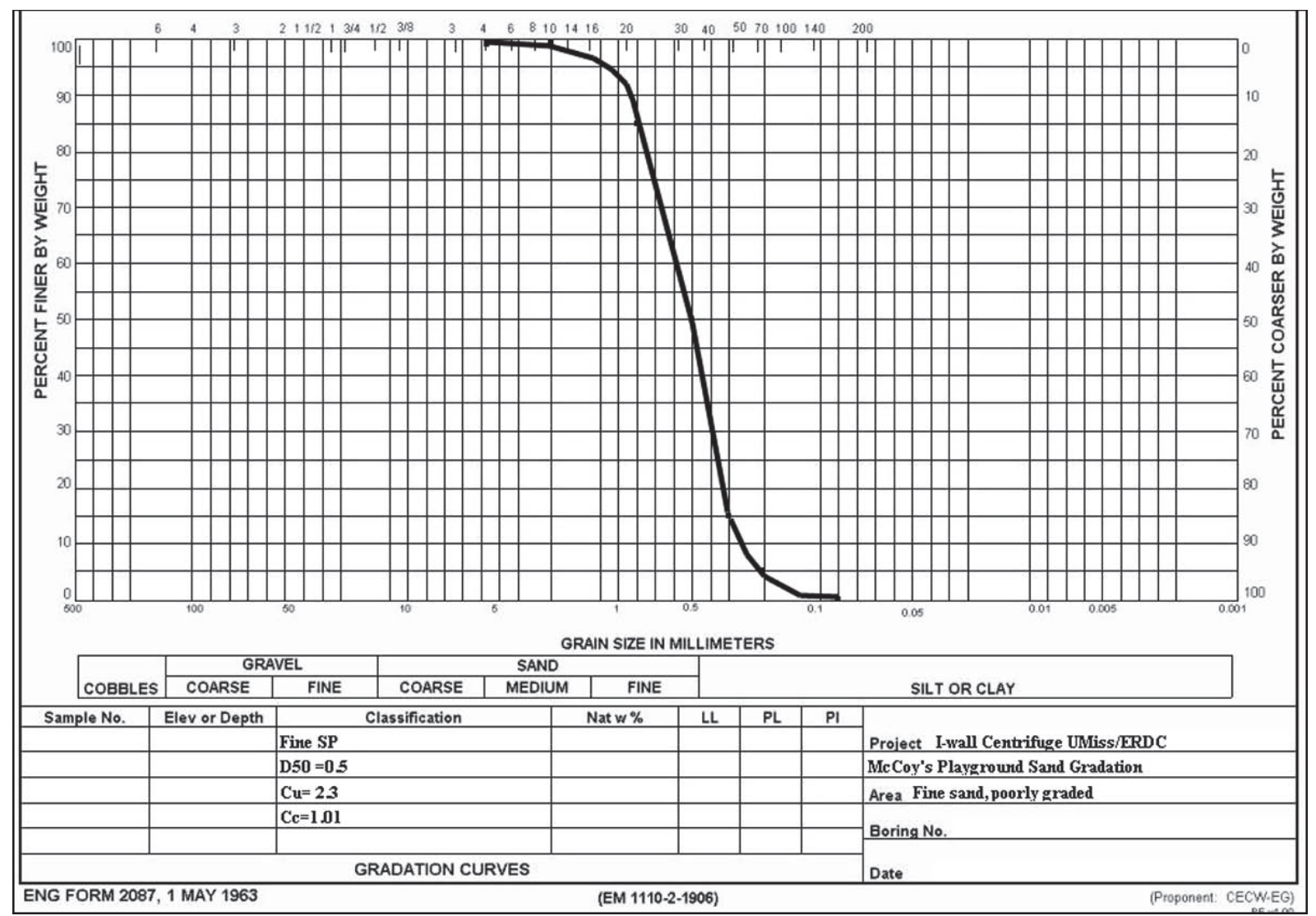

Average in-place bulk density was $110 \mathrm{pcf}(1.7-\mathrm{g} / \mathrm{cc})$, indicative of very soft saturated clay. The average liquid limit was 63 percent, the plastic limit was 30 percent, and the plasticity index was 33 percent.

\section{Kaolin clay levee}

\section{Materials and equipment}

1. 4 steel box molds with false bottoms (approximately 16 in. $\times 16$ in. $\times 16$ in.)

2. Black fabric cloth liner (nonwoven geofabric) for theinside of each mold

3. Kaolin clay dry powder (ASP 600 grade)

4. Water

5. Commercial food mixer made by Globe (comes with container and whisk)

6. Scale to obtain weight of clay and water before adding to mixer (measured in pounds)

7. Several buckets for holding clay and water while weighing

8. Small hand shovel for transferring clay powder from mixer to mold

9. Ruler for measuring clay depth in mold (filled to approximately 4-in. depth) 


\section{Procedure for producing and consolidating clay mixture}

1. Use the black fabric liner to cover the inside of the molds. Tape the overhanging fabric to the sides of the molds.

2. Set up the mixer and attach the bowl and the whisk to the machine.

3. Set the speed setting to level 1 and lower the bowl to add the clay and water.

4. Obtain the buckets and weigh out $15 \mathrm{lb}$ of clay and $25 \mathrm{lb}$ of water to start with.

5. Add the clay and water to the mixer, raise the bowl all the way to the top, and turn the mixer on.

6. Allow the mixer to run for a steady 15 to 20 min before stopping, use the hand shovel to mix the very bottom of the bowl, and again run for 15 to 20 min.

7. Continue adding clay and water and allow machine to spin.

8. When the mixture thickens to a paste, it has reached the appropriate consistency.

9. The mixture used was roughly a 1 to 1 ratio of water to clay.

10. Once the mixture is ready, remove the bowl from the mixer and use the hand shovel to transfer it to the steel mold. The depth of the mixture across the mold should be roughly 4 in.

11. When the molds are filled to the appropriate depth, move them to the vacuum chamber. Here all the entrapped voids will be removed from the mixture.

12. After removing the molds from the vacuum, place them on the centrifuge; here the mixture will further consolidate. The centrifuge ran for roughly 6 hrs at $100-g$.

13. Make sure the plugs are removed from the bottom of each mold before running the centrifuge; this will allow the water to escape during flight.

14. Remove molds from centrifuge and place in humid room in the soils test laboratory.

15. Trim clay blocks to $1 / 64$ th scaled down from the prototype dimensions.

The average moisture content of the trimmed clay blocks equaled 51 percent. The average wet bulk density equaled $105 \mathrm{pcf}$ (1.7-g/cc), and the nominal pressure exerted by the kaolin clay on the swamp clay layer was $12 \mathrm{psf}$. The pocket penetrometer and torsion vane shear tester yielded shear strengths of $250 \mathrm{psf}$ and $500 \mathrm{psf}$, respectively. The kaolin clay levee was slightly "stronger" than the swamp clay layer. 


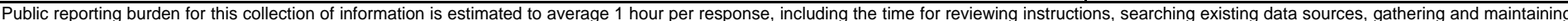

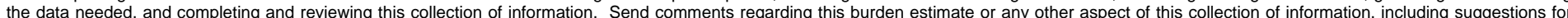

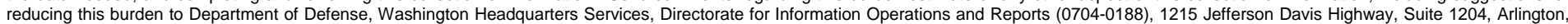

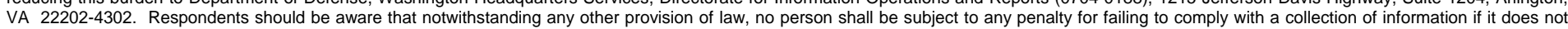
display a currently valid OMB control number. PLEASE DO NOT RETURN YOUR FORM TO THE ABOVE ADDRESS.
1. REPORT DATE (DD-MM-YYYY) 2. REPORT TYPE
December 2012 Final
4. TITLE AND SUBTITLE

3. DATES COVERED (From - To)
5a. CONTRACT NUMBER

Structural, Material, and Geotechnical Solutions to Levee and Floodwall Construction and

Retrofitting - Physical Modeling

5b. GRANT NUMBER

5c. PROGRAM ELEMENT NUMBER

6. AUTHOR(S)

5d. PROJECT NUMBER

Wipawi Vanadit-Ellis, Eric W. Smith, Landris T. Lee, and Jared S. Case

5e. TASK NUMBER

5f. WORK UNIT NUMBER

7. PERFORMING ORGANIZATION NAME(S) AND ADDRESS(ES)

8. PERFORMING ORGANIZATION REPORT NUMBER

Geotechnical and Structures Laboratory

U.S. Army Engineer Research and Development Center

ERDC/GSL TR-12-37

3909 Halls Ferry Road, Vicksburg, MS 39180-6199;

University of Mississippi

227 Brevard Hall, University, MS 38677

9. SPONSORING I MONITORING AGENCY NAME(S) AND ADDRESS(ES)

The University of Mississippi

Department of Civil Engineering

106 Carrier Hall, University, MS 38677

11. SPONSOR/MONITOR'S REPORT NUMBER(S)

12. DISTRIBUTION / AVAILABILITY STATEMENT

Approved for public release; distribution is unlimited.

\section{SUPPLEMENTARY NOTES}

\section{ABSTRACT}

This report presents the evaluations of two retrofitting methods for levees and floodwalls. Physical modeling in a centrifuge was used in testing the effectiveness of floodwall panel joint caps (or “clips”) and a gap filler. The clip connectors were U-shaped reinforced polymers with various thicknesses and strengths, mounted over the joints between I-wall panels. The expectation was that the clips would improve the overall performance of the wall if the panels were connected and behaved as a single unit. The second retrofit method evaluated what was called the gap filler, which was a mixture of sand and bentonite. The mixture was entrenched along the levee along the riverside of a sheet wall. The belief was that as water pressure on the wall caused the wall to move (or rotate) toward the landside of the levee; the filler would drop down into the gap and expand, thus reducing seepage under the wall. All test models were constructed, then placed on the centrifuge platform and subjected to various flood conditions representing those experienced during Hurricane Katrina.

\begin{tabular}{|c|c|c|c|c|c|}
\hline \multicolumn{2}{|l|}{$\begin{array}{l}\text { 15. SUBJECT TERMS } \\
\text { Centrifuge } \\
\text { Floodwall }\end{array}$} & $\begin{array}{l}\text { Gravity } \\
\text { I-Wall } \\
\text { Levees }\end{array}$ & & $\begin{array}{l}\text { Mitig } \\
\text { Mod } \\
\text { Retro }\end{array}$ & ion \\
\hline \multicolumn{3}{|c|}{ 16. SECURITY CLASSIFICATION OF: } & $\begin{array}{l}\text { 17. LIMITATION } \\
\text { OF ABSTRACT }\end{array}$ & $\begin{array}{l}\text { 18. NUMBER } \\
\text { OF PAGES }\end{array}$ & $\begin{array}{l}\text { 19a. NAME OF RESPONSIBLE } \\
\text { PERSON }\end{array}$ \\
\hline $\begin{array}{l}\text { a. REPORT } \\
\text { UNCLASSIFIED }\end{array}$ & $\begin{array}{l}\text { b. ABSTRACT } \\
\text { UNCLASSIFIED }\end{array}$ & $\begin{array}{l}\text { c. THIS PAGE } \\
\text { UNCLASSIFIED }\end{array}$ & & 48 & $\begin{array}{l}\text { 19b. TELEPHONE NUMBER (include } \\
\text { area code) }\end{array}$ \\
\hline
\end{tabular}

